Portland State University

PDXScholar

\title{
Successful Online Course Retention at Marylhurst University Constructing a Model for Online Course Retention Using Grounded Theory
}

Vincent Schreck

Portland State University

Follow this and additional works at: https://pdxscholar.library.pdx.edu/open_access_etds

Part of the Educational Leadership Commons, and the Higher Education and Teaching Commons Let us know how access to this document benefits you.

Recommended Citation

Schreck, Vincent, "Successful Online Course Retention at Marylhurst University Constructing a Model for Online Course Retention Using Grounded Theory" (2004). Dissertations and Theses. Paper 2176.

https://doi.org/10.15760/etd.2173

This Dissertation is brought to you for free and open access. It has been accepted for inclusion in Dissertations and Theses by an authorized administrator of PDXScholar. Please contact us if we can make this document more accessible: pdxscholar@pdx.edu. 
SUCCESSFUL ONLINE COURSE RETENTION AT MARYLHURST

UNIVERSITY: CONSTRUCTING A MODEL FOR ONLINE

COURSE RETENTION USING GROUNDED THEORY

by

VINCENT SCHRECK

A dissertation submitted in partial fulfillment of the requirements for the degree of

\author{
DOCTOR OF EDUCATION \\ in \\ EDUCATIONAL LEADERSHIP: \\ POSTSECONDARY EDUCATION
}

Portland State University

2004 


\section{DISSERTATION APPROVAL}

The abstract and dissertation of Vincent Schreck for the Doctor of Education in

Educational Leadership: Postsecondary Education were presented November 18,

2003 , and accepted by the dissertation committee and the doctoral program.

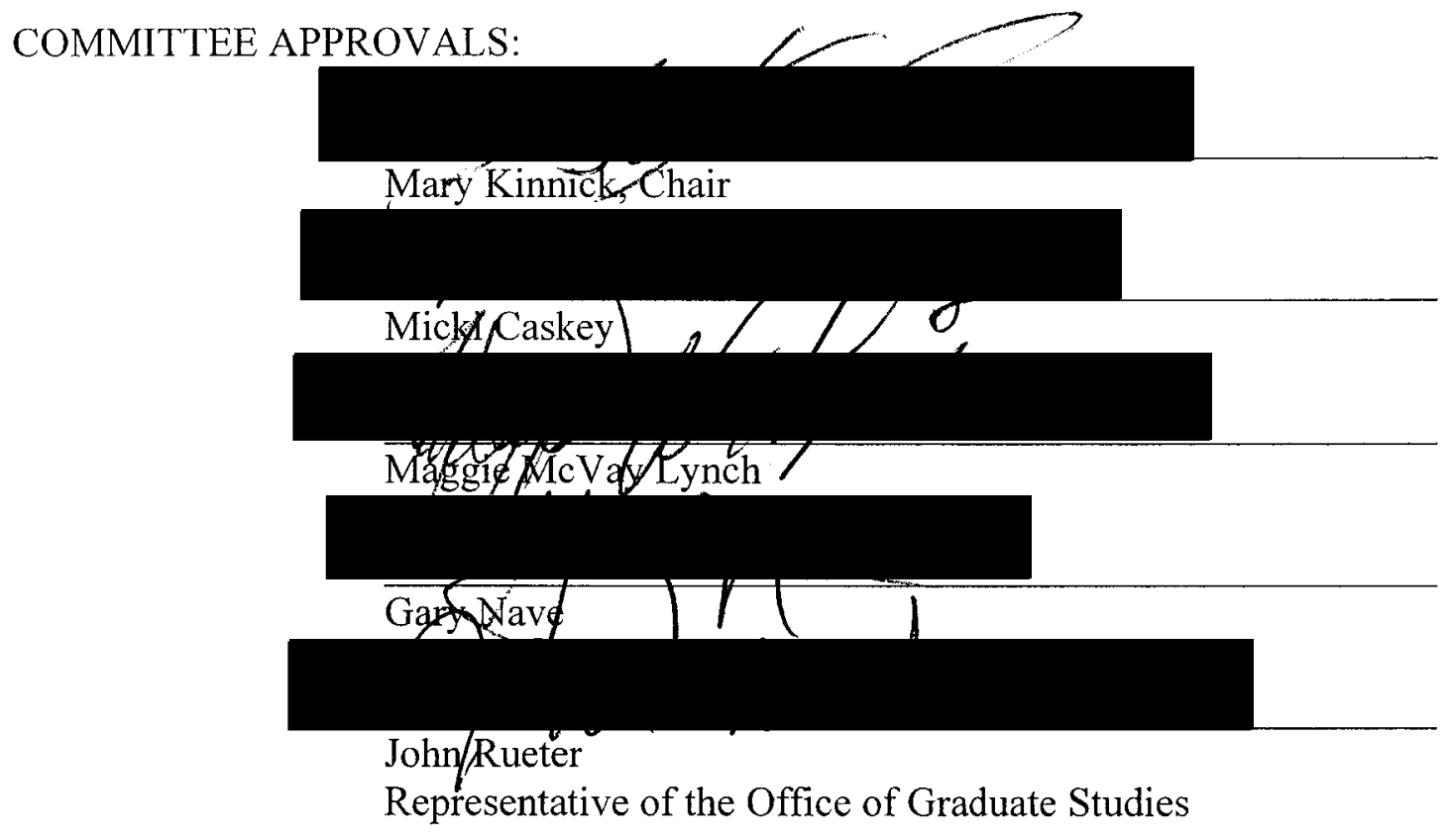

DOCTORAL PROGRAMAPPROVAL:

Phylis J. Edmundson, Dean

Graduate School of Education 


\begin{abstract}
An abstract of the dissertation of Vincent Schreck for the Doctor of Education in Educational Leadership: Postsecondary Education presented November 18, 2003.
\end{abstract}

Title: Successful Online Course Retention at Marylhurst University: Constructing a Model for Online Course Retention Using Grounded Theory

Over the past 6 years, the course retention rate for Marylhurst University's (MU) online courses was $91 \%$, which is within four percentage points of its on-campus course retention rate (Schreck, 2002). This appears to contradict a recent article in the Chronicle of Higher Education that stated, "Although there is significant variation among institutions with some reporting course-completion rates of more than $80 \%$ and others finding that fewer than $50 \%$ of distance-education students finish their courses, several administrators concur that course-completion rates are often 10-20 percentage points higher in traditional courses than in distance offerings" (Carr, 2000). Recent studies (Beatty-Gunter 2001; Crabtree, 2000; Cutler, 2000; Fox, 2000; Moore, Bartkovich, Fetzner, \& Ison, 2002; Morrow, Woodyard, Mora, \& Nather, 2001; Valdez, 2001) corroborate Carr's claim and were used to compare with MU results. This grounded theory, web-based, research study aims to explicate the reasons why MU online students complete 
courses at high rates and develop this understanding into an online student retention model. A grounded theory approach was used to conduct this study, which is described by Creswell (2002) as, "a systematic, qualitative procedure used to generate a theory that explains, at a broad conceptual level, a process, an action, or interaction about a substantive topic" (p. 439).

The research process helped discover and shape the Online Course Retention Model (OCRM). The OCRM theorizes four major areas for inquiry into online course retention (Administration, Course, Student, and Teacher). Each major area of inquiry is divided into three variables of varying importance to online course retention. Perhaps the most profound discovery was not the major themes and supporting variables, but rather, the relationships between variables, and how these relationships explain the MU situation. The research concludes with an examination of possible "best practices" in online course retention, ideas for future research, and recommendations for implementation. Successful online course retention at Marylhurst University: Constructing a model for online course retention using grounded theory. 
TABLE OF CONTENTS

PAGE

LIST OF TABLES $\ldots \ldots \ldots \ldots \ldots \ldots \ldots \ldots \ldots \ldots$ vi

LIST OF FIGURES $\ldots \ldots \ldots \ldots \ldots \ldots \ldots \ldots \ldots \ldots$ viii

\section{CHAPTER}

I INTRODUCTION AND OVERVIEW $\ldots \ldots \ldots \ldots \ldots$

Background to the Problem ............. 2

The Economics of Retention

The Infiltration of Online Learning

Online Learning: The Competition Factor

Online Course Retention: Are We Doing a Good Job?

The "Responsibility and Obligation" of Retention

Marylhurst University - Background and Selected

Results of Pilot Study . . . . . . . . . . . . 11

Marylhurst University Demographic and Historical Information

Enrollment History

A Final Note Concerning MU Online Retention

Statement of the Problem . . . . . . . . . . . 17

Significance

Limitations

Purpose of the Study . . . . . . . . . . . . . . . . . 19

Definitions 
Research Questions ................. . . 21

Central Question

Related Questions

Chapter I Summary $\ldots \ldots \ldots . \ldots . \ldots . \ldots 22$

II REVIEW OF RELEVANT DISCOURSES . . . . . . . . 24

Purpose of this Literature Review . . . . . . . . . . . 24

Student Retention Models . . . . . . . . . . . . . 26

Tinto: Student Integration Model

Bean: Student Attrition Model

Alexander Astin: Student Involvement Theory

Chapter II Summary . . . . . . . . . . . . 40 40

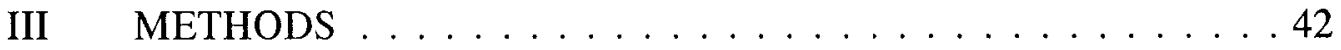

Purpose of the Study . . . . . . . . . . . . . . 42

Research Questions .................. . 43

Central Question

Related Questions

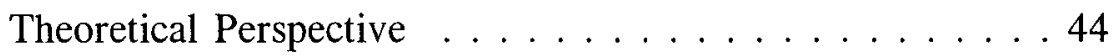

Using the Qualitative Paradigm

Guiding Theoretical Position

Guiding Collection/Analysis Model

Research Context

Sample ....................... 50

Subject Characteristics

Recruitment

Informed Consent

Potential Risks and Safeguards

Potential Benefits

Records and Distribution 
Strengths of Sample Group

Limitations of Sample Group

Data Collection and Analysis . . . . . . . . . . . . 61

WebCT as the Collection Area

Analysis Using Computer-assisted Technology

Research Procedures

Establishing Validity and Reliability

About the Researcher . . . . . . . . . . . . . 97

Chapter III Summary . . . . . . . . . . . 100

IV RESEARCH FINDINGS ................ . . 103

Research Question \#1 . . . . . . . . . . . . . 103

Step 1: Read and Reread Files

Step 2: Create Necessary Memos

Step 3: Code Text Units Into "Free Nodes" by

Identifying Relevant Text Units - Make

Annotations as Necessary

Step 4: Make a Report if Necessary

Step 5: Look for Larger or "Core Categories" -

Create Tree Nodes, Then Cut and Paste

Related Free Nodes into Tree Nodes

Step 6: Make Additional Subcategories as

Necessary and Append/Merge any Free

Nodes or Subcategories

Professional Review - Stage 1

Research Question \#2 . . . . . . . . . . . . . . 142

Step 1: Clarification of Subject Feedback -

Assigning Value and Importance

Student Characteristics

Fit with College

Online Course Organization

Teacher Characteristics

Teaching Methods

Culture/Subculture

Learning Theory 
Snapshot of the Learning Experience

Investment in Online Learning

STEP 2: Axial Coding - Connecting Properties

Using Dimensions

STEP 3: Narrow the Themes and Subthemes to

the Core Category and its Central Themes

Professional Review - Stage 2 (What was

Discussed and Outcomes)

Research Question \#3 . . . . . . . . . . . . . 172

Discursive Theoretical Propositions

Validation of Model - Credibility as Internal Validity

Chapter IV Summary . . . . . . . . . . . . . . . . 179

V RECOMMENDATIONS AND DISCUSSION . . . . . . . . 180

Research Question \#4 . . . . . . . . . . . 180

Fully Understand What Motivates Your Student Population

Develop an Administrative System that Supports Students' Educational Goals

Create and Foster Highly Organized Courses and Teachers

Offer Online Courses Focused on Meeting the Needs of Your Student Population

Recycle Online Courses

Develop a "Presence" Policy for all Online Instructors

Training and Development

Allow and Encourage Online Students to Create a Classroom Culture

Other "Best Practices" Considerations

Research Question $\# 5$. . . . . . . . . . . . . . . 189

Further Exploration into Course Retention

A Quantitative Analysis of the Variables and Their Relationships

Do the Variables, Subvariables and Their Relationships in the OCRM Have Importance Beyond the Realm of "Course Retention?" 
Other Research Considerations

Important Limitations to Consider for Further Research

Overall Conclusions

Metaphor 1: Broader Implications

Metaphor 2: Foundations

REFERENCES

APPENDICES
A ONLINE COURSE RETENTION STUDIES . . . . . . . 207
B INFORMED CONSENT LETTER . . . . . . . . . . . . 210
C RESEARCH JOURNAL SAMPLE . . . . . . . . . . 213 


\section{LIST OF TABLES}

TABLE

PAGE

1. Age Groups for WBL Students $(N=1032) S D 1.05 \ldots \ldots 12$

2. Unduplicated Headcounts and Duplicate Credits for WBL and On-campus Students at MU: A Term Analysis .... 15

3. Unduplicated Headcounts and Duplicate Credits for WBL Percentages of Increase Over a Six-Year Period by

Term

4. Online Course Retention Representing Various Demographic Groups ..................... . . 52

5. Sampling Plan of $12-15$ Subjects $\ldots \ldots \ldots 5$

6. True Study Sample (14 Subjects) . . . . . . . . . . . . . . 54

7. Subject Coding . . . . . . . . . . . . . . . . . . 59

8. Data Collection and Analysis Process ............ 63

9. Advantages and Disadvantages of Computer-assisted Analysis . . 64

10. Criteria for Examining Validity and Reliability . . . . . . . . 92

11. Collection Journal Example . . . . . . . . . . . . . 97

12. Free Node $1 \ldots \ldots \ldots \ldots$. . . . . . . . . . . . . .

13. Free Node $2 \ldots \ldots \ldots \ldots$

14. Free Node $3 \ldots \ldots$. . . . . . . . . . . . . . 109

15. Free Node $4 \ldots \ldots \ldots \ldots \ldots$

16. Free Node $5 \ldots \ldots \ldots \ldots \ldots$ 
17. Free Node $6 \ldots \ldots \ldots \ldots 11 \ldots \ldots \ldots$

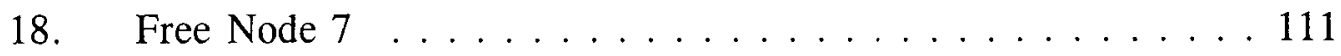

19. Free Node $8 \ldots \ldots \ldots 112 \ldots \ldots \ldots \ldots$

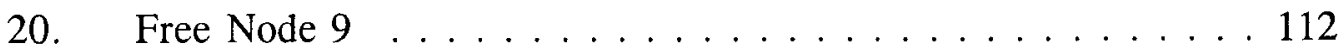

21. Free Node $10 \ldots \ldots \ldots \ldots \ldots$

22. Free Node $11 \ldots \ldots \ldots 113$

23. Free Node $12 \ldots \ldots \ldots \ldots 114$

24. Free Node $13 \ldots \ldots \ldots \ldots 114$

25. Free Node $14 \ldots \ldots \ldots \ldots \ldots$

26. Free Node $15 \ldots \ldots \ldots \ldots$

27. Free Node $16 \ldots \ldots \ldots \ldots \ldots$

28. Free Node $17 \ldots \ldots \ldots \ldots \ldots$

29. Free Node $18 \ldots \ldots \ldots \ldots \ldots$

30. Free Node $19 \ldots \ldots \ldots \ldots \ldots \ldots$. . . . . . . . . . . . . . . .

31. Free Node $20 \ldots \ldots \ldots \ldots \ldots \ldots \ldots$

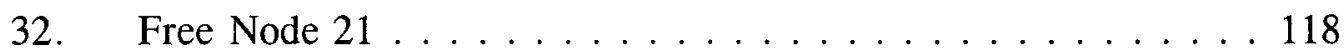

33. Themes from Stage $1 \ldots \ldots \ldots \ldots 121$

34. Condensed Themes with Properties ... . . . . . . . . 162

35. Themes, Properties and Connections . . . . . . . . . 166 


\section{LIST OF FIGURES}

FIGURE

PAGE

1. Tinto's Model of Student Departure . . . . . . . . . . . . . . . 29

2. Bean and Metzner's Model of Nontraditional Student

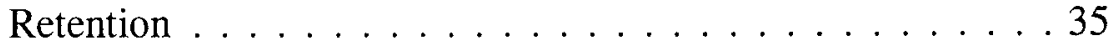

3. Discussion Board - Topic Areas . . . . . . . . . . . . . 67

4. Coding Illustrations $\ldots \ldots \ldots \ldots \ldots$

5. Threaded Discussion Strategy, Stage $1 \ldots \ldots 74$

6. Overview of Stage 1 Analysis . . . . . . . . . . . 75

7. Stage 1 Analysis $\ldots \ldots \ldots \ldots 1$

8. Discussion Board with Hypothetical Categorical Threads . . . . 84

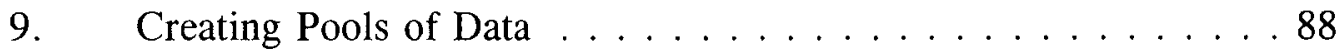

10. A Visual Example of Selective Coding . . . . . . . . . . . 91

11. Visual Summary of Process . . . . . . . . . . . . . . . 102

12. Teaching Methods - Establishing Properties in a Larger

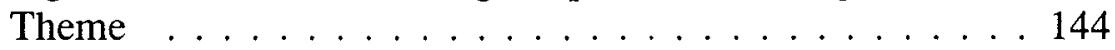

13. Initial Four-cornered Model . . . . . . . . . . . . . 164

14. Strongest Axial Coding Properties . . . . . . . . . . . . . 167

15. Second Strongest Axial Coding Properties . . . . . . . . 168

16. Building the Model . . . . . . . . . . . . . . . . . . . . . 169

17. Model to Stage $3 \ldots \ldots \ldots$. . . . . . . . . . . . . . . . 


\section{CHAPTER I}

\section{INTRODUCTION AND OVERVIEW}

After working in distance learning for more than 5 years using both telecourse and online technologies, I know each respective medium incites both compliments and criticisms. One criticism in particular from distance learning administrators and personnel concerns the poor retention rate of students enrolled in distance learning courses. Despite the lack of any national statistics, the higher education community continues to formulate a poor opinion of distance learning course retention (Carr, 2000; Frankola, 2001; McVay-Lynch, 2002). However, after working at Marylhurst University (MU) in the Web-based Learning Department (WBL/D) for more than 2 years, I noticed a minimal loss of students across all online courses. This observation led to a more in-depth look at MU WBL to discover our true online course retention rate.

In the fall of 2001, I began gathering institutional data with hopes of validating my initial observation concerning MU's online courses. The findings from this informal study verified my initial thoughts about our success with online course retention - only a small percentage of our students dropped online courses each term. When compared to existing, similar studies (Crabtree, 2000; Cutler, 2000; Mesa Community College, 2001; K. Moore, Bartkovich, Fetzner, \& Ison, 
2002; K. Keefe, personal communication, April 18, 2002; T. Manning, personal communication, January 1, 2002; Morrow, Woodyard, Mora, \& Nather, 2001; Valdez, 2001), my informal study (Schreck, 2002) revealed high online course retention rates that were within 5 percentage points of MU's on-campus courses. Rather than celebrate what appeared to be a significant discovery when compared to similar existing studies, I posed the question, "Why should anyone care about student retention in the first place?"

\section{Background to the Problem}

The following section contains background information concerning the financial aspects surrounding student retention, the popularity surge of online learning, and how competition has helped drive this popularity. This leads into a fundamental question behind this research project, "Are we doing a good job retaining students in online courses?" Finally, this section ends with the true importance of retaining students - that universities have a responsibility and obligation to monitor and improve retention in general.

\section{The Economics of Retention}

My first thought about retention concerns the economics of higher education where students' tuition dollars generate large percentages of college budgets. This observation is especially prevalent at $\mathrm{MU}$ where on a 5 year running average, MU's tuition revenue is up to $69 \%$ of the operating budget (MU Business Office 
personal communication, October 7, 2002). If tuition dollars decrease, higher education becomes more dependent on state funding. When fiscal forecasts are good for states, generally the forecast is also good for higher education. In turn, budget deficits within the state budget often cause alarm and force cuts in institutions' budgets. In a 1999 report to the National Center for Public Policy and Higher Education, Hovey made the following remarks:

...even with normal economic growth over the next eight years, the vast majority of states will face significant fiscal deficits. Given past state budget patterns of coping with fiscal deficits and avoiding tax increases, the report concludes that the projected shortfalls will lead to increased scrutiny of higher education in almost all states, and to curtailed spending for public higher education in many states.

(Hovey, 1999, I 1)

Now in 2002, many higher education institutions must deal with the harsh reality of Hovey's (1999) projections. These impossible deficits, cited in Johnson, Lav, and Carey (2001), surface while browsing state funding sources via the World Wide Web. For example, 2002 records show the state of California carrying a $\$ 14.5$ billion deficit, which leads to $\$ 857$ million in cuts to public education.

Oregon reported a deficit of $\$ 715$ million with one possible solution being a proposed alcohol and tobacco tax increase. With federal and state funding for higher education on the decline and many colleges and universities in a budget crisis, there is an increasing challenge for higher education to remain competitive in its market arena. Coming to the forefront of distance education, online learning has become the premiere delivery system for higher education and has infiltrated the majority of higher education institutions (Greene, 1999, p. 5). 


\section{The Infiltration of Online Learning}

Just like any organization, higher education needs to rethink, resize, rework and revitalize plans to help it survive and move into the future. A recent addition to the educational market, online learning (learning via the Internet) shows unprecedented growth in terms of the number of colleges offering online courses and programs, student enrollments and research initiatives. A research report by the National Educational Association (NEA, 2000) states that during the 1997-1998 academic year, $78 \%$ of public 4 -year institutions and $62 \%$ of public 2 -year institutions use distance learning Internet courses constitute $60 \%$ of the total number of distance learning offerings in the report (p. 2).

A recent research report from the Sloan Consortium (Allen \& Seaman, 2003) hints that colleges are moving beyond just offering courses. In this report, 3033 surveys were sent to public and private institutions (both for profit and nonprofit). Concerning the question, "Does your school offer online programs for a degree?" The following percentages were reported as "yes": $48.9 \%$ of public institutions; $22.1 \%$ of private, nonprofit; $20.2 \%$ of private, for profit; $34.5 \%$ overall (p. 7). In addition, the Sloan research states, "The Public sector offers the majority of all online courses, with more than $90 \%$ of all institutions offering at least one online course" (p. 7). The following statistics were also included.

- More than 1.6 million students took at least one online course during fall 2002. 
- Over one-third of these students $(578,000)$ took all of their courses online.

- Among all U.S. higher education students in Fall 2002, $11 \%$ took at least one online course.

- Among those students at institutions where online courses were offered, $13 \%$ took at least one online course.

- The number of students taking at least one online course is projected to increase by $19.8 \%$ over the one-year period from Fall 2002 to Fall 2003, to include a total of 1.9 million students. (p. 1)

The use of Internet learning technologies to gain overall enrollment and increase revenue through student tuition dollars lures many schools into distance learning. Cited by Lorenzo (2002) in Educational Pathways, two instances of large increases in online enrollments, University of Illinois - Springfield (UIS) and St. Leo University (SLU), provide extreme examples of rapid, online learning growth. UIS saw an increase of 2,960\% from fall 1998 to fall 2001 ( 4-5). St. Leo University went from 12 enrollments in the fall of 1998 to 2000 enrollments in the fall of $2000-$ a $16,567 \%$ increase $(\$ 15)$. In the same online article, Michael Rogich, director of SLU's Center for Online Learning, stated, "...we are growing at about six to eight percent every eight weeks" ( 16 ).

Although these two examples show the possibilities of huge enrollment increases in online courses, this is not always the case. Hafner (2002) states the following: 
....according to Eduventures, an education research firm in Boston, American universities have spent at least $\$ 100$ million on Web-based course offerings...now the groves of academe are littered with the detritus of failed e-learning startups as those same universities struggle with the question of how to embrace online education but not hemorrhage money in the process. (p. 1)

Lev S. Gonick (cited in Hafner, 2002), vice president for information services and chief information officer at Case Western Reserve University in Cleveland, states "University presidents got dollars in their eyes and figured the way the university was going to ride the dot-com wave was through distance learning" (p. 1). Gonick goes on to say that e-learning technology has largely failed and that, "Across U.S. campuses today, e-learning technology investments are at risk, and many technology champions are in retreat" (p. 1). One possibility for the failure of such institutions is not the technology itself but rather, the competition factor involved in offering online education.

\section{Online Learning: The Competition Factor}

In the past, family and/or work constraints limited prospective students to nearby educational institutions. Such constraints do not exist for online students and consequently, online students may choose from literally hundreds of higher educational institutions, courses, programs and even, professors. Thus, when higher education institutions enter the online education market, the recognition that other local universities are no longer their only competition is crucial. Therefore, while using the Internet makes the opportunity for enrolling more students 
possible, with this new opportunity for more students comes the wide-expansion of competition.

Despite growing competition, the two previous examples (UIS/SLU) illustrate the possibilities of generating revenue via online learning. Whether or not it works to improve enrollments and actually generate increased revenue, higher education seems to be moving in this direction. In 2003, it is hard to find a higher education institution that does not offer online learning or use some other form of distance learning. A recent study from California community colleges, Distance Education Report (Morrow et a1., 2001), said, "During the period of 1998 to 2000 , Internet based courses increased by 238 percent, going from 328 sections to $1001 "$ (p. 2).

The indisputable fact is that higher education offers a vast number of online courses, which may financially benefit colleges and universities. Since higher education has committed to online learning at such a high level, it follows that an exploration of online course retention rates is important. For instance, is higher education truly benefitting if and when students fail to complete large percentages of online courses?

Online Course Retention: Are We Doing a Good Job?

A recent Chronicle of Higher Education article stated:

Although there is significant variation among institutions with some reporting course-completion rates of more than 80 percent and others finding that fewer than 50 percent of distance-education students 
finish their courses, several administrators concur that coursecompletion rates are often 10 to 20 percentage points higher in traditional courses than in distance offerings. (Carr, 2000, \10)

This article points to "distance offerings," however, and does not address online learning specifically. McVay-Lynch (2002) states, "By 1997 the majority of US colleges and universities were reporting averages ranging from 30 percent to 75 percent of students not completing Web-based courses" (p. 12). Since no national statistics currently exist concerning online course retention, I looked at existing informal studies and anecdotal reports and found most corroborated Carr's claim (see Appendix A).

Out of seven reports (Crabtree, 2000; Cutler, 2000; M. Keefe, personal communication, January 31, 2002; T. Manning, personal communication, January 31, 2002; Mesa Community College, 2001; Morrow et al., 2001; Valdez, 2001) gathered concerning course retention in online courses at community colleges (Schreck, 2002), Washington state community colleges and technical schools reported the highest retention rate of $71 \%$ for a single term (spring 2001) and the highest rate averaged during a 3-year period representing spring terms 1999, 2000, 2001 at $68 \%$ (Valdez, 2001).

Despite a relatively high online course retention rate, Washington state community colleges and technical schools remain $12 \%$ below their on-campus retention rate of $83 \%$ averaged over a three-year period. The average retention rate for all community colleges in the research report was $58 \%$, a dismal 16 
percentage points below the average for community college on-campus courses $(74 \%)$.

Of four online course retention studies for 4-year colleges (Beatty-Guenter, 2001; Fox, 2000; Schreck, 2002; R. Schroeder, personal communication, November 8,2001 ), by far the best results come from the University of Illinois Springfield (UIS) and Marylhurst University (MU) in Portland, Oregon. Ray Schroeder, Director of Technology-Enhanced Learning at UIS, forwarded the results from his informal research via e-mail.

The informal report examined online retention rates from spring 1999 through summer 2001. Averaged over this 3-year period, UIS' overall online course retention rate is $90 \%$, with an on-campus rate around $94 \%$. Marylhurst's online course retention rate over a 5-year period is $91 \%$ with the on-campus rate being in the mid $90 \%$ range (Schreck, 2002). Since no national studies of online course retention rates currently exist, the details of most studies regarding online course retention are somewhat sketchy; therefore, comparing studies is problematic. How is a "drop" from a course defined? Are the courses graduate or undergraduate? What are the characteristics of the student population?

The "Responsibility and Obligation" of Retention

While economic stability is one reason to care about course retention and student retention in general, Tinto (1993), a leading researcher in student retention, stresses responsibility and obligation - values that exist in higher education to 
serve students. Tinto likens this sense of responsibility and obligation to other human communities, stating, "The essential character of such communities lies not in the formal structures and programs which they construct, but in the underlying values which inspire their construction" (p. 205). Essentially, courses and/or programs based on some values or guiding principles are more likely to retain students. Thus, retention is not the primary issue but rather, the educational experience itself.

Marylhurst University defies current statistics pertaining to deficiencies in online course retention and how these deficiencies can be detrimental to both the economic outlook and ethical considerations suggested by Tinto (1993). With an on-campus course retention rate of $95 \%$ and an online course retention rate of $91 \%$ ( $87 \%$ undergraduate and $95 \%$ graduate), MU shows the highest retention rates for online courses cited in this research proposal. Perhaps even more significant, MU students complete online courses at a rate that is very close to their on-campus courses. Therefore, MU represents a good example for further study and such a study may yield results helpful to struggling online courses, programs and/or distance learning departments.

In addition, MU's accomplishments concerning online course retention occurred over a 5-year period of sustained growth. Not only did MU retain its online students in courses, they did so at a high level of student satisfaction. ${ }^{1}$

\footnotetext{
${ }^{1}$ Course evaluation data were collected over a 1 year period. Eighty-five percent of the responses were favorable.
} 
What is it about the university that has consistently produced relatively high, online course retention rates, consistent with course retention on-campus? Can existing retention theory and models (Astin, 1975, 1977, 1984; Bean, 1982; Bean \& Metzner, 1985; Tinto, 1975, 1993) shed some light on why students complete online courses at MU? Are current retention models adequate for explaining retention in an online environment or do we need to fashion a retention model from researching online students exclusively?

$$
\begin{gathered}
\text { Marylhurst University - Background and Selected } \\
\text { Results of Pilot Study }
\end{gathered}
$$

Recognized by U.S. News and World Report as one of the top 30 universities in the Western region of the United States $(2001,2002)$ and ranked a "Best Value" (2003), MU is a small (approximately 1,000 students), private university, 10 minutes south of Portland, Oregon. P. Wittenberg (personal communication, October 31, 2003), Director of Marketing and University Communications, states:

MU serves non-traditional students, many who attend school while continuing to work. The University's focus on flexible scheduling, online course offerings, integrated coursework, credit for learning gained through life experience and liberal transfer credit policy helps students achieve their goals without skimping on academic quality. The outcomes-based Liberal Arts Core requirements ensure that MU graduates acquire skills needed to pursue the next step in their career or education.

Founded in 1893, Marylhurst was initially a women's college. In 1974, the school opened its doors to men, and in 1997 Marylhurst 
College became Marylhurst University. It offers bachelor's, master's and professional certificate programs.

\section{Marylhurst University Demographic and \\ $\underline{\text { Historical Information }}$}

Demographic information concerning MU's online courses certainly aligns with the part of the stated mission to "...make innovative post-secondary education accessible to self-directed students of any age." As seen in Table 1, featuring five age-groupings, the "traditional-aged" group $(<25)$ represents only $14 \%$ of the MU online learning community. The 25-34 age group represents the largest grouping of WBL students with a significant number represented in the two age groups that span from $35-54$. The mean age is 32 with the majority of students (68\%) being women. In addition to serving its mission, $\mathrm{MU}$ recognizes the current and future significance of online learning to the economic prosperity of the university.

Table 1

Age Groups for WBL Students $(N=1032) S D 1.05$

\begin{tabular}{|c|c|c|}
\hline Age Group & Number in Group & Percentage \\
\hline$<25$ & 142 & $14 \%$ \\
\hline $25-34$ & 343 & $33 \%$ \\
\hline $35-44$ & 272 & $27 \%$ \\
\hline $45-54$ & 234 & $23 \%$ \\
\hline $55+$ & 33 & $2 \%$ \\
\hline
\end{tabular}


N. Wilgenbusch (personal communication, October 8, 2002), Marylhurst University President, made the comments "Although, WBL has a vital economic impact now, starting online courses and programs was not a matter of economics but a matter of serving our student population. In the spring of 1996 , there was no research that supported the economic benefits of offering online education."

Even today, there is no guarantee that institutions can make money in online and/or distance learning. Carr (2001) states, "While distance-education programs are not going under like their dot-com counterparts, administrators are recognizing that the costs of expanding programs are - in some cases - greater than had been anticipated" ( $\$$ ). Carr also references six studies on distance learning, which conclude that universities are not really making or losing money and that the fiscal outlook depends a great deal on how costs and revenues are defined.

\section{Enrollment History}

Before online learning, MU's enrollments sufficiently sustained the university and at times, exceeded forecasts. Viewing online learning as the panacea to declining enrollments inaccurately portrays the MU situation. Since its inception, WBL's growing enrollments meant that more and more on-campus students took online courses as an option for their education. Thus, it is true that MU provides a service (online learning) to accommodate adult learners with busy lives. But, while WBL enrollments increased over the past 5 years, on-campus 
enrollments decreased. Essentially, most of the WBL students originate from the existing pool of on-campus students.

Marylhurst University, just like many other institutions, used online learning as a way to better meet the needs of its on-campus, adult learner population. Thus, MU did not see the significance of "virtually" expanding the physical boundaries of the college, attracting the global market that is possible using online learning. A historical picture of online and on-campus enrollments can be viewed in Tables 2 and 3.

During the summer of 2001 , credits generated through WBL were as high as $29 \%$ of the total credits generated at MU. With an ever-increasing amount of FTE originating via MU's WBL/D, the demand for more and better online student services, special "online student policies," and additional WBL/D employees continues to permeate the MU community.

Table 3 highlights several significant accomplishments in MU - WBL history between like-terms. Web-based Learning courses saw only one, percentage-of-decline in either students or credits generated (spring $2001,-4 \%$ in credits). An $838 \%$ increase highlights the largest single gain in student headcounts from winter 1997 to winter 1998, and over the last 6 years, when comparing like terms, the average percentage of increase is $20 \%$. From fall 1996 to fall 1997 , WBL showed its biggest increase in credits generated at $519 \%$; and over the last 6 years, when comparing like terms, the average percentage of increase in credits is $15 \%$. Over the past 6 years, MU's WBL growth is evident. 
Table 2

Unduplicated Headcounts and Duplicate Credits for WBL and On-campus Students at MU: A Term Analysis

\begin{tabular}{|c|c|c|c|c|}
\hline & $\begin{array}{l}\text { WBL Students/ } \\
\% \text { of MU Total }\end{array}$ & $\begin{array}{l}\text { WBL Credits/ } \\
\% \text { of MU Total }\end{array}$ & $\begin{array}{l}\text { MU Total } \\
\text { Students }\end{array}$ & $\begin{array}{l}\text { MU Total } \\
\text { Credits } \\
\end{array}$ \\
\hline Fall 96 & & 84 & & \\
\hline Fall 97 & $111 / 8 \%$ & $520 / 6 \%$ & 1417 & 9327 \\
\hline Fall 98 & $142 / 11 \%$ & $795 \quad / 9 \%$ & 1272 & 8579 \\
\hline Fall 99 & $190 / 14 \%$ & $935 /$ & 1350 & $?$ \\
\hline Fall 00 & $295 / 29 \%$ & $1641 / 21 \%$ & 1028 & 7754 \\
\hline Winter 97 & 13 & 91 & $?$ & $?$ \\
\hline Winter 98 & $122 / 11 \%$ & $517 / 6 \%$ & 1108 & 8889 \\
\hline Winter 99 & $177 / 17 \%$ & $946 / 11 \%$ & 1062 & 8579 \\
\hline Winter 00 & $252 / 25 \%$ & $1427 / 17 \%$ & 1013 & 8176 \\
\hline Winter 01 & $301 / 32 \%$ & $1589 / 22 \%$ & 934 & 7171 \\
\hline Spring 96 & $?$ & 100 & $?$ & $?$ \\
\hline Spring 97 & 261 & 136 & $?$ & $?$ \\
\hline Spring 98 & $127 / 11 \%$ & $692 / 9 \%$ & 1172 & 8100 \\
\hline Spring 99 & $183 / 16 \%$ & $997 / 12 \%$ & 1132 & 8243 \\
\hline Spring 00 & $263 / 26 \%$ & $1567 / 20 \%$ & 1021 & 7595 \\
\hline Spring 01 & $288 / 31 \%$ & $1511 / 22 \%$ & 943 & 6813 \\
\hline Summer 96 & $?$ & 73 & $?$ & $?$ \\
\hline Summer 97 & $52 /$ & 204 & $?$ & $?$ \\
\hline Summer 98 & $109 / 12 \%$ & $502 / 11 \%$ & 879 & 4525 \\
\hline Summer 99 & $130 / 17 \%$ & $542 / 13 \%$ & 751 & 4129 \\
\hline Summer 00 & $157 / 24 \%$ & $762 / 19 \%$ & 664 & 3916 \\
\hline Summer 01 & $208 / 34 \%$ & $957 / 29 \%$ & 605 & 3322 \\
\hline
\end{tabular}


Table 3

Unduplicated Headcounts and Duplicate Credits for WBL - Percentages of Increase Over a Six-Year Period by Term

\begin{tabular}{|c|c|c|c|c|}
\hline & WBL Students & $\begin{array}{l}\% \text { WBL Student } \\
\text { Increase }\end{array}$ & WBL Credits & $\begin{array}{l}\% \text { of WBL } \\
\text { Credit Increase }\end{array}$ \\
\hline Fall 96 & & & 84 & \\
\hline Fall 97 & 111 & & 520 & $+519 \%$ \\
\hline Fall 98 & 142 & $+28 \%$ & 795 & $+53 \%$ \\
\hline Fall 99 & 190 & $+34 \%$ & 935 & $+17 \%$ \\
\hline Fall 00 & 295 & $+55 \%$ & 1641 & $+76 \%$ \\
\hline Winter 97 & 13 & & 91 & \\
\hline Winter 98 & 122 & $+838 \%$ & 517 & $+468 \%$ \\
\hline Winter 99 & 177 & $+45 \%$ & 946 & $+83 \%$ \\
\hline Winter 00 & 252 & $+42 \%$ & 1427 & $+51 \%$ \\
\hline Winter 01 & 301 & $+19 \%$ & 1589 & $+11 \%$ \\
\hline Spring 96 & $?$ & & 100 & \\
\hline Spring 97 & 26 & & 136 & \\
\hline Spring 98 & 127 & $+388 \%$ & 692 & $+36 \%$ \\
\hline Spring 99 & 183 & $+44 \%$ & 997 & $+409 \%$ \\
\hline Spring 00 & 263 & $+44 \%$ & 1567 & $+44 \%$ \\
\hline Spring 01 & 288 & $+10 \%$ & 1511 & $-4 \%$ \\
\hline Summer 96 & $?$ & & 73 & \\
\hline Summer 97 & 52 & & 204 & $+179 \%$ \\
\hline Summer 98 & 109 & $+110 \%$ & 502 & $+146 \%$ \\
\hline Summer 99 & 130 & $+19 \%$ & 542 & $+8 \%$ \\
\hline Summer 00 & 157 & $+21 \%$ & 762 & $+41 \%$ \\
\hline Summer 01 & 208 & $+32 \%$ & 957 & $+26 \%$ \\
\hline
\end{tabular}


A Final Note Concerning MU Online

Retention

Besides the noticeable difference between graduate $(95 \%)$ and undergraduate $(87 \%)$ students, Schreck (2002) found no significant difference between other groupings of online students at MU. For example, out-of-state students who never come to the MU campus retain at the same level as students who take a combination of on-campus and online courses. To continue, age differences seem to have nothing to do with online course retention at MU for 18-25 year-old students retain at similar percentage levels as students in the 45-54 year-old range. Finally, online course retention rates are similar for all academic departments offering online education.

\section{Statement of the Problem}

Concerning "the problem," Creswell (1998) states, "it might be clearer if we call it the need for the study" (p. 94). As highlighted and explained in chapter 3, "Review of Relevant Discourses," the need in this study becomes evident when examining existing retention models that clearly do not address online learners and/or online course retention. This in turn creates a problem for administrators looking to the literature in an effort to improve their online course retention. Through a grounded theory approach, taking a look at the MU phenomenon may provide the necessary information to create such a model - a model for online 
course retention. Thus the problem becomes, "Can a model for online course retention be fashioned by further investigation into the MU phenomenon?"

\section{$\underline{\text { Significance }}$}

The findings from my initial study (Schreck, 2002) generated considerable interest among selected distance learning/student retention communities. A posting concerning online student retention to the "Student Retention Listserv," which is administered by the Journal of College Student Retention, resulted in immediate response from more than 20 distance learning/retention professionals. WebCT quickly approved my proposal for a paper presentation concerning the preliminary research conducted at MU (Shreck, 2002). Other professionals conducting similar research quickly shared their results with me and wanted as much information from me to help explain MU's online course retention rates. The question I am most asked is, "How can we [a particular institution] improve our retention rates?"

Although interest in a topic is welcome, it does not make it particularly significant in the eyes of the research community. Therefore, in this study, I believe the literature review that accompanies this proposal provides strong support for the need and significance of this study. Existing theoretical models of retention - models developed during a time when online learning did not even exist and formulated in the context of on-campus, student populations - have limited applicability to online learning environments. New models need to be developed for the distance learning community. 


\section{$\underline{\text { Limitations }}$}

Perhaps the first study of its kind, this study focuses on a specific phenomenon (MU online course retention); thus, the overall scope is narrow. People often suggest, "Why not compare the results to other institutions?" The purpose of this study is not to compare the results of the phenomenon to other institutions. The purpose of this study was to discover what was happening at MU and consider the results to generate a new theoretical perspective for online course retention. Because this study used a grounded theory approach with a narrow focus, generalizing the results to all online courses and/or programs is not realistic.

As currently proposed, the "Methods" section may not address the significance of what actually occurs in an online course. Meaning, the Subjects' interactions will not be tracked with an objectively created checklist - examining each class in quantitative fashion looking for the number of posts to the bulletin board per week by the Subjects or recording how many times they check-in. At this time, I do not see the relevance of doing such a thing unless identified in the data. Regardless, it is a limitation.

Purpose of the Study

The study explicates the reasons why MU online students complete courses at current rates and develops this understanding into an online student retention model. When generating a new model, the importance of comparing and 
integrating my interpretations with other relevant topics (e.g., learning theory, adult development, teaching methodologies, best practices) to see if relationships exist was vital. I used a "grounded theory" approach, Creswell (2002) describes as, "...a systematic, qualitative procedure used to generate a theory that explains, at a broad conceptual level, a process, an action, or interaction about a substantive topic" (p. 439).

Glaser, as cited in Charmaz (2000), "...argues that the purpose of grounded theory methods is to generate theory, not to verify it" (p. 513). Therefore, generating theory was the primary outcome of this study; however, I included a validation process as outlined in the "Methods" section, and reported in "Research Findings." At this stage in developing the research, I defined online course retention as "students completing courses offered via the Internet." Other important definitions follow.

\section{$\underline{\text { Definitions }}$}

Student retention: Most often associated with a college's ability to keep students enrolled in their institution over consecutive years and graduate students with undergraduate/graduate degrees.

Course retention: Refers to students completing online courses.

Program retention: Associating retention to a student's enrollment in a particular educational program or major. 
Student attrition: The leaving of a college, program or course prior to completion.

Dropping a course: A drop usually occurs within an established time period (drop date) at the beginning of each term or semester. If a student drops a course, they will usually get all or a percentage of their money back and the course will not appear on a transcript.

Withdrawal from a course: A withdrawal is when a student drops a course after the drop date. The result usually is a loss of most or all of the student's tuition and a "W" on a transcript. The "W" does not affect the student's grade point average (GPA).

Dropout: A student chooses to leave an educational institution permanently.

Stop out: A student temporarily leaves an educational institution.

\section{Research Questions}

The research process was guided by a central research question and subsequent, related questions. These questions provided a dynamic platform for further inquiry and according to Creswell (1998), "...will change several times during data collection and analysis" (p. 179). However, I found this to be untrue, and in actuality, the questions were like a roadmap throughout the entire research process. 


\section{Central Question}

After studying successful online learners at MU, what theory emerged from the raw data to help explain MU's current success with online course retention?

\section{$\underline{\text { Related Questions }}$}

1. What were the predominant categories that were pulled from the raw data and how do they connect to current literature concerning online retention?

2. How did the properties (main attributes) of each category relate and/or interconnect and how did these relationships lead to the development of a core category?

3. After each category's properties were dimensionalized on a continuum, how was the theoretical model built and did it lead to discursive theoretical propositions about online course retention.

4. Whether a model is constructed or not, can anything be discovered in the raw data to inform the distance learning community about "best practices" for online course retention?

5. What is next for further development and research into this model for online course retention?

\section{Chapter I Summary}

The introduction attempted to provide insight into the question "Why should we care about retention in the first place?" What is the "need" to care about retention? A summary of the rationale for the study follows: 
1. Economically, it makes sense to care about retention. Institutions are dependent upon student tuition dollars.

2. More and more students use online learning as a viable option for their higher education experience.

3. A greater number of higher education institutions use online learning as a delivery method for courses; thus, competition in the online learning environment becomes an important factor.

4. We need to care about retention because based on the research gathered for this study, we are not doing a good job at retaining online students at the course level.

5. Finally, the background to the problem ends with the important assumption that institutions have a responsibility to do a good job at retention.

Based on steps 1-5, MU provides an example of a school that is doing a good job at online course retention and is worthy of a closer look.

The final step in this process of identifying the problem is the careful examination of existing student retention models. As Creswell (1994) states, For a grounded theory study, the theory takes center stage, and I would expect to learn how we need to modify an existing theory because it ill suits a population or issue or how we need to generate a theory because no existing theoretical perspective fits a particular issue. (p. 95) 


\title{
CHAPTER II
}

\section{REVIEW OF RELEVANT DISCOURSES}

\author{
Purpose of this Literature Review
}

In quantitative research, a literature review provides direction for the study and guides the development of research questions and hypotheses. According to Creswell (1994), "In qualitative research the literature should be used in a manner consistent with the methodological assumptions; namely, it should be used inductively so that it does not direct the questions asked by the researcher" (p. 21). As May (1986) states, the literature review in a grounded theory study, "neither provides key concepts nor suggests hypotheses as it does in hypotheticodeductive research" (p. 149). To sum-up the use of literature in a grounded theory study Creswell (1998) adds, "Instead, this literature review shows gaps or bias in existing knowledge, thus providing a rationale for a grounded theory study" (p. 179).

While the purpose of the literature review may now be clear, there is some dissension on placement of the literature in research reports. Creswell (1994, 1998), Cooper (1984) and Strauss and Corbin, (1998) suggest various placements of literature, starting with framing the "problem" in the "Introduction," to the more traditional "literature review chapter" using an integrative approach that 
summarizes past studies and finally, the use of literature at the end of the study to compare and contrast with the findings of the study. For a grounded theory study, Creswell (1994) recommends the literature at the end "because it uses the literature inductively" (p. 22).

For purposes of this study, I did not adhere to one particular location. I used Cooper's (1984) "integrative summary" approach to cover various studies in the "Introduction." This helped give some urgency to the importance of online course retention and the fact that many institutions are finding it hard to keep their online students. This chapter uses a theoretical approach to highlight retention theory/models with hopes of convincing readers of their inadequacy toward online learners and presents possibilities for a new theoretical model for online students. Chapter 4, "Research Findings," uses the literature to compare and contrast with the research findings. "Literature support" was one of the factors I used when analyzing the importance of emerging findings.

As stated previously, the retention literature and theoretical models of Tinto (1975, 1993), Bean (1982), Bean and Metzner (1985), and Astin (1975, 1984, 1993) provide context to student retention in general and form the foundation from which to examine other relevant discourses. In this case, "other relevant discourses" refers to any literature that pertains directly to the findings of this study and thus, appears later in chapter 4 . Examining the significance of these major theoretical models and their significance to MU's online course retention rate is essential for further study. Do we need a new model to examine online 
student retention? Are there crucial gaps in these existing models that cannot explain certain phenomena in MU's distance learning program? This literature provides an excellent starting point for answering these questions and pondering the significance of recent studies concerning online course retention.

\section{Student Retention Models}

Previous retention models focus on attainment of a college degree (retention), or making sure students do not leave college (attrition). The theoretical models covered in this chapter were not intentionally developed to account for course-specific-retention. If models exist explaining course-specificretention, I was unable to locate any for this study. Due to the lack of theoretical support for course-specific-retention, the institutional retention literature was the next logical step for inquiry.

Why do students dropout of a college course, program or institution? As an initial reaction, some might attribute this to academic failure - academic failure that was caused by external or institutional factors. While these external and institutional factors are critical with regards to retention, Kalsner (1991) states "only $15 \%$ actually drop out because of dismissal from the institution and...most of the students who remain in college have lower grade point averages then the students who drop out" (p. x). The issue of college student retention, whether it is course, program or institutional, is complex and has been the subject of vast 
amounts of research. Three theorists and researchers provide models for explaining student retention: Tinto, Bean and Astin.

Tinto: Student Integration Model

Tinto's (1975) student integration model forms the basis for modern views of student retention. Originally developed in 1975, Tinto revisited the student retention literature and re-articulated his model into the "student retention model of institutional departure" in 1993. The model hypothesizes "persistence is a function of the match between an individual's motivation and academic ability and the institution's academic and social characteristics" (Cabrera, Castaneda, Nora, \& Hengstler, 1992, p. 145). Tinto believes the greater the level of "match" between the individual and the institution, the greater the chances for persistence within that particular institution. In addition, Tinto (1993) offers three principles that underlie effective retention programs:

1. Effective retention programs demonstrate a commitment to the welfare of students above other institutional goals.

2. Effective retention programs exhibit a commitment to the education of all students.

3. Effective retention programs show a commitment to the formation of supportive social and educational communities that strive to integrate all students as full members into such communities. 
Tinto's model places a great emphasis on the power of institutions to influence a student's chances for persistence. For example, the academic and social background (family, high school academic performance, etc.) helps to formulate a set of goals and commitments in each student's mind. In turn, students bring these goals and commitments with them to higher education institutions. Although the level of goals and commitments are different in each student and are greatly influenced by background, when mixed with the academic and social settings at their respective colleges, the restructuring of goals and commitments commonly occurs.

As seen in Figure 1, Tinto's model has two major tracks of institutional integration: academic and social. Students carry goals and commitments into the academic realm where academic performance (formal) and/or faculty/staff interactions (informal), either positively or negatively influence them. Both formal and informal interactions set the level of academic integration into the institution. In the social realm, extracurricular activities (formal) and peer group interactions (informal) form the two major systems of influence. These formal and informal social interactions shape the level of social integration into the institution. At this point, a student is able to construct new goals and commitments and thus, a new paradigm for either persistence or departure. 
Tinto's Model of Student Departure

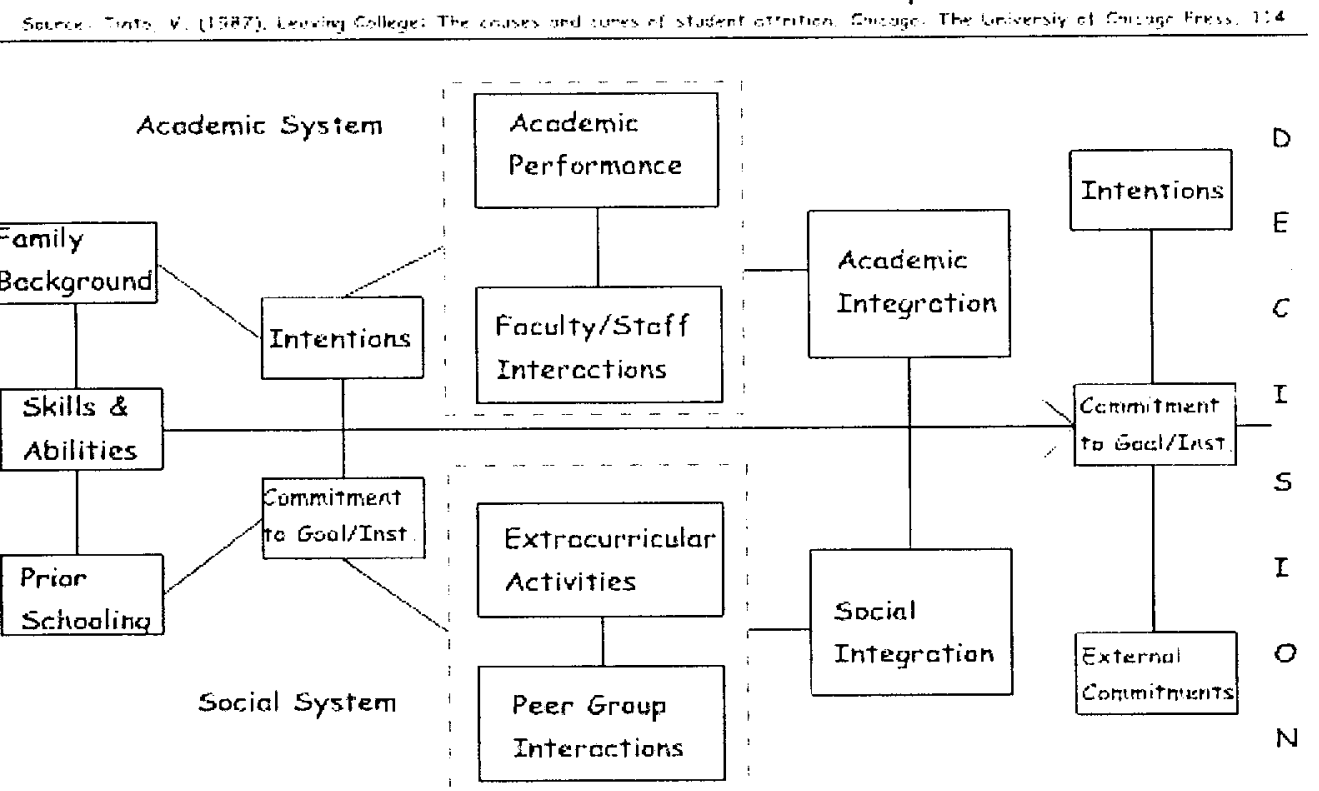

Figure 1. Tinto's model of student departure. Source: Tinto (1993).

With respect to Tinto's model, students with excellent high school GPAs, high test scores and supportive families probably visualize what their goals and/or commitments will be in the college environment. Under these circumstances, the achievement of goals and commitments is at a high level. However, imagine in the freshman year, a student's academic performance is substandard and they are placed on probation. When examining the student's social interactions, it becomes evident that the student's peer group is also in the same boat academically. In a sense, the student's level of social integration with peers has not reinforced positive academic integration. Therefore, when the student reassesses goals and 
commitments, either they formulate a plan for steady improvement or they may consider departing from college or dropping out all together.

This example brings to light the possible importance of factors external to the college. Tinto's analysis of existing research and subsequent theory of student departure centered on the "traditional college student." Essentially, the traditional college students were in the 18-25 year age group and attended a residential college. Few if any of these college students had the pressures of holding down a professional career, raising kids and worrying about financial stability. Although socialization in peer groups could be considered something "external" acting on a student, it is more often considered an "environmental" factor. External factors are outside the institution. Since most retention researchers focused on traditional aged students, consideration for the external pressures of today's adult students did not occur.

Regardless of this limitation, Tinto's model remains significant and influential. Braxton and Sullivan (1997) reconfigured Tinto's model into 15 testable propositions. The main research question being, "What is the magnitude of empirical support, in the aggregate, for each of the 15 testable propositions derived from Tinto's Theory?" (Braxton \& Sullivan, 1997, p. 109). Partial support for four propositions was discovered through research and is clearly stated in Braxton (1999):

1. student entry characteristics affect the level of initial commitment to the institution; 
2. the initial level of commitment to the institution affects subsequent commitment to the institution;

3. the greater the degree of social integration, the greater the degree of subsequent commitment to the institution; and

4. the greater the degree of subsequent institutional commitment, the greater the likelihood of student persistence in college (p. 95).

Braxton (1999) also stated that, "Although these four propositions possess logical internal consistency, social integration remains unaccounted for by these

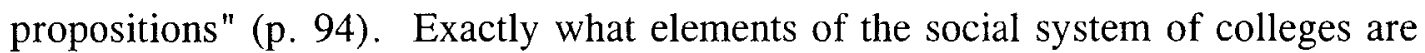
participating and aiding social integration? Tinto (1975) states that "...informal group associates, extracurricular activities and interactions with faculty and administrators are mechanisms of social integration" (p. 107). However, the research does not demonstrate the extent to which these factors influence persistence.

Ashar and Skenes (1993) showed that outside the realm of traditional students, Tinto's model has less applicability. Their study tested Tinto's propositions with adult students - all management majors who returned to school for work-related reasons. "Overall, the results of this study only partially support Tinto's claims. While the social integration has a significant and positive effect on retention, the academic integration as well as the career integration do not have such an effect" (Ashar \& Skenes, 1993, p. 98). 
The study also found that when working with adult students, there is a correlation between the class-size and retention. In this particular study the mean class size was 15 , which is comparable to the mean class-size of MU online courses. Considering the testable propositions in Tinto's model and adult students, "The data suggest that what keeps adult learners in educational programs is the social environment" (Ashar \& Skenes, 1993, p. 90). Can this "social environment" be recreated in online courses? If so, to what extent and how is it different than on-campus social interaction?

Let us explore the description of what an online course looks like with respect to Tinto's model. First, there is evidence of new, online students undergoing some type of assessment of skills and abilities as they relate to technology and learning. Essentially, MU inquires if the new student has any previous online experiences and/or courses with another institution. Perhaps, someone asks the student, "Is a computer used in the home and to what extent? What is the general level of competency of other users in the household?" The WBL/D would use this information to custom design an orientation package that would outline the student's use of online courses to fulfill other commitments, goals and intentions within MU.

In addition, the central core themes of Tinto's model are academic and social integration. When developing his model, Tinto's parameters for describing academic and social integration did not include online or virtual environments. Therefore, it is difficult to compare his definitions to what they may look like in an 
online environment. Part of this study had to do with examining student experiences in online environments for how such experiences relate to academic and social integration processes.

For instance, I have overheard MU instructors describe their time commitment to an online learning course as being three times that of an on-campus course. As one instructor recently stated, "most of that time is spent communicating with individual students in an effort to help them better understand course material." Therefore, several MU online instructors have concluded: "I get to know the students both personally and academically way more than in a face-to-face situation."

\section{Bean: Student Attrition Model}

The Bean (1982) model considers the environmental factors that constantly affect students including family pressure, instructor difficulties, and a disagreement with an administrator over a college policy. Identifying the exact environmental factor is not as important as identifying the attitudes the environmental factor elicits in a student. Bean's model demonstrates a more "people are products of their environment" example of retention. "In this context, the student attrition model presumes that behavioral intentions are shaped by a process whereby beliefs shape attitudes and, attitudes, in turn, shape behavioral intents" (Cabrera et al., 1992, p. 145). 
In a 1992 report published in the Journal of Higher Education, Cabrera et al., tested Bean's model for predictive validity and found "...only six of fifteen structural paths hypothesized in the Student Attrition Model were found to be statistically significant" (p. 152). These six factors were parental approval of institutional choice, finance attitudes (satisfaction with financial support), opportunity to transfer, institutional fit and quality, secure future employment, and friends' rating of institutional quality.

In 1985, Bean and Metzner decided to expand research on student retention to include, "non-traditional" students and created the nontraditional student attrition model as seen in Figure 2. They did this for two reasons: (a) Prior models, including Tinto's, used only traditional-aged students and, (b) A growing population of "adult" or "non-traditional" students entered higher education. Bean and Metzner (1985) define "non-traditional" as follows:

A non-traditional student is older than 24 , or does not live in a campus residence (i.e., is a commuter), or is a part-time student, or some combination of these three factors; is not greatly influenced by the social environment of the institution; and is chiefly concerned with the institution's academic offerings (especially courses, certification and degrees). (p. 489)

With the inclusion of external factors and the emphasis on non-traditional students, Bean and Metzner's theory appears to make more sense when considering the non-traditional majority that depicts MU's online learners. 


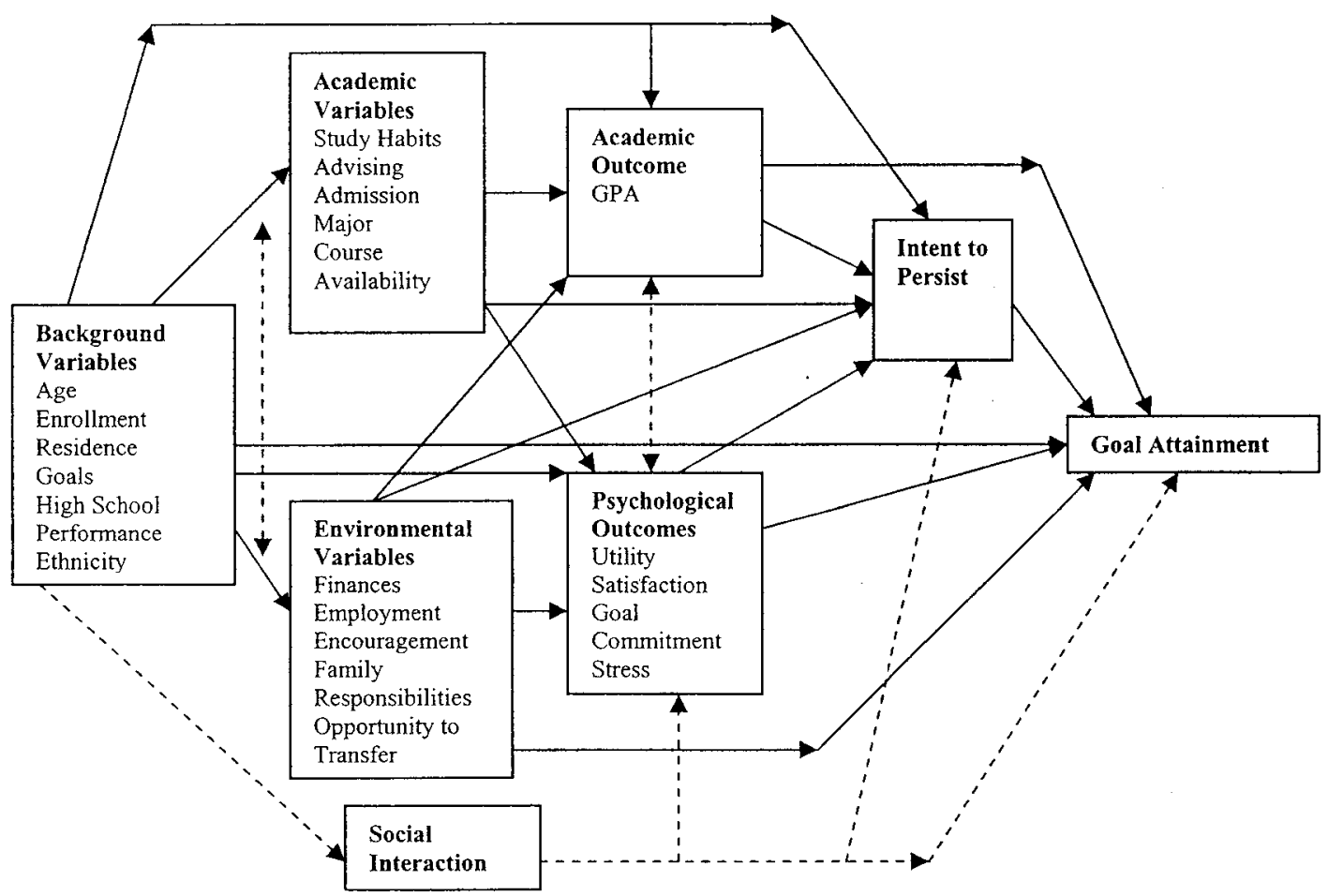

Figure 2. Bean and Metzner's model of nontraditional student retention.

Essentially, Bean and Metzner (1985) do not place the emphasis on an institution's social structure and the subsequent socialization associated with traditional students in Tinto's model because they are firmly entrenched within adult lives outside the institution. Bean and Metzner believe "the nontraditional student does not greatly change his/her social environment" (p. 489). Not easily influenced or swayed by social groups and social pressures, an adult student's worry comes more from the external factors of a busy life.

Bean and Metzner's view of adult socialization sits in direct contrast with the findings from Ashar and Skenes (1993) discussed earlier. In their research report, Ashar and Skenes found that socialization correlates the highest with 
retention. With conflicting information, I find it interesting to see how adult learners in online courses rate socialization and their ability to complete courses. Ashar and Skenes did not examine external, environmental variables, which Bean and Metzner found vital in the retention of adults.

The emphasis on external, environmental variables (e.g., finances, hours of employment, outside encouragement, family responsibilities) fits well with adult students. One might describe online learning as providing the type of learning that accommodates for such common, outside interference. Marylhurst University online courses give students the flexibility to come and go as they please, and allow long periods for posting assignments. One MU student recently stated:

Online learning is perfect for me because I can spend time with my family, read to my kids, put them to bed and then go check into my course. Sometimes, I may spend an hour. Other times, I may be in for up to three hours. Going to an on-campus course is such a setregime - even if there's not much to cover, you still go and sit there. Online, you can pick and choose your battles. All time spent seems relevant with little waste.

In a sense, online students create their own levels of academic and social participation in a course and do so on their own terms.

\section{Alexander Astin: Student Involvement} Theory

Astin $(1975,1977,1993)$, a prolific voice in the study of student retention as well as various other topics, provides an in-depth look at student retention in Preventing Students From Dropping Out and Four Critical Years. Four Critical 
Years used large pools of existing longitudinal data to discover three major areas of involvement as key factors in retention.

1. Academic involvement - "The extent to which students work hard at their studies, the number of hours they spend studying, the degree of interest in their courses, good study habits..." (Astin, 1984, p. 303).

2. Involvement with faculty - Refers to the amount of time students spend with faculty both inside and outside of class. Astin (1984) believes that students who interact often with faculty members express greater satisfaction with the overall college experience (p. 304).

3. Involvement with student peers - Refers to the amount of time spent interacting with other students. This is most often shown through the benefits of living in a residence hall, which Astin (1984) cites as the "...most important and pervasive of all environmental factors" (p. 302).

While Tinto (1975, 1993), Bean (1982), and Bean and Metzner (1985) focused on how well students integrate both academically and socially, Astin examined the extent to which the level of a student's involvement affects their retention. Astin (1984) defines involvement as "...the amount of physical and psychological energy that the student devotes to the academic experience" (p. 297); thus an "...involved student is one who devotes considerable energy to academics, spends much time on campus, participates actively in student organizations and activities, and interacts often with faculty" (p. 297). Based on Astin's (1975, 1977 , 1993) findings, involvement is the essential factor in keeping students enrolled. 
Astin's student involvement theory differs from other models in this section due to its focus on students' learning experiences. While Tinto and Bean consider "academic" integration, they fail to address specific qualities of the learning experience and how those qualities translate into retaining students. Astin believes that the more a student is involved in both the academic and social aspects of the college experience - the richer their learning experiences and, therefore, the better their academic performance. The focus on the quality of the learning experience is not the only thing that distinguishes Astin's model from those of Tinto and Bean.

Bean (1982) and Tinto $(1975,1993)$ encourage academic and social integration but such integration is not necessarily an active process for the student. Bean and Tinto view integration not as a way to "get involved," or insist that students seek out ways to become integrated both academically and socially. Rather, integration occurs rather covertly within the academic and social structures of the institution. One might observe this covert integration in a college mentoring program, faculty-advising sessions, and social programs available in the residence halls, etc. However, integration does not imply that "more is better." Astin's research does imply that integration is an active process that is marked by "joining" and "participating." By doing so, the learning experience is improved and thus, students retain their status in the institution.

For Astin's student involvement theory to apply to online learning, recognizable characteristics of involvement as defined by Astin must be present. In online learning, expending physical energy relates to the time spent typing and 
preparing assignments. It certainly is not how Astin (1984) explains it in a previous passage "spending much time on-campus, participating actively in student organizations and activities" (p. 297).

Despite the unique nature of online learning, MU online courses produce more involvement than one might think. If involvement levels are high, then one assumes resulting high levels of student satisfaction, student development and student learning. Astin (1984) states, "The theory assumes that student learning and development will not be impressive if educators focus most of their attention on course content, teaching techniques, laboratories, books, and other resources" (p. 301), to the neglect of involvement.

Where might one observe such involvement in online courses? A first place to look is the discussion board where the posting of messages takes place. Since $100 \%$ of this conversation is in writing, there is more time for an instructor to gather a better sense of each respective student's thought-structures and logic as compared to a face-to-face course. Faculty may be putting their texts aside, worrying less about "does the class get it" and focusing more on "does this individual student understand." If not, there may be an intentional emphasis to help individual students; thus, student involvement with faculty increases.

Astin (1984) also states that,

the most precious institutional resource may be student time. According to the theory, the extent to which students can achieve particular developmental goals is a direct function of the time and effort they devote to activities designed to produce these gains. (p. 301) 
If MU online students mention the importance of time as a major issue in persistence through courses, this may suggest the relevance of Astin's theory of student involvement at MU. On campus, students have two to three hours per week to construct an understanding of a particular topic. Online, there is a possibility of spending much more time working with both the instructor and other students in order to build a better understanding.

\section{Chapter II Summary}

While the models of Tinto $(1975,1993)$, Bean (1982), Bean and Metzner (1985), and Astin $(1975,1977,1993)$ present a theoretical basis for assessing retention and retention-related issues, the models do not focus on course level retention and more specifically on online course retention. All models except Bean and Metzner (1985) focus on traditional-aged students in residential-collegesettings. Ashar and Skenes (1993) note the importance of two variables in Tinto's model (socialization and class-size) to adult learner retention. However, their results reflect on-campus learning in a single, academic discipline (business management).

Online students may not have access to many of the experiences outlined in the retention models (e.g., peer group interactions, extracurricular activities, instructor interactions, student organizations, student services) or they interact with the institution in different and unique ways. For example, an online student might 
do all their academic advising using computer conferencing via a synchronous (at the same time) chat tool. 


\section{CHAPTER III}

\section{METHODS}

Charmaz (2000) states, "Grounded theory methods specify analytic strategies, not data collection methods" (p. 514). After completing this chapter, I can now see why Charmaz made that statement. However, as a newcomer to grounded theory research, I found it essential to frame the increasingly complex and detailed analysis within the context of three, distinct, collection stages. Therefore, following some initial discussion concerning the research context and sampling, the three-stage process for collection and analysis is fully explained and detailed. This chapter culminates with the validation plan for the Online Course Retention Model (OCRM).

\section{Purpose of the Study}

The purpose of this study was to explicate the reasons why MU online students completed courses at current rates and develop this understanding into an online student retention model. The study used a "grounded theory" approach. Creswell (2002) describes this approach as, "a systematic, qualitative procedure used to generate a theory that explains, at a broad conceptual level, a process, an action, or interaction about a substantive topic" (p. 439). Glaser, as cited in 
Charmaz (2000), "argues that the purpose of grounded theory methods is to generate theory, not to verify it" (p. 513).

\section{Research Questions}

\section{Central Question}

After studying successful online learners at MU, what theory emerged from the raw data that helps to explain MU's current success with online course retention?

\section{Related Questions}

The first three questions related to specific research stages in the collection and analysis process. Chapter 5 addressed the remaining research questions.

Stage 1: What predominant categories emerged from the raw data, and how did they connect to current literature concerning online retention?

Stage 2: How did the properties (main attributes) of each category relate and/or interconnect, and how did these relationships lead to the development of a core category?

Stage 3: After each category's properties were dimensionalized on a continuum, how were the theoretical model built and what, if any, theoretical propositions about online course retention were made? 
Chapter 5: Whether a model was constructed or not, what was discovered in the raw data to inform the distance learning community about "best practices" for online course retention?

Chapter 5: What is next for further development and research into this model for online course retention?

\section{Theoretical Perspective}

\section{Using the Qualitative Paradigm}

Marshall and Rossman (1999) state, "In short, the strengths of qualitative studies should be demonstrated for research that is exploratory or descriptive and that stresses the importance of context, setting, and the participants' frames of reference" (p. 58). While many people have speculated on how to retain online students in light of rather dismal projections, no single peer-reviewed research report could be identified that provides theoretical grounding. Thus, Marshall and Rossman recommend such research be conducted "...on little-known phenomena or innovative systems" (p. 57). Without further study, colleges will continue to struggle with online course retention.

\section{Guiding Theoretical Position}

Hatch (2002) recommends that the research methodology match both the researcher's ontological and epistemological views. Ontology, meaning the nature of reality, ranges from the positivist view - "Reality is out there to be studied, 
captured, and understood" (p. 13) to the poststructuralist view - "Order is created within individual minds to ascribe meaning to a meaningless universe" (p. 13). Epistemology, meaning the relationship of the researcher to that being researched, ranges again from the positivist view - "Knower is distinct from the known" (p. 13) to the poststructuralist view - "Researchers examine the world through textual representations of it" (p. 13). These extreme views and all the other theoretical paradigms in between (e.g., postpositivist, constructivist, critical theory/feminism) dictate the specific qualitative approach, which theoretically guides a study.

Ontologically (re: the nature of reality), I found myself steering away from the constructivist stance. Constructivists believe "...absolute realities are unknowable, and the objects of inquiry are individual perspectives or constructions of reality" (Hatch, 2002, p. 15). In this study, I wanted to capture some semblance of the reality that online students experience at MU and make it available to a larger audience.

In order to accomplish this task, I interpreted meaning from written text and built connections to create a larger theoretical picture. Is it possible for research subjects to recreate their "reality" when answering questions about online courses? Is it possible for me to accurately capture their reality and build a cohesive picture? Subjects' comments are not the actual experiences but accounts of the actual experiences. My analysis is also a reconstruction of mounds of data or "accounts." I felt this was possible but only to a certain extent - in a sense, I 
believe that reality exists but "...it is never fully apprehended, only approximated" (Hatch, 2002, p. 13).

Epistemological assumptions are based on what can be known and/or the relationship of knower and known. My relationship with the "known" in this study was one of "data collection instrument." The reality I reported is only my "approximation" of what occurred. This may sound constructivist; however, in constructivist epistemology, the "Researcher and participant co-construct understandings" (Hatch, 2002, p. 13). My plan was to approximate a model based on my interpretations of the Subjects' realities. Therefore, ontologically and epistemologically, my stance pointed me squarely in the postpositivist direction.

According to Charmaz (2000), postpositivists assume an objective, external reality and differ from positivists in that they give their research subjects a voice - a voice that is used to promote accuracy, validity and reliability. Hatch (2002) describes postpositivist methodology as "rigorously defined" and the "products" as grounded theory. While the views of constructivist and poststructuralist research do little to address validity, reliability and generalization, the postpositivist perspective recommends addressing all of these in the Methods section.

\section{Guiding Collection/Analysis Model}

Emerging theoretical perspectives such as critical theory, feminism and postmodernism all point the grounded theory researcher in different directions when considering collection and analysis of data. Indeed the observation of 
grounded theory in many different forms is common and debate concerning what truly is and is not grounded theory is somewhat contentious (Babchuk, 1996; Charmaz, 2000; Haig, 1995; Hueser, 1999; Kinach, 1995). The theoretical perspective of postpositivism as outlined previously fits well with the rigorously defined research methods of Strauss and Corbin (1998) who recommend three coding stages (open, axial, selective) and a validation process. Therefore, Strauss and Corbin's techniques for conducting grounded theory research served as a template for collection and analysis in the research process. If deviation and/or modification occurred, these changes have been explained within the various collection stages.

\section{$\underline{\text { Research Context }}$}

This section provides the reader with the necessary information concerning online courses or the "setting" of the study. What do online courses at MU look like? How are they run? Are there any specific policies for online courses or course development? What is the level of faculty involvement in the course development stage? What grade-level and academic departments are recognized?

At MU, online courses are developed and delivered using a software package called "WebCT." WebCT stands for "Web Course Tools." WebCT is merely a collection of tools (e.g., content display, discussion board, private mail, chat, whiteboard), which, when used properly, create opportunities for teaching and learning. WebCT cannot make a bad teacher a good teacher and it does 
nothing to promote best practices ${ }^{2}$ in online pedagogy. WebCT is simply the vehicle used by MU to deliver online courses.

Creating new courses in WebCT is usually an involved process but reusing existing courses is fairly easy. At the end of each term, the WebCT administrator saves all online courses (minus the students' information and recorded interactions). This saving of the course-content, files, PowerPoint presentations, quizzes, syllabi, etc., makes recalling the course for later use easy. When an existing course runs, making only minor changes is customary. Even if the faculty member is new to online teaching, the existing course is inherited, making the course development process much easier.

Developing new courses is more involved and time consuming than reusing an existing online course and usually requires the effort of many individuals. This process typically begins with some WebCT training followed by a one-on-one meeting with the instructional designer. The instructional designer's job is to evaluate the instructor's on-campus course materials and process to determine how to translate that experience into the online environment.

The first step toward getting this done is clearly articulating the differences between on-campus instruction and online instruction. The primary difference is that "materials heavy" courses focusing on PowerPoint presentations, multimedia resources, lectures, guest-speakers, and handouts are difficult to translate. At MU,

\footnotetext{
${ }^{2}$ A best practice refers to Chickering and Ehrmann's (1997) reconfiguration of Chickering and Gamson's (1991) original "best practices."
} 
there are both instructor-centered courses where instructors view themselves as the primary disseminators of knowledge, and student-centered classes where students have a responsibility for the direction and outcomes of the course. Online courses are usually low on materials, and focus more on the "Subject" of the course. Weekly and/or daily conversations develop on the discussion board and center around topics. Topic or subject development is usually what drives MU online education.

Graduate business courses dominate the online course offerings at $\mathrm{MU}$, and the retention rate for these courses is $95 \%$ (Schreck, 2002). MU's online undergraduate, degree completion program (a cohort) generates a large percentage of online credits because students take 9 credits per term. Other undergraduate programs with sizeable enrollments include Communications, Human Sciences, Undergraduate Business, Interdisciplinary Studies and Cultural and Historical Studies. Most of our online instructors continue to teach at $\mathrm{MU}$; consequently, we have to train very few new instructors each term.

Finally, class-size varies greatly; however, it is rare to see an online course (excluding graduate business courses) with more than 15 students. Most online courses have between 8 and 15 students. In a class with $20+$ students, dividing it into two smaller sections is common. Small class size is not an exclusive characteristic of online education at MU but rather, a value that has been consistent in on-campus education at MU for years. As previously stated, Ashar and Skenes 
(1993) found that class size was right behind social interaction as the most important factor in Tinto's $(1975,1993)$ model for student retention.

\section{Sample}

Grounded theory studies employ "theoretical sampling" as a way to represent the phenomenon being examined. According to Charmaz (2000), theoretical sampling is less about a product (e.g., 13 Subjects) and more about a process.

As we grounded theorists refine our categories and develop them as theoretical constructs, we likely find gaps in our data and holes in our theories. Then we go back to the field and collect delimited data to fill those conceptual gaps and holes - we conduct theoretical sampling. At this point, we choose to sample specific issues only; we look for precise information to shed light on the emerging theory. (p. 519)

Defined by Creswell (2002), theoretical sampling "...is intentional and focused on the generation of a theory" (p. 449). Therefore, this study systematically extracted data in a purposeful manner aimed at online students who were successful at completing online courses.

To be labeled as a "successful completer," the Subjects had at least a $90 \%$ course completion rate for a minimum of two online courses. For example, if a student had taken two online courses, both courses must be completed (i.e., 2 courses $=100 \% ; 1$ course $=$ only $50 \%$ ). If 10 online classes had been taken, nine must have been completed and so on. $90 \%$ is consistent with MU's online course completion rate, and is, therefore, representative of the particular 
phenomenon being examined. A minimum of two courses allows the Subjects to acquire a better understanding of the online environment here at $\mathrm{MU}$. Due to the exploratory nature of this study and the total online students at MU (200-300/term) the sample size was 14 students. Since the study outcome attempted to articulate a clearer understanding of the MU situation, it was the only institution involved in the study.

Also of note, Hatch (2002) states, "Qualitative researchers argue that no direct relationship exists between the number of participants and the quality of a study..." (p. 48). The sample will be used until "...emerging findings feel saturated; that is, you begin to see or hear the same things over and over again, and no new information surfaces as you collect more data" (Merriam \& Associates, 2002, p. 7). Charmaz (2000) corroborates this method by stating, "Thus the aim of this sampling (theoretical sampling) is to refine ideas, not to increase the size of the original sample" (p. 519).

For purposes of this study, undergraduate students who were not part of MU's Online Degree Completion program (ODC) formed the sample pool. The ODC program uses a cohort model; cohort models suggest specially designed learning communities that may or may not resemble non-cohort programs. Since most of the existing retention literature concerned the on-campus student and the services and educational experiences of college campuses, such cohort models may introduce some unwelcome, extraneous variables into the study. 
When presenting selected results from the Schreck (2002) study, the introductory section " $A$ final note concerning $M U$ online retention" notes that "successful completers" can be seen in all demographic groupings of online students. Table 4 is a sampling (spring 1996 - fall 2000) of some demographic groupings and related course retention rates. In the table, "Combination" refers to students who have taken a combination of on-campus and online course with MU. "Exclusively Online" refers to students who have never taken an on-campus course with MU - all enrollments have been online (usually out-of-state) students.

Table 4

Online Course Retention Representing Various Demographic Groups

\begin{tabular}{|l|l|l|}
\hline \multicolumn{1}{|c|}{ Demographic Group } & \multicolumn{2}{c|}{ Course Retention Rates } \\
\hline & Combination & Exclusively Online \\
\hline Age Group < 25 & $88.5 \%$ & $87.1 \%$ \\
\hline Age Group 25-34 & $89.7 \%$ & $87.2 \%$ \\
\hline Age Group 35-44 & $92.2 \%$ & $92.2 \%$ \\
\hline Age Group 45-54 & $91.6 \%$ & $89.7 \%$ \\
\hline Age Group 55+ & $74.1 \%$ & $64.1 \%$ \\
\hline All online enrollments & $90.6 \%$ & $88.7 \%$ \\
\hline Undergraduate online enrollments & $87.7 \%$ & $86.6 \%$ \\
\hline Graduate online enrollments & $95.0 \%$ & $93.5 \%$ \\
\hline Male online enrollments & $90 \%$ & $91 \%$ \\
\hline
\end{tabular}

Therefore with respect to the original findings in Schreck (2002), the sample was a diverse group representing: exclusively online (e.g., no on-campus 
courses ever), combinations of on-campus and online courses, various age groups, gender, academic majors, undeclared majors, etc.

- Students cannot be members of the Online Degree Completion Program (Cohort Model).

- Subjects must show a track record of "successful completion" of online courses. This means completing at least $90 \%$ of their online courses with a two-course minimum.

- Subjects must be undergraduate students but not enrolled in the ODC.

\section{Subject Characteristics}

Demographic data were collected via a website/database application and are summarized in the next section. The data were used to help analyze the sample group in relation to the outlined "Sample Plan." Table 5 reflects the proposed sample outcome for this study.

\section{Table 5}

Sampling Plan of 12-15 Subjects

\begin{tabular}{|l|l|l|l|l|l|l|l|}
\hline \multicolumn{7}{|c|}{ AGE GROUPS } \\
\hline Male & Female & Exclusively & Combination & $<25$ & $25-34$ & $35-44$ & $45-54$ \\
\hline $50 \%$ & $50 \%$ & $33 \%$ & $66 \%$ & $10 \%$ & $40 \%$ & $40 \%$ & $10 \%$ \\
\hline
\end{tabular}

Due to the difficulty in attracting Subjects and more importantly, Subjects who met the selection criteria, the true sample did not meet the proposed expectations. Table 6 reflects the true sample for this study. 
Table 6

True Study Sample (14 Subjects)

\begin{tabular}{|l|l|l|l|l|l|l|l|}
\hline \multicolumn{7}{|c|}{ AGE GROUPS } \\
\hline Male & Female & Exclusively Online & Combination & $<25$ & $25-34$ & $35-44$ & $45-54$ \\
\hline $\begin{array}{l}21 \% \\
3\end{array}$ & $79 \%$ & $14 \%$ & $86 \%$ & $7 \%$ & $\begin{array}{l}21 \% \\
3\end{array}$ & $\begin{array}{l}50 \% \\
7\end{array}$ & $\begin{array}{l}21 \% \\
3\end{array}$ \\
\hline
\end{tabular}

In addition to the Sample Plan, the following statistics were gathered from the demographic web application.

- 8 of 14 were in-state $(57 \%)$;

- average age: 39.7 years;

- academic major:

Art - 1

Business -3

Communication - 3

English - 1

Interdisciplinary Studies - 4

Religious and Philosophical Studies - 1

Human Sciences - 1;

- 12 of $14(86 \%)$ are currently enrolled at MU;

- majority of online courses taken in the academic area:

Interdisciplinary Studies - 4

Business - 3 
Communication - 4

Religious Studies - 1

Variety of departments -2 ;

- number of online courses with MU:

$2-3$ courses $(4-29 \%)$

$4-5$ courses $(7-50 \%)$

$6-10$ courses $(1-7 \%)$

more than $10(2-14 \%)$

- completion rate of online courses with MU - $100 \%$ for all participants.

\section{$\underline{\text { Recruitment }}$}

The recruitment process was consistent with the research methods, which focused entirely on collecting data via a WebCT course shell. Instead of calling students, a simple message and link were posted on Marylhurst University's, Webbased Learning homepage (http://online.marylhurst.edu). The message read, "If you are interested in participating in an online study concerning Marylhurst University online course retention, please click here." The link brought them to a document outlining the details of the study and the criteria for participation. If interested, potential Subjects were asked to contact me directly via email. This message had the potential of being viewed by several hundred online students at MU. 
Responding students were directed to the research course ( $\mathrm{RC})$ and asked to read the letter of consent. If they agreed to the letter of consent, they were asked to contact me directly via email. Twenty-two Subjects responded through this recruitment process and that number was decreased to 14 final participants after review of the criteria (i.e., some misunderstood the criteria and were notified). Following final approval, Subjects were asked to provide a limited amount of demographic data.

\section{Informed Consent}

To coincide with the nature of this web-based study, informed consent was gathered via the World Wide Web. Once Subjects were selected according to the sampling criteria and plan, they were directed to the WebCT "research course" (a course established solely for the purpose of gathering consent and conducting research for this project). The research course (RC) contained the informed consent letter and was available for Subjects to preview. The letter clearly stated that if they "post a message" in the discussion board under the topic area "START HERE," they agreed to the terms of consent and would participate in the study. They were asked to print a copy of the letter, sign it and keep it for their personal records.

\section{Potential Risks and Safeguards}

This study was neither a high-risk nor a potentially controversial research project. The main concerns with risk involved the protection of confidentiality 
(which is explained in the section Records and Distribution) and the inherent inconvenience related to the time spent working on a computer.

To protect student identity, an alias login name was used while working in the WebCT research course. The only person with the alias identification was the researcher and that information was stored in files inaccessible to anyone but the researcher. Simply stated, I was the only person who worked on my computer; thus, the discovery of alias information was highly unlikely.

Because I required a rather rigorous amount of computer time, the potential for Subjects to be inconvenienced was high. Hopefully, the reciprocity was more than enough to compensate for this inconvenience. However, due to the nature of web-based, asynchronous research, Subjects had a great deal of flexibility when contributing to the project. The Subjects logged-in any time, 24 hours a day, 7 days per week. If they experienced technical problems, the MU web-based support team was available Monday through Friday, $8 \mathrm{am}-5 \mathrm{pm}$. I was also available during those times and on the weekends.

\section{$\underline{\text { Potential Benefits }}$}

Participants were given a $\$ 15$ gift certificate to the MU bookstore. Hopefully, this compensated for any inconvenience associated with the time requirement for this study. Besides compensation, the direct benefits cannot easily be known. From the final comments concerning the research process, it was 
evident that some Subjects benefitted from the inherent self-introspection involved

in this study. Several others echoed Subject 12's comments:

The benefits I have received from participating in this study are reflection and clarification of my own online experience. I also learned some valuable things about how qualitative research is conducted and about the insights and opinions of other online students. I participated in this study so that I could make a contribution to online learning and to Marylhurst University.

I feel that the researcher asked questions that facilitated my own clarification process. I feel satisfied that my voice was heard and understood and that together with the other Subjects, we will make a positive difference in the field of online learning.

Participation in this study was a very satisfying experience. Although I did not expect or receive college credit for involvement, I feel that I received the value and education of a well-presented college class. Education is one of the areas of focus of my Interdisciplinary Studies degree. It was exciting to be involved in this aspect of education.

The indirect benefits of this study varied from Subject to Subject depending on their level of participation and their overall contributions in the WebCT research course. All participants were at least partially responsible for the creation of a theoretical model to help improve online course retention. Special notes concerning the Subjects' participation are now contained in the acknowledgment section of this dissertation.

\section{$\underline{\text { Records and Distribution }}$}

As discussed earlier, the protection of Subjects' identities was vital to the integrity of this study. The following steps were used to assure that Subject anonymity was protected. 
The consent letter verification process (see Appendix B - Informed Consent) occurred via a "secure server."

1. A secure server means that transmitted data is encrypted (similar to online banking technology) while being sent over the Internet. This encryption process greatly decreases the chances of people intercepting the data. The servers are maintained by Mandala-Designs (www.mandala-designs.com).

2. When students were confirmed as research Subjects, their names were coded in the order in which they are received (see Table 7).

Table 7

Subject Coding

\begin{tabular}{|l|l|l|}
\hline Real Name & WebCT Username & WebCT Password \\
\hline Jane Doe & Subject_1 & Doe_1 \\
\hline John Smith & Subject_2 & Smith_2 \\
\hline Robert Redford & Subject_3 & Redford_3 \\
\hline
\end{tabular}

3. In this document, "Real Names" were fabricated but that column contained the actual Subjects' names. While another Subject might have guessed the common protocol for Username login, the password was practically impossible to figure out because last names were not revealed. The coding continued until all 14 Subjects were placed in the WebCT research course. It was the WebCT Username that was revealed whenever the student communicated within the course. 
4. When Subjects entered the course, Subjects were reminded to communicate using only their WebCT Username (e.g., Subject_1, Subject_2).

5. My dissertation does not mention specific names.

6. WebCT Usernames labeled my Subjects, not their real names.

7. The invitation to a public presentation was given to all participants but attendance was not mandatory.

\section{Strengths of Sample Group}

The strengths of the sample group cannot be displayed with a series of statistics, especially in a qualitative study. The strengths of the sample group become evident as the researcher explores and interacts. As the researcher working with these Subjects, I will attest to their commitment and enthusiasm for producing a high quality of responses and online interactions. All 14 participants were actively engaged in the research process throughout all three stages - no one was left behind or dropped out. Not only did they answer the questions from the researcher, the Subjects actively engaged with each other - sometimes being supportive, sometimes challenging each other's assumptions.

Although a $50 / 50$ percentage-split was proposed for the male to female ratio, the approximate $20 / 80 \%$ ratio is closer to the actual numbers at $M U$, where $70 \%$ of the online students are female. All tolled, the actual sample reflects a diverse group of students representing different academic majors, varying levels of online experience, various age groupings, and even included two students who 
have never taken on-campus courses at MU. Based on the quality of the interactions, level of engagement and the sample demographics, the sample demonstrates a high level of integrity.

\section{$\underline{\text { Limitations of Sample Group }}$}

The obvious limitation of the sample is in the age-groupings. While the sample plan proposed $50 \%, 71 \%$ of the resulting sample is between the ages of 35 and 54. Although traditional-aged students persist in online courses just as well as any other age group, these students were not represented equitably in this study.

Another limitation might be the fact that all participants' completion rates were $100 \%$. The goal of this grounded theory study was to focus on online students who have an online course completion rate of at least $90 \%$. However, the argument could be made that because the Subjects completed at a perfect rate, none of the Subjects reported negative experiences. The fact is, the Subjects did have their fair share of negative, online-course-experiences, but were able to persist.

\section{Data Collection and Analysis}

This next section details the data collection and analysis process for each of the three research stages.

\section{$\underline{\text { WebCT }}$ as the Collection Area}

Regardless of a particular theoretical perspective (e.g., positivist or constructivist) or methodology (e.g., ethnography, grounded theory, case study) it 
is common for qualitative researchers to interact with their Subjects (Creswell, 1994; Marshall \& Rossman, 1999). This interaction often occurs in the field, meaning that qualitative researchers interact in the Subject's environment and/or place from which the problem originates. Thus, I chose to collect data within the confines of a WebCT course shell - from this point forward referred to as the "research course" (RC). In order to articulate the process of online learning, with respect to letting the data set the course of the research process, Marshall and Rossman (1999) indicate that asynchronous, in-depth interviews best-capture the "individual lived experience" (p. 61).

In the $\mathrm{RC}$, data collection followed the "emerging design" through three distinct stages (Table 8). Creswell (2002) defines the emerging design as "...the process in which the researcher collects data, analyzes it immediately rather than waiting until all data are collected, and then bases the decision about what data to collect next on this analysis" (p. 450). Emerging design is often referred to as "constant comparative analysis." The emerging design for collection provided the necessary structure to fit both the ontological and epistemological positions of the postpositivist perspective, and also allowed me the flexibility of revisiting stages and/or extending the duration of stages if necessary. 
Table 8

Data Collection and Analysis Process

\begin{tabular}{|c|c|c|c|}
\hline Stage & Collection Format & Analysis Goal & Duration \\
\hline $\begin{array}{l}\text { Stage 1: } \\
\text { Identifying } \\
\text { categories }\end{array}$ & $\begin{array}{l}\text { private } \\
\text { asynchronous } \\
1 \text {-on-1 discussion }\end{array}$ & $\begin{array}{l}\text { open coding } \\
\text { generate categories } \\
\text { generate properties and } \\
\text { dimensions }\end{array}$ & $\begin{array}{l}\text { Collection: } \\
\text { 1-2 Weeks } \\
\text { Analysis: } \\
2 \text { Weeks }\end{array}$ \\
\hline $\begin{array}{l}\text { Stage } 2 \text { : } \\
\text { Identify core } \\
\text { category and } \\
\text { construct model }\end{array}$ & $\begin{array}{l}\text { public } \\
\text { asynchronous } \\
\text { group discussion }\end{array}$ & $\begin{array}{l}\text { axial coding } \\
\text { interconnect categories } \\
\text { causal conditions } \\
\text { build "core" category }\end{array}$ & $\begin{array}{l}\text { Collection: } \\
\text { 1-2 Weeks } \\
\text { Analysis: } \\
2 \text { Weeks }\end{array}$ \\
\hline $\begin{array}{l}\text { Stage } 3 \text { : } \\
\text { Review/refine } \\
\text { model }\end{array}$ & $\begin{array}{l}\text { public } \\
\text { synchronous } \\
\text { show model and gather } \\
\text { input }\end{array}$ & $\begin{array}{l}\text { selective coding } \\
\text { build story of how categories } \\
\text { relate } \\
\text { discursive theoretical propositions } \\
\text { address research questions }\end{array}$ & $\begin{array}{l}\text { Collection: } \\
2 \text { Weeks } \\
\text { Analysis: } \\
2 \text { Weeks }+\end{array}$ \\
\hline
\end{tabular}

\section{Analysis Using Computer-assisted}

Technology

N.U.D.I.S.T (Non-numeric Unstructured Data Indexing Searching

Theorizing), a computer program, now called N6, was used to assist with the data analysis process. Hatch (2002) indicates that "It [computer-assisted analysis in qualitative research] is not and never can be a satisfactory alternative to doing the mindwork associated with analyzing and interpreting data" (p. 207). However, using a computer-assisted program such as N6 followed the online format (i.e., electronic format) of the students, courses and data collection procedures (WebCT RC). It also allowed the researcher to keep data in its raw, electronic form without any transcription. Raw data files were easily imported into N6 for 
analysis. Thus, the organization (i.e., categorization and searching capabilities) of large amounts of data was made easier. Table 9 highlights some advantages and disadvantages of using computer-assisted analysis (Hatch, 2002, p. 208).

Table 9

Advantages and Disadvantages of Computer-assisted Analysis

\begin{tabular}{|l|l|}
\hline \multicolumn{1}{|c|}{ Advantages } & \multicolumn{1}{c|}{ Disadvantages } \\
\hline $\begin{array}{l}\text { Programs provide file systems that assist } \\
\text { researchers in storing and organizing large } \\
\text { amounts of textual data. }\end{array}$ & $\begin{array}{l}\text { Most programs are complex, and their } \\
\text { manuals not very helpful, meaning it takes } \\
\text { nonproductive time to learn to use them to } \\
\text { their full advantage. }\end{array}$ \\
\hline $\begin{array}{l}\text { Computers can save time and reduce } \\
\text { drudgery, especially in the areas of coding, } \\
\text { retrieving, displaying, counting and sorting. }\end{array}$ & $\begin{array}{l}\text { Researchers may make analytic decisions } \\
\text { based on what the computer can do rather } \\
\text { than what should be done. }\end{array}$ \\
\hline $\begin{array}{l}\text { Computers force researchers to be organized } \\
\text { and to plan well, thus encouraging systematic } \\
\text { approaches to analysis. }\end{array}$ & $\begin{array}{l}\text { Computer use may encourage researchers to } \\
\text { lose sight of the contexts of the study and } \\
\text { the data set as a whole. }\end{array}$ \\
\hline $\begin{array}{l}\text { Most analysis programs force researchers to } \\
\text { study data line by line, ensuring a more } \\
\text { careful reading of the data. }\end{array}$ & $\begin{array}{l}\text { As categories are set within computer } \\
\text { programs, researchers may be reluctant to } \\
\text { rethink or change them. }\end{array}$ \\
\hline $\begin{array}{l}\text { Some programs can create graphic displays } \\
\text { from analyses that would take much longer } \\
\text { and/or require expertise. }\end{array}$ & $\begin{array}{l}\text { Data and completed analysis can potentially } \\
\text { be lost through technical failures and human } \\
\text { errors. }\end{array}$ \\
\hline
\end{tabular}

The disadvantages noted by Hatch (2002) were easily avoidable. While the qualitative analysis program was complex, I had some prior experience using N6 for data analysis at MU. So as not to lose or misplace data, regular computer backups were done during the study. N6 "categories" were easily changed, and raw data easily shifted into relevant categories. I believe the validity and reliability checks that were used during the analysis stage helped give perspective and kept 
me involved with the data. The N6 program did not label the categories, assign subcategories and move/assign the data wherever appropriate - that was the job of the researcher. Therefore, N6 was merely a tool used to help in the theorybuilding process and provided a secondary check of the analysis process, as well as an electronic repository of data and process.

\section{$\underline{\text { Research Procedures }}$}

General guidelines for interviewing. According to Hatch (2002),

"Standardized interviews will likely be used by postpositivist researchers..." (p. 97) and provide the necessary structure to maintain Strauss and Corbin's (1998) original research framework. Several modifications to the standardized interview process were necessary with regards to the process that follows. Essentially, in standardized interviews participants are asked to respond to a series of the same questions during a set-time-frame. For the process that actually occurred, question-time varied greatly depending on when Subjects checked-in and out of the RC. In addition, only the initial research questions (i.e., guiding questions to get the collection process started) were asked at the same time and were based on Berg's (1998) model.

Berg (1998) suggested using four types of interview questions: essential, extra, throwaway and probing. Throwaway questions were actually more aligned with background-type questions. These were used to put the Subject at ease and began the interview process. Extra questions allowed a break in the rigorous, 
prescribed structure, and allowed me to ask questions that seemed to be logical follow-ups based on participants' responses. Essential questions were formulated with an overarching purpose and reflected the research questions. These questions got at the heart of the research problem and provided the necessary information to proceed in the study. Finally, probing questions were used to supplement any unfinished business, especially in areas that needed further elaboration. Throughout the proposed research process, Berg's different question types were used and helped provide the necessary guidelines to conduct a standardized interview.

External professional support. I used a process of "external professional support," which existed outside the validation process (see Establishing validity and reliability). This process brought an expert in at each stage of analysis to provide support, monitor the process and to ask critical questions. The professional reviewer neither read and interpreted data nor made judgments that might have influenced the researcher's findings. Babchuk (1996) reinforces the importance of just such a person in a grounded theory study.

Whenever possible, grounded theory should be a collaborative enterprise. This methodology - with its emphasis on memoing, constant comparison, coding, selection of a core category, etc. appears to be particularly amenable to collaborative forms of inquiry, enabling researchers to engage in an on-going dialogue at all phases of the research project and helping facilitate a form of internal triangulation and peer review. (I 19)

Dr. Maggie McVay-Lynch, at Portland State University, agreed to offer professional support for this research project. Dr. McVay-Lynch has more than 
10 years experience specifically in online educational development. She has consulted with universities around the world on online pedagogy and delivery issues and is the author of two well-received books in the field, the most recent being The Online Educator: A Guide to Creating the Virtual Classroom published by Routledge-Falmer. She has also undertaken and published several qualitative research studies, and has previously supervised a graduate student in grounded theory work.

Stage 1 collection: Interview protocol. After logging into the RC, Subjects were directed to the discussion board (See Figure 3) and the initial thread "START HERE!" This initial thread contained the letter of consent and further directions if they wished to participate.

Topic
STAFT HERE!
Main
Wotes
Subject 1
Subject 2
Subject 3
Subject 4
Subject 5
Subject 6
Subject 7
Subject 8
Subject 9
Subject 10
Subject 11
Subject 12
Subject 13
Subject 14

$\begin{array}{lll}\text { Unread Total } & \text { status } \\ 0 & 1 & \text { public, unlocked } \\ 0 & 0 & \text { public, unlocked } \\ 0 & 0 & \text { public, unlocked } \\ 6 & 6 & \text { private, unlocked } \\ 6 & 6 & \text { privite, unlocked } \\ 5 & 6 & \text { private, unlocked } \\ 6 & 6 & \text { private, unlocked } \\ 7 & 7 & \text { private, unlocked } \\ 6 & 6 & \text { frivite, unlocked } \\ 6 & 6 & \text { private, unlocked } \\ 6 & 6 & \text { privite, unlocked } \\ 6 & 6 & \text { frivite, unlocked } \\ 6 & 6 & \text { frivate, unlocked } \\ 6 & 6 & \text { privite, unlocked } \\ 7 & 7 & \text { privite, unlocked } \\ 6 & 6 & \text { privite, unlocked } \\ 6 & 6 & \text { private, unlocked }\end{array}$

Figure 3. Discussion board - Topic areas. 
The thread also contained the statement, "By moving into your private topic area (e.g., Subject_1, Subject_2), you are agreeing to the terms of the letter." After reading the letter and making a copy, Subjects were directed to the "Stage 1Question" area (see Figure 3) and were given the following introduction and instructions.

Welcome to Stage 1 of the research process. As you know from the consent letter, Stage 1 is a private, one-on-one experience between you and me. Before sharing with the larger group, I wanted to work with each participant individually. For me, this assures that other participants will not influence your opinions.

At this point, I don't want to give you too many questions and would prefer to follow your lead. In a sense, I want to see where your answers take me. Therefore naturally, short or non-descript answers will have little value in the research process. Details are critical in helping me make sense of your experiences when compared and contrasted with others. While not looking for you to write a book (that's my job!), I am looking for insight, substance and honesty.

I will check in everyday to see what you have written and ask for clarification or perhaps, ask you to explore certain comments in further detail. At the end of this week, I'll let you know if you will need to check in next week at all. Thank you once again for your participation. You may now proceed to your private topic area, which corresponds to your Username.

All Subjects then checked into their corresponding topic areas for one week's worth of private conversation and grappled with the following questions/issues. The first two aimed at attaining important background information, which ultimately lead to a comparison of variables with the Tinto (1975, 1993) and Bean and Metzner (1985) models. The questions in italics (essential/probing questions) were not shown immediately but rather, released 
when the Subject had answered the background questions sufficiently and/or it was deemed appropriate by the researcher.

- Please begin by giving me any information about your background that you deem important or significant when describing where you are educationally at this point in your life (e.g., family educational history, prior schooling, skills/abilities, current family/work situation).

- What were the factors that led up to you taking online courses and how have they aligned (or not) with the background you described?

- Most likely, you began your higher education career in a face-to-face classroom. Describe or characterize your experiences with online learning at Marylhurst University. How have the experiences been similar to face-to-face classrooms and how have they been different?

- What are some of the pros and cons of online learning?

- How has the educational environment that is "online learning" enabled you to complete the majority of your online courses?

Stage 1 collection. During this first stage, Subjects were asked to check-in to the RC at least five days out of seven and at least once during the second week if applicable. The goal of Stage 1 was to collect data for open coding where "...the researcher examines the text (e.g., transcripts, field notes, documents) for salient categories of information supported by the text" (Creswell, 1998, p. 150). I also looked for the properties, - "the general or specific characteristics or attributes of a category" (Strauss \& Corbin, 1998, p. 117) - which are 
represented in the creation of subcategories. Properties or subcategories are then "...dimensionalized and presented on a continuum" (Creswell, 1998, p. 151) as seen in Figure 4.

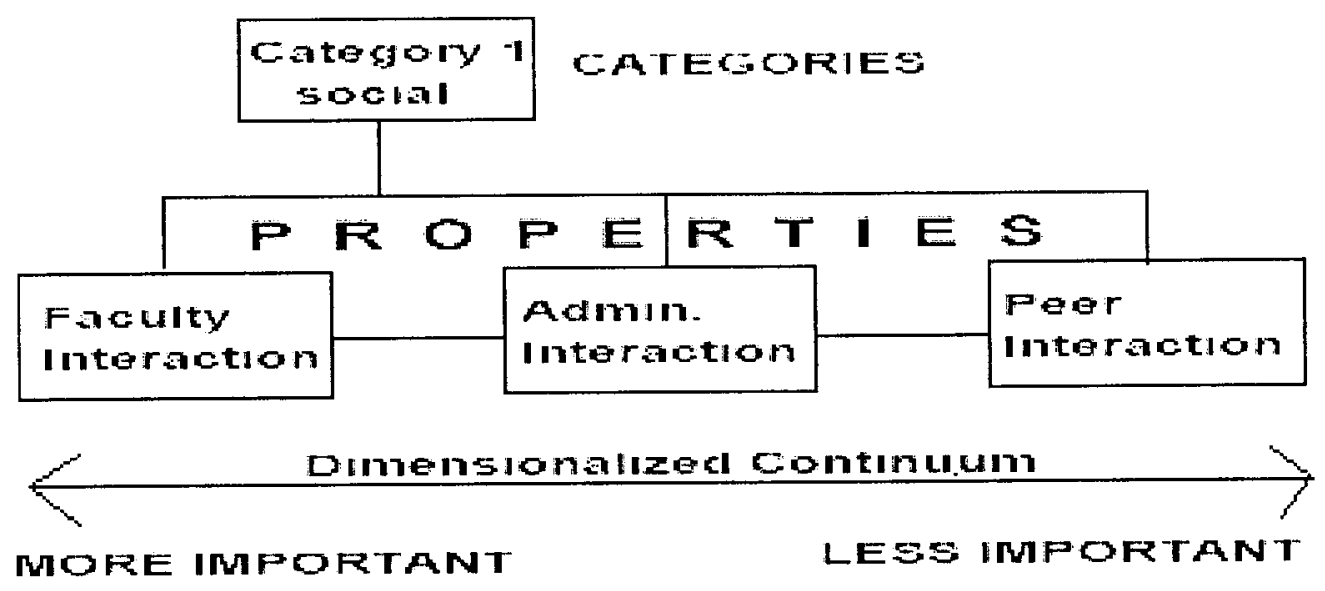

Figure 4. Coding illustrations.

Dimensions help the researcher demonstrate the relationship between various properties under a category and eventually are compared to other property dimensions when constructing the model. According to Strauss and Corbin (1998), "Dimensions represent the location of a property along a continuum or range" (p. $117)$ and serve like "connectors" between categories. For example, in Figure 4 the properties (Faculty Interaction, Administrative Interaction and Peer Interaction) of the main category "social" were dimensionalized according to importance. However, not all continuums have to represent the importance of properties. In the above example, the continuum could represent the frequency (i.e., number of times) that the properties were mentioned in the research. Therefore, the labeling 
displayed on the continuums will vary depending on the nature of the properties being dimensionalized.

The major question during the research process was, "How do I determine which defining properties are more and/or less important?" I knew I wanted to communicate the level of importance of the categories in my model; therefore, my continuum had to display levels of vitality. I also needed to know the importance of properties in order to make the judgment of whether or not to continue further exploration. In my review with Dr. McVay-Lynch, I suggested using quantity as a measure of importance - the importance of a property was determined by the amount of discussion. This simply did not work.

I quickly noticed that the Subjects spent the most time, and thus, made the most responses in the discussion threads near the top of the screen. In addition, areas with more data often contained simple affirmations of another's response (e.g., I feel exactly the same way as Subject_9). Therefore, my original idea of using frequency-of-response simply did not reflect the importance of individual properties. Thus, I made the judgment to gauge importance based-on the depth and quality of exploration into a particular property area. I did not ask the Subjects to rate the importance of properties during the first-two, collection phases; however, they did offer opinions during the validation phase - Stage 3. I believe when I made decisions during Stages 1 and 2, they were validated and justified during Stage 3. 
The Subjects, not me, ultimately judged the level of "depth and quality." I simply presented them with my interpretations. Therefore, depth and quality were not quantitatively judged and differed from Subject to Subject. Just like in any classroom situation, relationships develop, and teachers begin to look for more than a standardized response from certain students. I found myself looking more at the individual, and how that person is trying to be heard and understood. It was not always subjective. For example, I tried to look for keywords or for phrases that led me to believe the Subject was passionate about his/her response:

You know what? I don't care how you teach the classes. If you want to give multiple-choice tests, fine. If you want to give a series of lecture notes with PowerPoint presentations, fine. I don't even care if you want to use a role-play like what was done in the Reading the Genome course.

Comments like this would be used to start to understand online pedagogy and its role in online course retention.

Stage 1 analysis using N6. The study began by offering the same two, initial questions to all the participants privately. To ensure independent insight, I interacted privately with each participant at this level in the study. The first question focused on gathering any pertinent background information concerning their educational experience to this point. The second question asked them to review that background information for any clues that might have led them to online learning. Both questions (listed below) were fairly general and used to guide the subsequent follow-up questions. 
Question \#1: Please begin by giving me any information about your background that you deem important or significant when describing where you are educationally at this point in your life (e.g., family educational history, prior schooling, skills/abilities, current family/work situation).

Question \#2: What were the factors that led up to you taking online courses and how have they aligned (or not) with the background you described?

I offered an initial follow-up question to each of the Subjects and a second follow-up for 11 of the 14 Subjects. After the first week of data collection, the emerging findings felt saturated. No new data were being collected and I kept hearing many of the same types of comments.

Since data were analyzed using the constant comparative analysis method, I was constantly thinking about categories for Stage 2. Saturation occurred when I was convinced that no other categories would emerge from the discussion, even if it continued on for weeks. The major categories were entered into the RC discussion board, and Subjects knew they could always suggest other categories that were not represented. However, Subjects felt that all categories were present right from the start of Stage 2. Figure 5 illustrates the threaded discussion strategy for Stage 1. 


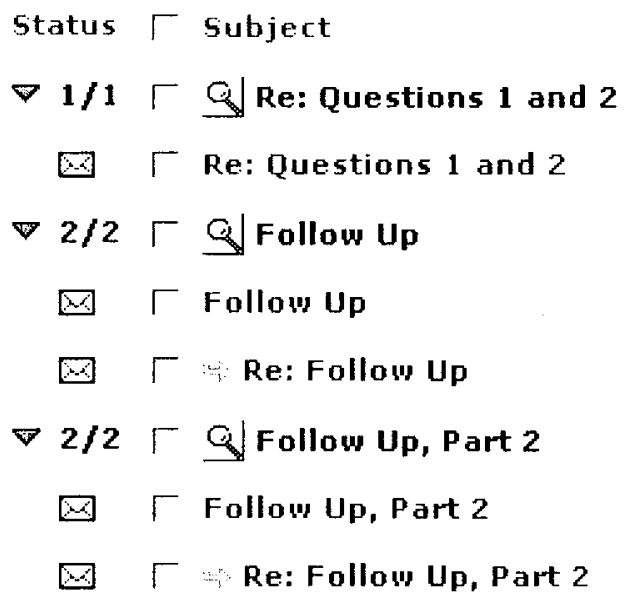

Subject 3

Vince Schreck

Subject 3

Vince Schreck

Subject 3

Figure 5. Threaded discussion strategy, stage 1.

Before analysis began with the computer program N6, data were exported from WebCT from each private discussion area. For analysis purposes, likequestion-threads were compared for categories. For example, in Figure 5 Subject 3's answers to Question 1 were compared to all other Subjects' answers for the same questions, and so on. Respective follow-up questions were also compared with each other. As explained earlier in this chapter, I used N6 for secondary coding, organization and searching. All categories and supporting data were organized within this program. The following process was first used by hand, and then replicated in N6 (see Figure 6).

1. Read and reread text files

2. Create necessary memos

3. Code text units into "Free Nodes" By identifying relevant text units (Data dictates Free Nodes). Continue to annotate as necessary. 
4. Make a report if necessary

5. Look for larger or "core categories" - create TREE NODES, then cut and paste related Free Nodes into Tree Nodes

6. Make additional subcategories as necessary, and append/merge any Free Nodes or subcategories.

7. Look for connections and/or support in the literature.

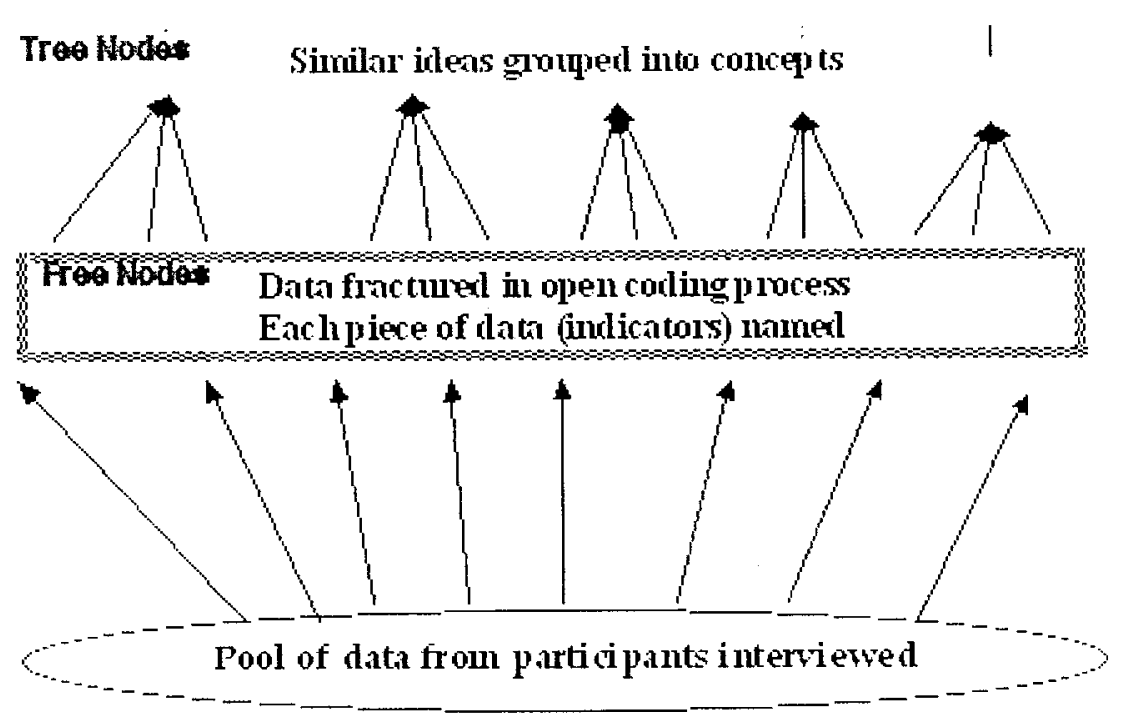

Figure 6. Overview of stage 1 analysis.

Process of analysis: Stage 1. The first step of analysis was to read and reread the Subjects' comments from the first-two, initial questions - this was difficult to do onscreen, and I wanted first-hand experience with the data. Therefore, all online interactions were printed and much of the initial coding was done with pen and paper. Questions one and two were analyzed together for each individual Subject and both follow-ups were also individualized. During the paper 
and pen coding for the initial, two questions, the goal was to underline/highlight anything that was particularly striking or interesting for each Subject. I viewed this coding as survey work, and did very little to narrow, refine or characterize the responses at this time.

How did I determine what was particularly striking or interesting? For this process, I used a method borrowed from the medical field (S.O.A.P. Notes Subjective, Objective, Analysis, and Plan). I first scanned the text for subjective statements such as, "I think online learning is great because it is learning my way." These types of statements almost demand further inquiry because I did not know what the Subject meant by "great" or "learning my way." Second, I looked for objective statements such as factual information about their academic backgrounds: "Online learning would have been a challenge if it were not for my years of experience in higher education." Third, during the analysis phase I wrote out specific questions or memos to myself, and how one Subject's comments related to others'. These memos helped guide the final phase "plan." The plan was usually a list of follow-up questions, and directions for further inquiry.

I gave the "areas of interest" back to the Subjects in the form of follow-up questions. Essentially, Stage 1 was a three-step process: (a) gather information at a very general level without making judgments regarding categories or themes, (b) explore these individualized responses further as they relate (or not) to online course retention, and (c) build themes/categories to take into Stage 2 for further exploration. The data accounted for and was representative of these new themes. 
The follow-up questions specifically targeted how and/or if the area of interest related to course retention. At the end of each data document, questions for further exploration were noted and possible themes recorded. Below is an example of how data were gathered and continually analyzed during Stage 1.

Question \#1 - Subject 3 response: I've worked some part-time jobs for the school and for neighbors over the last few years. We are financially not in a good situation for me to go to school, but it's not getting any better, so I decided to finally go for it, get my degree and head for my teaching certificate.

Question \#2 - Subject 3 response: I'm computer literate, so it's not uncomfortable for me to sign on and find things on the Web. I'm good at keeping up with things without supervision, so I find it easy to keep up with assignments online.

Researcher's Follow-up \#1: I know that you talked about money being an issue for you right now. Being someone who is in a difficult financial situation, has online learning provided a relief in some way? Some feel that they can work and/or manage the household while taking online courses -vs- actually going to class. You also noted being able to work on the course "without supervision." What do you mean by this? Can you give me an example and/or metaphor that might explain this?

Subject 3 response: Well-organized, online classes definitely give me more flexibility in organizing my days. I can be much more efficient by using otherwise unproductive hours in the day. For instance, while my kids are doing homework, I can do some online research, and still be available for their questions. I can do laundry all day while working on an assignment. Also, I can use the daylight hours for things that have to be done during the day, including some paid work, and still have 2-3 hours after the rest of the world shuts down to write up my homework.

Some people really need someone looking over their shoulder and requiring rough drafts week to week, in order to stay on track with a project. I work on many projects at once as a matter of course, so I have a good sense of time management and priorities. I keep lists and a whiteboard with reminders of what's still hanging in the fire. 
Another thing I like about online classes is that I can indulge my long intellectual digestion phase - I take a long time to reflect on things and make them my own. Because I'm a slow thinker, I'm sometimes intimidated by people who are very quick with opinions and analysis of something we've just read in a live class.

Researcher's Follow-up \#2: I'm getting this from you...that if a student has good time-management strategies and priorities and operates within a well-organized course, he/she has a better chance for a quality experience online, correct?

How would you define a well-organized course? What would it "look" like? What are some "indicators?" Meaning, what are some characteristics? Do you think a self-directed learner (i.e., a learner who doesn't need someone looking over his/her shoulder) could persist in a disorganized, online course? Could a non-self-directed learner persist in an organized, online course? I guess what I'm looking for here is, "What's more important in terms of retaining students?"

Subject 3 response: Yes, I think those are some crucial qualities for unqualified success. One could work under the, "Omigod, I didn't do my online homework and it's due today, but that's okay I have till midnight," model and still pull through, but being able to stay on task is less stressful and gives one more time to provide thoughtfully produced work.

A well-organized course has an outline that is updated to match what happens in the course. There are clear statements of what is due this week and what will happen next week. The instructor posts responses within a day of our postings. Links are provided to readings, course materials and related areas of the Marylhurst website. We students get to 'talk' to each other and see how other students respond to questions. That always gives me a chance to see new directions and depth of thinking. Instructions about what happens next are provided in the course outline, in the discussion area and sometimes in private mail. Especially for first-timers, it's hard to know where to go. It's good to have arrows at every corner, so to speak. 
Unfortunately, I also had the opportunity to experience a poorly organized class through PCC. Or poorly written, I'm not sure which. It was a database programming class. Anyway, I couldn't follow his train of thought to save my soul. I never completed that course. I wanted to, and if I'd had the time, I might have gone to get some supporting materials and enhanced the lesson myself, but TIME was one of the reasons I was taking it online. Very frustrating. I had just finished two other Access classes through PCC that were very well organized (written by someone else).

In a classroom setting, you have a professor who says at the beginning of class, "Here's what we're going to do tonight. You'll have a paper to write. Here's what will happen next week." At the end of class, he reiterates, "Your homework is.... Come prepared to discuss..." With the equivalent online, I think that a non-selfdirected learner (NSDL) could persist. The key would be finding a way to keep the class in the NSDL's mind between logins. With an on-campus class, you have a note on the calendar. With an online class, you have a screen with the Sims or Myst on it, which doesn't remind you of the class at all. Successful teaching is usually linked to communication, and with good online classes, that communication is clear and frequent. I think that is the difference.

By using this questioning and follow-up process, themes emerged and were entered into the N6 computer program for open coding. The program proved essential for coding and searching the supporting-data. Stage 1 analysis using N6 was based on Hatch's (2002) "Inductive Analysis" model (p. 162) and the N6 Workshop Handbook (Richards, 2002). Analysis began with a careful read and reread of the imported text documents. As I read the raw data, I created datedmemos regarding any personal thoughts or insights, and some transferred from my initial work with the hard copies. The memos were created when coding text units and were done on-screen and stored within the N6 project coding. 
"Text units" are bits of text (data) that help define and shape the Free Nodes. Text units included my own personal annotations. These annotations become part of the text unit and help provide context to individual text units. Text units represented anything particularly striking or representative in the raw data and were coded (given a numerical code) into the imported "Free Nodes." The raw data dictated the development of Free Nodes. Essentially, Free Nodes were simply coded representations of bits of raw data. They were not categories but were the building blocks for the development of categories. After establishing the Free Nodes, printed reports gave a hardcopy representation.

The next step entailed examining the Free Nodes for common themes or "Tree Nodes." These Tree Nodes became the main theoretical constructs of the research study and were referred to as "categories." Categories must be defined and given a set of properties. This is where the original Free Nodes came back in the process. The original Free Nodes were pasted into their respective categories and became subcategories and as defined above, provided both the properties and dimensions of the categories. I estimated that Stage 1 analysis would take up to two weeks, but it ended-up lasting only one week. Then, categories and subcategories were moved back into the WebCT RC in preparation for Stage 2 (see Figure 7). 


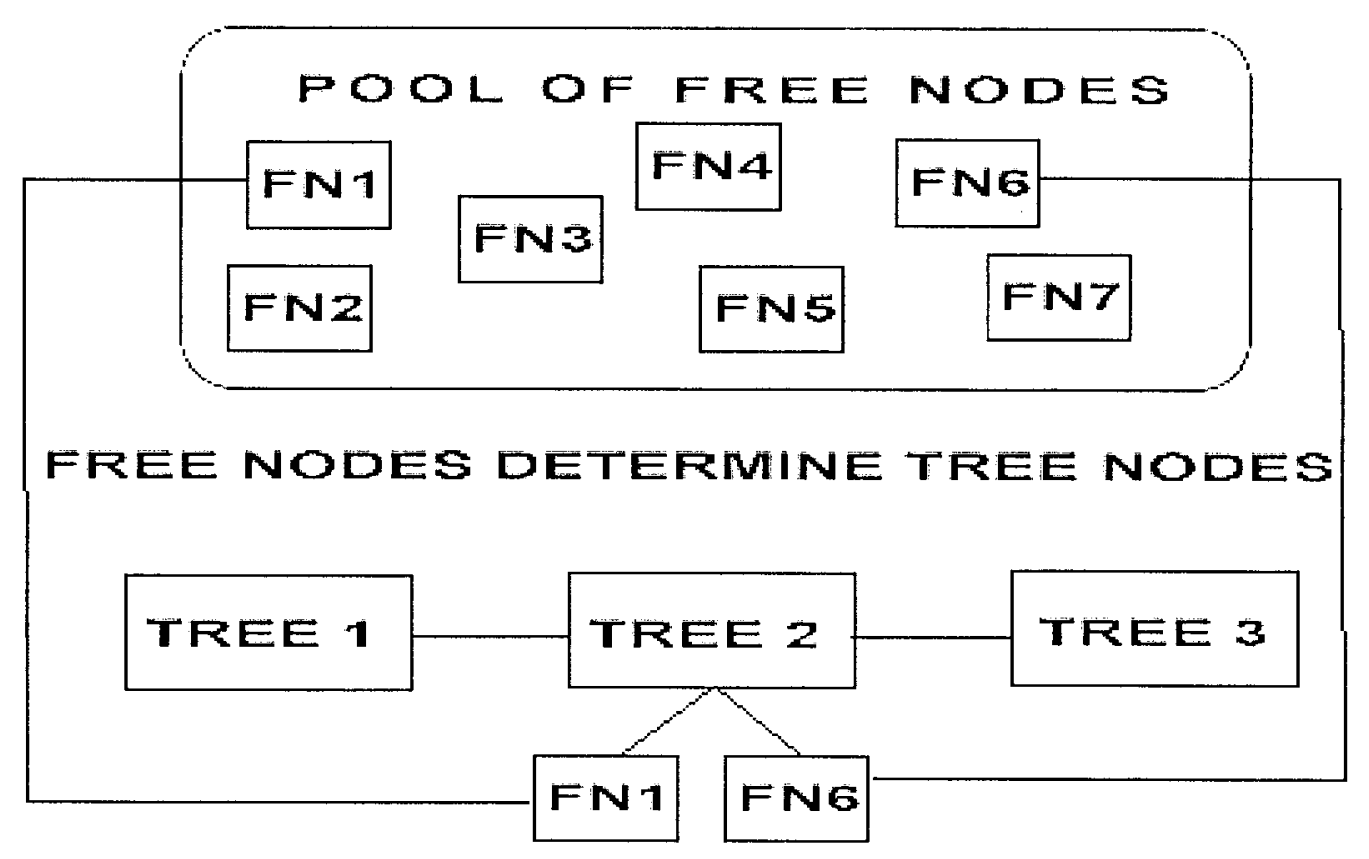

AND LATER, FILL IN AS SUB-CATEGORIES

Figure 7. Stage 1 analysis.

Establishing a clear understanding of the formulation of categories was critical to the validation of the model as a whole. Most qualitative researchers use memos, "...written notes to yourself about the thoughts you have about the data and your understanding of them" (Hatch, 2002, p. 182). A particular text unit might be, "I think a real pro to online learning is the fact the courses seem a lot easier than face-to-face courses." This is a very strong statement and could be saying a lot about the academic experience of online courses at MU. Or, the text unit might be saying something more about the student and his/her environmental factors. Either way, it almost demands some type of follow-up and even saying it 
hypothetically makes me wonder. These moments of wonder were recorded in memos such as:

- Pro: Student believes online courses are easier than face-to-face. Does he mean they are easier because he has more time? Or, does he mean they are easier academically (i.e., classes have fewer assignments)?

- Earlier in the background section, the student went on and on about how he had so much more time now that he doesn't have to travel back and forth to MU. Does this explain why online courses are easier?

- Need to explore this notion of "easier classes" and discover more about the properties and dimensions.

Since categories represented the major theoretical constructs of this study, once established they were compared to existing retention models covered in chapter 2, and any other relevant literature. Similarities were noted in memos in N6 and in the research journal (see Appendix - research journal sample). These comparisons were used later when addressing the research questions.

Stage 2 collection. Following Stage 1 analysis, the categories were moved back into the WebCT discussion as a beginning point. While Stage 1 focused on generating categories and subcategories, Stage 2 spoke directly to these new categories and built interconnectedness between them. Characterized by public, asynchronous, group discussions between the Subjects and me, Stage 2 lasted two weeks. During this second stage, Subjects were asked to check-in to the RC at least five days out of seven and at least once during the second week if applicable. 
The primary goal of Stage 2 was collecting data for axial coding. Axial coding is "The process of relating categories to their subcategories, termed 'axial' because coding occurs around the axis of a category, linking categories at the level of properties and dimensions" (Strauss \& Corbin, 1998, p. 123). While connecting categories was important, the main "product" of axial coding was the collective creation of a "core category" or "central phenomenon." Along with identification of the core category, Creswell (1998); Strauss and Corbin (1998) suggest developing a "coding paradigm" during the axial coding stage. According to Creswell (1998), a coding paradigm is a "...theoretical model that visually portrays the interrelationship of these axial coding categories of information" (p. 151). This model is presented and discussed in Stage 3 of this study.

The set of questions for Stage 2 was developed only after completion of Stage 1 with the categories generated. My interactions with the students at this juncture were critical in assuring sound relationships among categories, subcategories and the central phenomenon. I read messages on a daily basis and asked questions such as, "What is the connection between the central phenomenon and category 'A'? It seems that Subject 'A' and Subject 'B' disagree on the relationship between subcategory ' $A$ ' and main category ' $A$,' can anyone else weigh-in here and clarify the connection?" My interaction at this stage of the research was active, inquisitive, and at times, directive in order to shape a comfortable but contentious level of discourse. 
Stage 2: Interview protocol. After logging into the RC for Stage 2, participants found the following message waiting for them under "Stage 2 Instructions" (see Figure 8).

Hello and welcome to stage 2. I took your comments from Stage 1 and tried to categorize them into themes. You'll notice that each theme is listed in a separate discussion thread. I would like you to visit each theme and address my comments and questions. Your job in each thread is to first compose a message and then please check back into the course on 5 separate days and respond to at least 3 of the other participants' messages. I want to see a discussion develop here that is more than rudimentarily answering a bunch of questions in isolation. This is where the study will most reflect a normal online course. In this stage, discourse, discussion, contentiousness as well as cooperation are all welcome.

This is not a focus group. We are not necessarily trying to converge on an issue, formulate an opinion and/or discuss a solution. There are no right or wrong answers. Please let your voice be heard. If it aligns with what others are saying, please let us all know. If not, let us know as well.

\section{Status Subject}

\section{$\triangleright 1 / 1 \quad\ulcorner$ Q Stage Two Instructions \\ $\diamond 1 / 1 \quad\ulcorner$ Q Theme1_Flexibility \\ $\otimes 1 / 1 \Gamma$ Q Theme2_Culture \\ 1/1「 $Q_{\text {Theme3_Socialization }}$}

Figure 8. Discussion board with hypothetical categorical threads.

After reviewing the instructions for Stage 2, Subjects entered the various categorical threads and interacted with their fellow Subjects. 
The objective during Stage 2 was to further solidify these categorical threads by examining their properties and dimensions in greater depth, and trying to interconnect categories at the dimension level. At this stage, the discovery of new categories and/or the reconfiguring of existing categories were a possibility based on the collection of new data. Any changes to categories were added to the established categorical threads in Figure 8. Listed below are some examples of questions that one might find in these categorical threads - the first representing a properties-type question, the second representing a dimension-type question and the third representing the connection between categories.

1. Your job in each thread is to first compose a message and then please check back into the course on 5 separate days and respond to at least 3 of the other participants' messages. Consider the following in your narrative...Define "flexibility" as a concept here...what does it mean to you (e.g., characteristics and/or attributes)? How have the characteristics and/or attributes helped you with your educational experience?

2. What is the single most "flexible" aspect of online learning and why does it help you (e.g., assignments, your time)? What is the least flexible?

3. If we think of characteristics of online learning (e.g., flexibility, ease of use, technical support) on a continuum, what characteristics might be at the same ends of the spectrum and why? Do these characteristics interact with each other and how does that reflect in the educational experience for online students? 
Stage 2 analysis: Researcher as participant. Because Stage 2 was an asynchronous process that occurred over a period of two weeks, I had to constantly monitor (several times per day) the research course. Sometimes, I just observed the Subjects interacting with one another. Other times, the interaction was free flowing, and there were several times when the communication became synchronous (at the same time) due to the fact that the Subjects and I were online at the same time. During this interaction, I often formulated questions, comments and concerns off the top of my head with the intention of getting the "lived experience" of being an actual online participant. I used constant comparative methods such as member checks, peer reviews, triangulation, clarifying researcher bias, rich thick description, and external audits. For more information concerning these methods, see the Internal Validity section near the end of this chapter.

Stage 2 analysis: Hand coding data. Following my participation in the research course, I grouped all categorical data together and exported it to hardcopies. For example, all the data from the "Culture discussion" were kept together in one file. I felt it was important to understand each particular discussion first before comparing and contrasting data. To analyze these data, I used the same procedure as outline in the prior Stage 1 - Process of Analysis section. Data were examined for subjective statements - statements that demanded further follow-up to explain the basis for their opinions. I noted objective observations, and usually underlined these or noted them in side margins. These subjective and objective statements helped shape the formulation of an analytical statement (memo) that 
helped capture my interpretation of the data at that particular moment. Finally, I wrote a plan for action for the examined data.

Stage 2 analysis using N6.

1. Search text to code responses to questions

2. Code the searched text into new question nodes

3. Search for patterns in the data

4. Create additional coding

Step one involved creating text searches that identified specific text strings within imported text documents. These text strings were used to answer specific research questions or to re-categorize existing data. Step two involved coding the text strings, which were bits of supporting data, into new question nodes. Just as nodes were used to create categories, these new nodes represented questions I wanted the data to address.

For example, in step one I did a text search for "educational goals." In this example, "educational goals" represented a subcategory or property that helps define the construct "Background." When the search was done, 15 text strings associated with the words "educational goals" were found. The immediate thing to do at that point was cleanup all irrelevant data associated with the search. After locating relevant, supporting text strings, which gave further meaning and context to the subcategory of flexibility, I was in a position to recode these new text strings into new question nodes. New question nodes contain supporting-data to 
potentially address research questions or any other relevant questions that may arise during Stage 2 analysis (Figure 9).

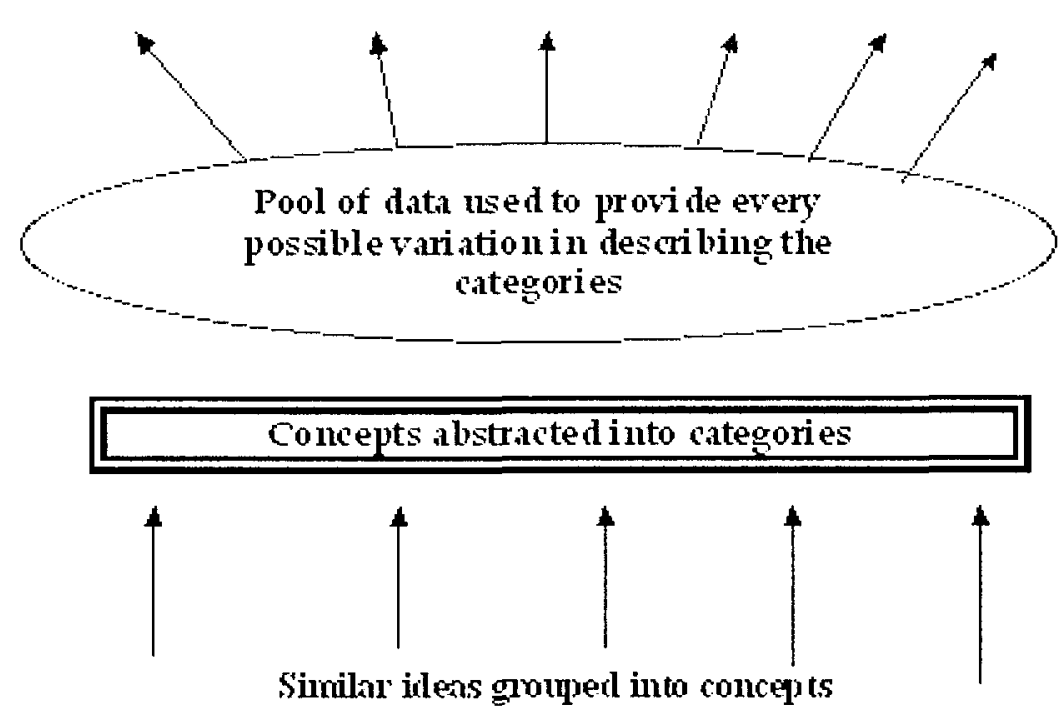

Figure 9. Creating pools of data.

During the search in step two, I often discovered recurrent text strings that had little to do with a new question node, but provided me additional insight into my main categories. This could have been a statement that was in direct conflict with a particular subcategory (property). In the example above, one Subject could have replied, "Educational goals have little to do with taking online courses. I have taken the course for my work." These recurring themes that do not match the general direction of the findings were grouped together and discussed as external question nodes. Again, citing the above example, I could have made an external question node labeled, "Are work goals and educational goals the same thing, especially if the work goal leads students back to higher education?" 
Step two was a very important stage because it helped establish the necessary data to start interconnecting categories and dimensionalizing properties. Therefore, step two was often revisited during the analysis stage in order to find data that were missing or perhaps, to find data to support lingering questions. With any amount of experience conducting electronic, text-searches, one quickly discovers that it is not always easy finding relevant information. To help counter this, I conducted visual, hard-copy searches, of the data to supplement my findings with N6.

Step three used "...a set of search tools, the node searches, which will find the text you need for whatever question you want to ask of the data-providing you have nodes for each of the concepts in the question, or can generate them" (Richards, 2002). If nodes did not exist to help answer my research questions, further exploration was done (i.e., a return to Stage 1 analysis and/or collection).

The final step in Stage 2 is adding any additional coding that might help answer questions, clarify raw data and/or identify a core category. As stated earlier, the goal of Stage 2 is to construct a visual representation (model) of the categories, subcategories and their connection to the core category/central phenomenon. If a model cannot be determined at this time, the research process would move back into Stage 2 for a second look. If a model is generated, this model is passed-on to the final research event - Stage 3 analysis.

Stage 3 collection and analysis. The primary goal of Stage 3 was selective coding. Selective coding is the "...final step in analysis - the integration of 
concepts around a core category and the filling in of categories in need of further development and refinement" (Cresswell, 1998, p. 237). While the integrity of the study was preserved, Stage 3 turned-out to be very different than originally proposed.

The proposed method was to use a live, chat-room to synchronously discuss the model and validation of the model. The initial idea was to put all 14 Subjects into the same chat room, navigate through the model, answer questions and discuss validation. Many Subjects expressed concern over this method and did so with the experience to backup their trepidation. Most believed it would just be too chaotic in a live chat-room with that many people. ,Therefore, I planned smaller group sessions during the final week of the study. I proposed several different time slots, and the Subjects were to sign up in groups of 3-4 each.

This process alone was the most difficult of the entire research process. Trying to coordinate times to accommodate all of the Subjects' schedules was problematic. Eventually, the scheduling nightmare was complete and the first live session was about to begin. Based on the experience, a trial run should have been conducted beforehand just to make sure everyone could participate. Unfortunately, only one Subject out of four could actually connect to the live session. A second did make it on for the last few minutes. After the session, I made the decision of transferring the Stage 3 process over to private mail where I posed questions concerning the process, and the Subjects answered me via private email. 
During Stage 3, a model such as Figure 10 was shown to the research participants via a website. Selective coding attempts to put Tree Nodes (categories) into relational visualizations and to explain the relationships via the Subject's narratives. In this example, the three Tree Nodes on the upper-left side of the model (TN1, TN2 \& TN3) all must interact with one another in order to affect the core category. The same is true for Tree Nodes on the upper-right side (TN4, TN5 \& TN6). In isolation, Tree Nodes 1-6 are merely categories; however, when grouped together, the interconnectedness influences the core category, which may be "course retention." Selective coding also involves filling in holes in the theoretical model. TN7 and TN8 serve as categories that do not fit into the upper-structure of this particular example but are nonetheless vital to the application of the model.

SELECTIVE CODING

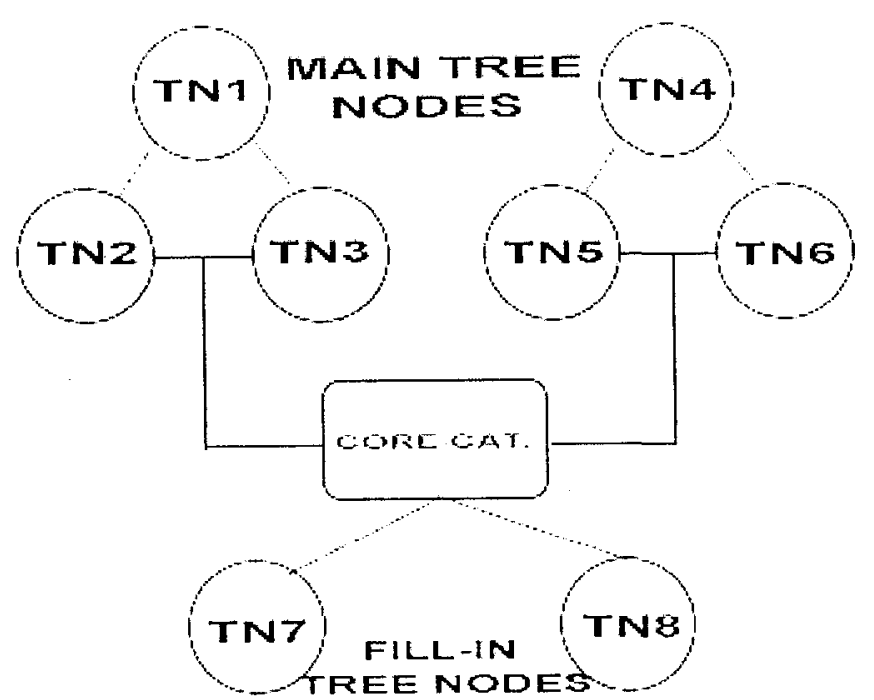

Figure 10. A visual example of selective coding. 
Finally, selective coding helped create stories of how categories relate and how the model works. Thus, during Stage 3, I reconstructed some of the Subjects' narratives, which were used to explain and support the model. After the initial explanation and narrative review, I asked the Subjects for additional narratives and/or explanations to help clarify the model. The goal here was not only to create but also to validate. Validation is an important part of the postpositivist view of grounded theory and is built into the research process.

Establishing Validity and Reliability

The postpositivist position argues for the existence of validity and reliability in qualitative research studies. Merriam and Associates (2002) state, "Currently, there is much debate and discussion in the literature and at conferences as to how to think about validity and reliability in qualitative research" (p. 24). Out of this debate, researchers have developed new ways to view old-standards from quantitative research. For example, Table 10 (Trochim, 2002) illustrates Guba and Lincoln's (1989) four criteria for examining validity and reliability.

Table 10

Criteria for Examining Validity and Reliability

\begin{tabular}{|l|l|}
\hline \multicolumn{1}{|c|}{$\begin{array}{c}\text { Traditional Criteria for Judging } \\
\text { Qualitative Research }\end{array}$} & \multicolumn{1}{|c|}{$\begin{array}{c}\text { Alternative Criteria for Judging } \\
\text { Qualitative Research }\end{array}$} \\
\hline Internal validity & Credibility \\
\hline External validity & Transferability \\
\hline Reliability & Dependability \\
\hline Objectivity & Confirmability \\
\hline
\end{tabular}


Validation of model: Credibility as internal validity. According to Merriam and Associates (2002), "Internal validity asks the question, how congruent are one's findings with reality?" (p. 25). As stated previously, my view of reality mirrors that of postpositivists "...it is never fully apprehended, only approximated" (Hatch, 2002, p. 13). Essentially, there is a level of interpretation employed by the researcher in order to give meaning to the data. "Most agree that when reality is viewed in this manner (i.e., that it is always interpreted) internal validity is considered a strength of qualitative research" (Merriam \& Associates, 2002, p. 25). To establish internal validity, I used member checks, peer reviews, triangulation, clarifying researcher bias, rich think description, and external audits.

Member checks were consistently presented throughout the research process. Member checks are a means for clarifying a particular statement and/or position. Essentially, it is a form of constant validation, "From what you have typed, I believe you mean that . Is that correct?" Thus, I constantly asked the Subjects to verify or negate my assumptions. Here is an example of a member check.

Researcher: First of all, you stated that "Financial is the reason for me taking online classes."

I'm not sure what you mean here because Marylhurst classes, whether online or not, are not cheap! What is the financial reason to which you're referring?

Researcher: I gathered from your comments that you're comfortable online because of your (very impressive!) background with computers, correct? 
Peer review relies on interaction among the Subjects themselves. Stage 2 collection is a good example of peer-reviewed validation. During Stage 2 , the RC discussion board was alive with arguments and counter-arguments, and the sharing of information.

Triangulation "...typically involves corroborating evidence from different sources to shed light on a theme or perspective" (Creswell, 1998, p. 202). Triangulation was a constant process throughout the analysis of the data, and is most evident in chapter 4 , which used multiple sources of literature to support various themes. This process of triangulation helped compare emerging themes with existing literature, and other emerging themes to help build interconnectedness between the themes.

Clarifying researcher bias is located in the "About the Researcher" section of chapter 3. This process of identifying bias went beyond the researcher to also describe the entire educational system at MU, and the Web-based Learning environment. Rich, thick description from the researcher helped provide a doorway into these biases, and also into the explanations of how major and subvariables were formulated. Finally, I used external audits, which were known as "Professional Review" in this chapter. Creswell (2002) recommends using at least two procedures for assuring internal validity in any study. I used six different methods, which all contributed to the integrity of this study. 
Validation of model: Transferability as external validity. In this study, external validity or "transferability" is the extent to which the results can be generalized to different online learning contexts. In other words, can the findings be applied to another setting or grouping of people experiencing the same phenomenon? Since the model was constructed at MU only, and was based-on a relatively small sample size of successful completers, it is probably not safe to suggest a specific level of transferability at this time. Rather, I think it is important to summarize the major variables, their relationships, and the connections to the existing retention models. The more clarity and understanding with the model, the better chance for an institution to gauge relevancy.

Validation: Dependability as reliability. "Reliability refers to the extent to which research findings can be replicated" (Merriam \& Associates, 2002, p. 27). It might be possible to replicate the $\mathrm{RC}$ itself and to follow the same collection procedures; however, it would be impossible to replicate respondents' answers and my interpretations of that data. Based on this procedural quandary, Guba and Lincoln (1989) introduced the notion of "dependability." In clarifying dependability, Trochim (2002) states:

The idea of dependability, on the other hand, emphasizes the need for the researcher to account for the ever-changing context within which research occurs. The researcher is responsible for describing the changes that occur in the setting and how these changes affected the way the research approached the study. ( $\$$ ) 
Accountability of my actions was documented by the use of an "audit trail." Merriam and Associates (2002) describe an audit trail as some type of documentation (in my case: research journal, memos, the WebCT RC and all exported documents in N6) that helps explain how my results were derived. In grounded theory research, it is not important that another researcher could look over the audit trail and find similar results. Rather, it is more important that other reviewers see the logic of how I could derive the results via the outlined process. Based on the documentation provided within the research process, text and appendices, a high-level of dependability has been achieved.

The research journal was divided in sections that were representative of the research process (e.g., Stage 1 Collection, Stage 1 Analysis, Stage 2 Collection) and all documentation was stored as a Microsoft Word document. Each step of the current process was matched with what was originally proposed and what actually occurred. Memos created during the research process in N6 formed the justification/evidence for making decisions between the proposed elements and what actually did occur. Table 11 provides an example of what the research journal might look like and provides only three steps of a 10 -step process. 
Table 11

\section{Collection Journal Example}

\begin{tabular}{|l|l|l|l|}
\hline \multicolumn{4}{|c|}{ Stage 1 Collection Journal } \\
\hline Stage 1 Process & \multicolumn{1}{|c|}{ Proposed } & \multicolumn{1}{|c|}{ Actual } & \multicolumn{1}{c|}{ Evidence } \\
\hline $\begin{array}{l}\text { Read and reread } \\
\text { text files }\end{array}$ & $\begin{array}{l}\text { Text files will be } \\
\text { read and reread } \\
\text { before assigning } \\
\text { categories. }\end{array}$ & $\begin{array}{l}\text { Text files were read } \\
\text { through once. Second } \\
\text { read, I grouped the } \\
\text { responses to similar } \\
\text { questions. }\end{array}$ & $\begin{array}{l}\text { Memo: "After first read } \\
\text { through, I started to think } \\
\text { thematically about the } \\
\text { answers. It made sense to } \\
\text { group their responses around } \\
\text { similar questions I asked." }\end{array}$ \\
\hline $\begin{array}{l}\text { Create necessary } \\
\text { memos }\end{array}$ & $\begin{array}{l}\text { The first stage of } \\
\text { memos represent } \\
\text { initial concerns, } \\
\text { thoughts, and } \\
\text { feelings about the } \\
\text { text files. }\end{array}$ & $\begin{array}{l}\text { Rather than memos } \\
\text { representing the entire } \\
\text { "batch" of data, I } \\
\text { found myself creating } \\
\text { memos around } \\
\text { individuals and like- } \\
\text { questions. }\end{array}$ & $\begin{array}{l}\text { Memo: "Subject_1 did not } \\
\text { understand the line of } \\
\text { questioning and his answers } \\
\text { are rather sparse when } \\
\text { compared to the entire } \\
\text { group. I'm going to have to } \\
\text { ask him to elaborate." }\end{array}$ \\
\hline $\begin{array}{l}\text { Begin coding by } \\
\text { identifying } \\
\text { relevant text units } \\
\text { - make } \\
\text { annotations as } \\
\text { necessary }\end{array}$ & $\begin{array}{l}\text { Text units come } \\
\text { from line-by-line } \\
\text { analysis of the } \\
\text { data and are } \\
\text { labeled and } \\
\text { become "Free } \\
\text { Nodes," the } \\
\text { building blocks of } \\
\text { categories. }\end{array}$ & $\begin{array}{l}\text { The creation of text } \\
\text { units was exactly how } \\
\text { I defined it in chapter } \\
\text { 3. I found using N6 } \\
\text { really helped here } \\
\text { because it } \\
\text { automatically assigns } \\
\text { a coding protocol. }\end{array}$ & $\begin{array}{l}\text { Memo: "Subject_1's } \\
\text { statement here implies a } \\
\text { strong connection with } \\
\text { Social Integration. They } \\
\text { even offered some } \\
\text { properties, which may be } \\
\text { useful in the near future." }\end{array}$ \\
\hline
\end{tabular}

About the Researcher

Grounded theory originates from a group of Subjects who are representative of a particular phenomenon. The researcher's job is to ask the right types of questions and interpret their recollections into a cohesive, singular representation, which is "the model." From this model, one is in a better position to make theoretical propositions concerning (in this case) online course retention. 
Essentially, the researcher is like a telescope, which when looked through, allows others to view the Subjects (where the theory originates). However, all the settings of the telescope (power of the lens, focus, direction of aim, etc.) established by the researcher have already been established. Some of these "settings" were set by the research context; however, many of the settings come from the researcher's bias. Perhaps, under certain circumstances, the telescope may provide a clearer picture.

I am an employee of MU's Web-based Learning department (WBL/D) and have been so for more than 3 years. Before coming to work for MU, I had some previous experience in distance learning (i.e., I coordinated a telecourse program) with Pueblo Community College in Cortez/Durango, Colorado. Overall, I have a favorable attitude toward distance learning and wish online learning existed when I was an undergraduate student. I definitely could have seen myself interacting and doing well in an online learning environment.

I do not believe that online learning is better or worse than face-to-face courses; rather, I believe that each system possesses a system of strengths when dealing with specific Subject matter. For example, to me lab work in the natural sciences is best done using a hands-on approach in person. Online learning does quite well in courses laden with postmodern-type constructs - where discussions often reflect philosophical arguments.

I have observed online classroom discussions that were far more in-depth and intricately constructed than one could ever hope to achieve in two, face-to- 
face, class-periods per week. However, there have also been online courses where the conversation was done in short choppy sentences like two people standing next to one another sharing small talk. According to students, just like face-to-face courses, online courses run the gamut from high quality to low quality. MU does not have an exclusive formula for creating nothing but high-quality online courses. Also, MU does not have the best services for online students and, in fact, had very few before I started working in the WBL/D.

Before beginning this study, I developed several explanations for high online course retention rates at $\mathrm{MU}$, and faculty and students often shared their ideas with me informally. The notion of online culture often arises in these informal conversations. This cultural position suggests that somehow MU students have migrated from on-campus courses to online courses and consequently recognize many of their fellow online students by name. This culture forms a support system and students are better able to persist in online learning. It is often suggested that MU online students persist because they are "adult students." Indeed MU has a high population of adult students taking online courses; however, that does not explain the equally high rate of retention for our traditional-aged students (Schreck, 2002).

Being an MU employee and working directly for the WBL/D, automatically creates a level of personal bias in this study. A potential for bias exists when interpreting Subjects' responses and/or moving responses into categories. My interpretations may not represent a Subject's intended meaning and the coding of 
these interpretations may end up in what I have determined to be the "right" category. Charmaz (2000) states:

Every qualitative researcher should heed warnings about forcing data into preconceived categories through the imposition of artificial questions. However, data collecting may demand that researchers ask questions and follow hunches, if not in direct conversation with respondents, then in the observers' notes about what to look for. (p. 514)

I relied on the Subjects to minimize this bias when reviewing categories and the model itself. In addition, the "Professional Review" process provides an opportunity for an external reviewer to read memos, the research journal and review the overall process of each stage of collection and analysis - checking for clarity and bias.

\section{Chapter III Summary}

Based on the need to both explain the MU phenomenon and to create a theory for online course retention, a grounded theory study guided the research paradigm. As stated in the "researcher's position," ontologically and epistemologically I found myself within the realm of a postpositivist research orientation. Therefore, I believed that there was a "Truth" or external reality, but my interpretation is what guided the understanding of this "Truth." In order to maximize the level of "Truth," postpositivist research demanded a level of validation and a rigorous set of collection and analysis methods. My methods were based-on Glaser and Strauss' 1967 book, The Discovery of Grounded Theory. 
Before addressing the research procedures, I described the research context in an effort to give the reader a better understanding of MU online courses. This context led to the sampling procedure. Grounded theory uses "theoretical sampling" which is less about a product (e.g., 14 Subjects) and more about a process that aims to purposefully identify Subjects who identify with the phenomenon being studied. I then took the Subjects through the coding procedures as outlined in the "Procedures" section.

The Procedures section used open, axial and selective coding as prescribed by Strauss and Corbin (1998) in order to facilitate an emerging research process of constant and comparative analysis. For this research project, I aligned three distinct collection/analysis stages to correspond with the coding procedures of postpositivist grounded theory. In summary, Stage 1 focused on the formation of categories and subcategories. Stage 2 combined categories, built interconnectedness and identified the central phenomenon or core category. The visual representation of the categories and their interconnectedness then became the suggested theoretical model. Finally, Stage 3 was both a creation and validation process of the model itself. I used narratives for clarification, and the research Subjects validated the model. Figure 11 is a visual representation of the entire research process. 


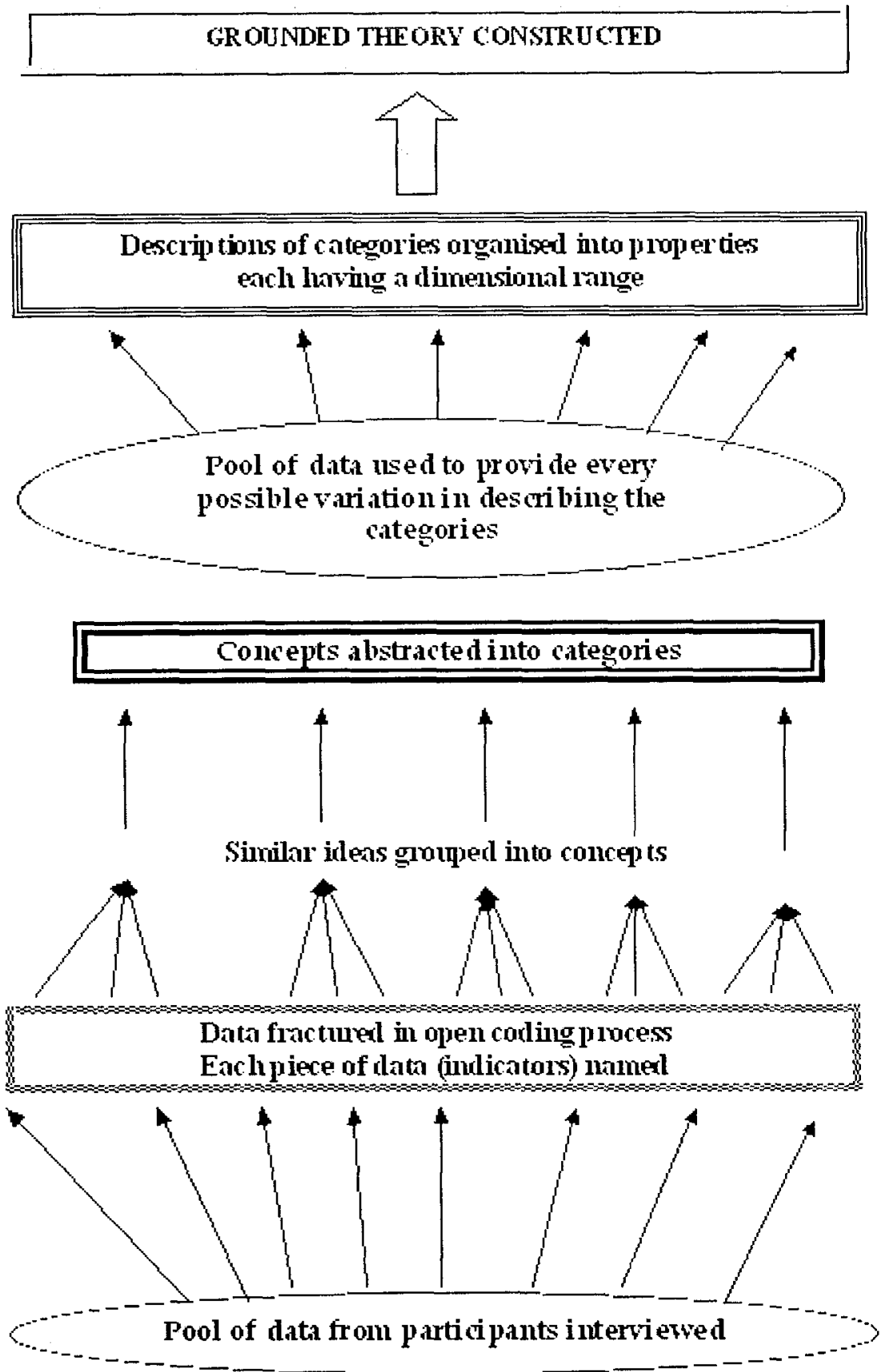

Figure 11. Visual summary of process. 


\section{CHAPTER IV}

\section{RESEARCH FINDINGS}

This chapter reports the findings from each of the three research stages. As the findings are reported, a concerted effort is made to connect these findings to relevant literature, theories, and/or models, whenever and wherever deemed appropriate by the researcher. The use of such literature is not to support the basis for this study, but rather to create understanding, give context, and to demonstrate and strengthen connections. The Stage 3 findings also contain the results from the validation process as described in chapter 3 (Methods). Finally, the section headings represent not only the various stages, but also the respective research questions.

\section{Research Question \#1}

Stage 1 - What predominant categories emerged from the raw data, and how did they connect to current literature concerning online retention?

The research process for Stage 1 was as follows and provided a framework for reporting the findings.

1. Read and reread text files.

2. Create necessary memos. 
3. Code text units into "Free Nodes" By identifying relevant text units (Data dictates Free Nodes). Continue to annotate as necessary.

4. Make a report if necessary.

5. Look for larger or "core categories" - create Tree Nodes, then cut and paste related Free Nodes into Tree Nodes.

6. Make additional subcategories as necessary, and append/merge any Free Nodes or subcategories.

7. Check for connections in the literature.

\section{Step 1: Read and Reread Files}

Reading and rereading the text files was important in familiarizing myself with the data before exporting it into N6. I did not want to rely on the computer analysis program for sole interpretation, and wanted to view the data in a more holistic fashion (i.e., in N6 the data analysis was done line-by-line). Therefore, using hard copies, I underlined sections of text that either supported the formulation of categories, and/or existing retention theory covered in chapter 2 . For a detailed description of how text units and initial categories were selected, please see chapter 3 - "Stage Collection."

To begin the research process, I offered the following introduction.

Welcome to Stage 1 of the research process. As you know from the consent letter, Stage 1 is a private, one-on-one experience between you and me. Before sharing with the larger group, I wanted to work with each participant individually. For me, this assures that other participants will not influence your opinions. 
At this point, I don't want to give you too many questions and would prefer to follow your lead. In a sense, I want to see where your answers take me. Therefore naturally, short or non-descript answers will have little value in the research process. Details are critical in helping me make sense of your experiences when compared and contrasted with others. While not looking for you to write a book (that's my job!), I am looking for insight, substance and honesty.

I will check in everyday to see what you have written and ask for clarification or perhaps, ask you to explore certain comments in further detail. At the end of this week, I'll let you know if you will need to check in next week at all. I sincerely thank you once again for your participation. You may now proceed to your private topic area, which corresponds to your Username.

The following two questions helped get the questioning process underway:

1. Please begin by giving me any information about your background that you deem important or significant when describing where you are educationally at this point in your life (e.g., family educational history, prior schooling, skills/abilities, current family/work situation).

2. What were the factors that led up to you taking online courses and how have they aligned (or not) with the background you described?

At this point in the study, my objective was to explore a broad range of possibilities and not direct the discussion with questions concerning online course retention. For example, when responding to question number two listed above, the following Subject mentioned that what led her to online learning was the flexibility and convenience it offered. I asked her to explain and/or provide examples of what "flexibility" and "convenience" meant to her. 
Subject: Surprisingly, I ended up moving in my last year of school to Wisconsin. I was able to do the move without missing a beat at school. Honestly, if it were not for the virtual option, I would not have my Bachelor's Degree today.

Comments such as this led me to start grouping similar text units under a category called, "flexibility." As categories were formed, I created the necessary memos to help provide context, and to justify my research process.

\section{Step 2: Create Necessary Memos}

As I read and reread the Subjects' responses, I created numerous memos to help me identify keywords, reflect on what was being said, and eventually to help with the coding in Step 3. For example, my memo for the Subject response noted above was:

Researcher Memo: Online learning offers students so much flexibility, that something as stressful as a move to a new state does not alter their persistence. I wondered if others felt the same way? Similarly, another Subject commented on the convenience of online learning.

Another Subject mentioned:

Subject: The freedom of time I can work when it is convenient for me, and no loss of time due to travel and hassle of getting in the car and driving in congested traffic, etc.

Researcher Memo: Time appears to be an essential part of flexibility. Similar examples were all grouped into an initial Free Node called "flexibility."

My notes on each Subject's transcript were memos to myself (such as those illustrated above) and were used to establish preliminary Free Nodes. The 
preliminary Free Nodes (i.e., the initial categories) were then loaded into the N6 computer program for descriptions, memoing and coding.

Step 3: Code Text Units into "Free Nodes" by Identifying Relevant Text Units Make Annotations as Necessary

Steps 3 was an involved process of identifying relevant text units, evaluating them, and coding as Free Nodes when appropriate. This process is one of constant reflection, evaluation, grouping, reflecting again, and regrouping as the data is presented. As I began the coding process, I started to notice where certain preliminary Free Nodes could be combined and/or deleted. I also created new Free Nodes that were not represented in the original transfer from hard copy to N6.

In the following tables (Tables 12-32), "Free Node" refers to a coded, preliminary representation of bits of data. The "Description" area gives a brief overview and/or definition of the Free Node. By the end of Stage 1, I managed to combine the Free Nodes into larger, representative Tree Nodes. The "Integrated Theme" column charts the path of each respective Free Node, and what it later became in the study. The "Sample Memo" column provides an example of how memos were used to provide both justification and rationalization of the coding strategies. Finally, some Free Nodes have a "Supporting Literature" bottom row. The Supporting Literature area was just another way of building a rationale for carrying the Free Node further in the study (note: not all Free nodes have 
supporting literature). Connecting Free Nodes to the literature was the final step in the Stage 1 process; however, I found myself constantly reviewing articles for supporting research.

\section{Table 12}

\section{Free Node 1}

\begin{tabular}{|c|l|l|}
\hline \multicolumn{1}{|c|}{ Free Node } & \multicolumn{1}{|c|}{ Description } & \multicolumn{1}{|c|}{ Integrated Theme } \\
\hline Background & $\begin{array}{l}\text { Anything that defines the Subjects as individuals } \\
\text { and provides context to their backgrounds. This } \\
\text { may be something as basic as common } \\
\text { demographics, but could be behaviors they } \\
\text { describe that work well with online learning. }\end{array}$ & $\begin{array}{l}\text { Student } \\
\text { Characteristics }\end{array}$ \\
\hline
\end{tabular}

Sample Memo: A very broad frame of reference for Subject characteristics. I suspect that I will have to break this down further before moving it to a Tree Node. This category has everything from age, scholastic information, personal information, information about family size and education, etc. Therefore, much of the coded data may end up being integrated into new or

Supporting Literature: In a recent study aimed at examining factors for retention in a "distancebased liberal arts program," Nessler (1999) found that "...retention in the liberal arts program was influenced by demographic characteristics such as educational background, ethnicity, gender, military status, and the number and types of credits transferred in by the student" (p. 10).

"If distance teachers had to pick one quality that differentiates successful distance learners from those who are unsuccessful, it would be communication with the teacher. Over and over, distance teachers told me that the students who communicate right away with the teacher do the best in their classes" (Dixon, 1996, p. 103).

K. Moore et al. (2002) show a $14.8 \%$ point difference in completion with classes taken online (41.7\%) and on-campus (56.5\%) for African Americans. 
Table 13

Free Node 2

\begin{tabular}{|l|l|l|}
\hline \multicolumn{1}{|c|}{ Free Node } & \multicolumn{1}{|c|}{ Description } & \multicolumn{1}{|c|}{ Integrated Theme } \\
\hline GED & $\begin{array}{l}\text { Subjects who obtained a GED, and any relevant text } \\
\text { to note why it was important and/or/how it relates to } \\
\text { retention. }\end{array}$ & $\begin{array}{l}\text { Student } \\
\text { Characteristics }\end{array}$ \\
\hline $\begin{array}{l}\text { Sample Memo: Any information concerning a Subject obtaining a GED verses a high school } \\
\text { diploma. In reading the hard copies, I noticed that several of the Subjects (at least 3) had a } \\
\text { GED. Hopefully, this Free Node will give some insight into why they dropped out of high } \\
\text { school. Frankly, I don't think it's very important at this time to the scope of the project. I just } \\
\text { found it interesting that so many Subjects have that characteristic. }\end{array}$ \\
\hline
\end{tabular}

\section{Table 14}

\section{Free Node 3}

\begin{tabular}{|c|l|l|}
\hline Free Node & \multicolumn{1}{|c|}{ Description } & \multicolumn{1}{c|}{ Integrated Theme } \\
\hline AA or AS & Subjects that have obtained an AA or AS degree. & $\begin{array}{l}\text { Student } \\
\text { Characteristics }\end{array}$ \\
\hline $\begin{array}{l}\text { Sample Memo: I don't think I'm gathering enough to support this as a genuine category. It } \\
\text { looks like only } 2 \text { Subjects followed this route. I think what is becoming more important is the } \\
\text { emphasis on a background of traditional, college-level, face-to-face experience, and how that } \\
\text { experience influenced their ability to persist in college courses. }\end{array}$ \\
\hline $\begin{array}{l}\text { Supporting Literature: While not citing an AA or AS degree specifically, K. Moore et al. (2002) } \\
\text { note that "Additionally, the fewer the higher education credits completed by these full-time } \\
\text { students, the less likely it was that they would succeed in online courses" and "First time, full- } \\
\text { time students were the least likely to succeed in online courses and had the largest difference } \\
\text { between online and traditional courses (-31.5\%)" (p. 10). }\end{array}$ \\
\hline
\end{tabular}


Table 15

Free Node 4

\begin{tabular}{|l|l|c|}
\hline \multicolumn{1}{|c|}{ Free Node } & \multicolumn{1}{|c|}{ Description } & \multicolumn{1}{c|}{ Integrated Theme } \\
\hline $\begin{array}{l}\text { Move/Life } \\
\text { Change }\end{array}$ & Data describing moving and/or life changes. & \multicolumn{1}{c|}{$\begin{array}{c}\text { Student } \\
\text { Characteristics }\end{array}$} \\
\hline $\begin{array}{l}\text { Sample Memo: It appears that many of the Subjects have described a process of both moving } \\
\text { around and/or life changes. This process has ultimately affected their values and opinions about } \\
\text { higher education. For example, many students would have never even considered online } \\
\text { learning. However, with moving around so much, they were unable to become associated or } \\
\text { affiliated with a particular university. Online seemed to best meet their needs based on what has } \\
\text { happened in their lives. }\end{array}$ \\
\hline
\end{tabular}

Table 16

Free Node 5

\begin{tabular}{|c|c|c|}
\hline Free $\mathrm{I}$ & Description & Integrated Theme \\
\hline $\begin{array}{l}\text { Characteristics of } \\
\text { the MU } \\
\text { Experience }\end{array}$ & $\begin{array}{l}\text { Data describing what it's like at Marylhurst, and } \\
\text { what it's like being a student at the University. }\end{array}$ & $\begin{array}{l}\text { Student } \\
\text { Characteristics }\end{array}$ \\
\hline \multicolumn{3}{|c|}{$\begin{array}{l}\text { Sample Memo: What makes an online experience worthwhile? I can see there are many } \\
\text { similarities between this category and Online Course Statements, which is more about the course } \\
\text { experience. These data will have to be combined, and possibly made into new Tree Nodes. }\end{array}$} \\
\hline \multicolumn{3}{|c|}{$\begin{array}{l}\text { Supporting Literature: "Online learners should be recognized for who they are and where they } \\
\text { stand in achieving their educational goals. Therefore, retention of online students is also } \\
\text { achieved by supporting their motivations to learn. This is best accomplished in a fast-paced } \\
\text { virtual environment utilizing activities that focus on their experiences" (Gibbons \& Wentworth, } \\
2002 \text {, p. 133). }\end{array}$} \\
\hline
\end{tabular}




\section{Table 17}

\section{Free Node 6}

\begin{tabular}{|l|l|l|}
\hline \multicolumn{1}{|c|}{ Free Node } & \multicolumn{1}{|c|}{ Description } & \multicolumn{1}{c|}{ Integrated Theme } \\
\hline $\begin{array}{l}\text { Online Course } \\
\text { Statements }\end{array}$ & $\begin{array}{l}\text { Data describing the process of online learning or } \\
\text { judgment statements about online learning. }\end{array}$ & $\begin{array}{l}\text { Pedagogy \& Learning } \\
\text { Theory }\end{array}$ \\
\hline
\end{tabular}

Sample Memo: This node is becoming HUGE! It will need to be divided into several subcategories when the follow-up questions are asked. Generally, I'm not as concerned about why they like or dislike online learning. I'm more interested in why they persist, even when the

Supporting Literature: Several students liked the fact that MU offers an online orientation to web-based learning and WebCT. The orientation is an essential part of every course, and is directed by the instructor. "Any student beginning any class wants information on class

\section{Table 18}

\section{Free Node 7}

\begin{tabular}{|l|l|l|}
\hline \multicolumn{1}{|c|}{ Free Node } & \multicolumn{1}{|c|}{ Description } & \multicolumn{1}{|c|}{ Integrated Theme } \\
\hline $\begin{array}{l}\text { Prior Learning } \\
\text { Assessment }\end{array}$ & $\begin{array}{l}\text { The influence of Prior Learning Assessment on course } \\
\text { retention. }\end{array}$ & Fit \\
\hline $\begin{array}{l}\text { Sample Memo: Prior Learning Assessment is a specific academic area at Marylhurst. The Prior } \\
\text { Learning Assessment (PLA) office evaluates both academic and life experiences to put together a } \\
\text { transfer-credit-plan. Many adults love this option because it validates much of their life- } \\
\text { experience that is non-academic and also, gives them a sense of pride in their accomplishments. } \\
\text { I think this adds value to their MU experience. }\end{array}$ \\
\hline $\begin{array}{l}\text { Supporting Literature: Regents College has shown progressively increasing retention rates in a } \\
\text { distance-based, liberal arts program over a ten-year period. Nessler (1999) states the Regents } \\
\text { uses both "...direct and indirect assessment methods for evaluating students' knowledge and } \\
\text { awarding credit. Indirect assessments of students' learning, and the associated transfer of credits } \\
\text { not obtained directly through the college's assessment, are dependent on explicit quality assurance } \\
\text { frameworks" (p. 4). }\end{array}$ \\
\hline
\end{tabular}


Table 19

Free Node 8

\begin{tabular}{|l|l|l|}
\hline Free Node & \multicolumn{1}{|c|}{ Description } & \multicolumn{1}{c|}{ Integrated Theme } \\
\hline Fit & $\begin{array}{l}\text { Data elements that describe online learning in terms of } \\
\text { "fit." }\end{array}$ & Fit \\
\hline $\begin{array}{l}\text { Sample Memo: I suspect "fit" will become a major theme in online course retention. Fit could } \\
\text { encompass several other Free Nodes. I believe that "fit" here has more to do with MU } \\
\text { organizational leadership and management. I think we're doing several things here that help } \\
\text { students persist in the online environment. I should try to check out some of the readings } \\
\text { regarding "fit" in my organizational culture and leadership class. }\end{array}$ \\
\hline $\begin{array}{l}\text { Supporting Literature: "The college fit theory asserts that the greater the congruence between the } \\
\text { values, goals, and attitudes of the students and those of the college, as well as between the } \\
\text { students' capabilities and the colleges' demands, the more likely a student is to persist in college" } \\
\text { (Rootman, 1972, p. 262). }\end{array}$ \\
\hline
\end{tabular}

Table 20

\section{Free Node 9}

\begin{tabular}{|l|l|l|}
\hline \multicolumn{1}{|c|}{ Free Node } & \multicolumn{1}{|c|}{ Description } & \multicolumn{1}{c|}{ Integrated Theme } \\
\hline Why Online? & Reasons for taking online courses. & Fit \\
\hline $\begin{array}{l}\text { Sample Memo: I suspect that Why Online? will become merged with the concept of "fit." Most } \\
\text { of the reasons described here have to do more with the Subject's lifestyle. This lifestyle is } \\
\text { something that usually aligns well with Marylhurst University and online learning. }\end{array}$ \\
$\begin{array}{l}\text { Supporting Literature: MU believes that online learning was necessary to meet the needs of their } \\
\text { adult-learner population. Although it seemed risky at a small liberal arts institution in 1996, they } \\
\text { have been quite successful. Gibbons and Wentworth (2002) point out "Recruiting efforts begin } \\
\text { with a marketing program specific to nontraditional students, a population that is the most } \\
\text { accepting of online education" (p. 129). } \\
\text { "Ironically, the very aspects of adult learners' lives that make online education so attractive in } \\
\text { theory can make the retention of those learners so precarious in practice. The additional } \\
\text { flexibility and assumed freedom allowed through online learning require increased responsibility } \\
\text { on the part of the adult learner to meet deadlines and stay on top of assignments without face-to- } \\
\text { face interaction" (Rankin, 2002, p. 143). }\end{array}$ \\
\hline
\end{tabular}


Table 21

Free Node 10

\begin{tabular}{|l|l|l|}
\hline Free Node & \multicolumn{1}{|c|}{ Description } & \multicolumn{1}{|c|}{ Integrated Theme } \\
\hline Persistence & $\begin{array}{l}\text { Hints at why Subjects may or may not persist in } \\
\text { online courses. }\end{array}$ & Fit \\
\hline $\begin{array}{l}\text { Sample Memo: I was hesitant to even ask the questions because it's what I'm really trying to } \\
\text { formulate via Subject responses. However, in some cases, the conversation just led me in that } \\
\text { direction. Therefore, the question was asked to several Subjects. Early indications seem to } \\
\text { moving in the direction of Fit - meaning, that online learning works well with the expectations of } \\
\text { their daily lives and meets their educational goals. }\end{array}$ \\
\hline $\begin{array}{l}\text { Supporting Literature: "The solution for retaining online students is the same for on-ground } \\
\text { students: keep them happy. To satisfy the typical online student, institutions must utilize } \\
\text { competent, trained instructors and offer online classes on a fast-paced schedule. Most online } \\
\text { students wish to pursue an entire degree online, not participate in one or two isolated courses" } \\
\text { (Gibbons \& Wentworth, 2002, p. 130). }\end{array}$ \\
\hline
\end{tabular}

Table 22

Free Node 11

\begin{tabular}{|l|l|l|}
\hline \multicolumn{1}{|c|}{ Free Node } & \multicolumn{1}{|c|}{ Description } & \multicolumn{1}{c|}{ Integrated Theme } \\
\hline $\begin{array}{l}\text { Course } \\
\text { Characteristics }\end{array}$ & Characteristics of online courses - good and bad. & $\begin{array}{l}\text { Pedagogy \& Learning } \\
\text { Theory }\end{array}$ \\
\hline
\end{tabular}

Sample Memo: Most of these statements helped formulate the major categories: Online course organization, online pedagogy and learning theory. Many of the statements deal with the learning process in online courses -vs- on-campus courses. I think I'll pull "comparisons" into this category.

Supporting Literature: "The asynchronous format allows more time to think than the typical classroom discussion, but the fact that comments are fixed in writing to be scrutinized by the student on her own, dictates that we take exceptional care in wording them, in the individual exchanges or in the class forum" (Payne, 2002, p. 120).

Fredericksen, Pelz, Pickett, Shea, and Swan (2001) surveyed 1406 online learners and discovered a correlation between the perceived level of interaction (both learner to learner and instructor to learner) and the "perceived learning effectiveness."

"Online instructors should keep in mind that their students are especially dependent upon the organization of the class website and its online materials to help them succeed. A poorly designed (or poorly written) site will cause unnecessary frustration" (Rankin, 2002, p. 144).

K. Moore et al. (2002) created a "Students' top 10 reasons for not completing online courses" Two responses had to do with characteristics of online courses: "Courses taking too much time, and Courses too unstructured" (p. 13). 
Table 23

Free Node 12

\begin{tabular}{|l|l|l|}
\hline \multicolumn{1}{|c|}{ Free Node } & \multicolumn{1}{|c|}{ Description } & \multicolumn{1}{c|}{ Integrated Theme } \\
\hline $\begin{array}{l}\text { Teacher } \\
\text { Characteristics }\end{array}$ & $\begin{array}{l}\text { Anything associated with online teachers } \\
\text { specifically. }\end{array}$ & $\begin{array}{l}\text { Pedagogy \& Learning } \\
\text { Theory }\end{array}$ \\
\hline $\begin{array}{l}\text { Sample Memo: The "comparisons" category, which made comparisons between online learning } \\
\text { and on-campus learning, was combined with teacher characteristics. Most of the discussion that } \\
\text { occurred in the original comparisons category focused on aspects of the teacher. }\end{array}$ \\
\hline $\begin{array}{l}\text { Supporting Literature: In a study that qualitatively researched a distance education program } \\
\text { aimed at continuing education for registered nurses across Canada, Care (1995) discovered six } \\
\text { themes, which center on teachers' actions and how they all correlate to student retention. The } \\
\text { six factors are teaching practices, evaluation practices, interpersonal relationships, personal } \\
\text { characteristics, professional competence, and availability to students. All of these directly relate } \\
\text { to the teacher characteristics subtheme. } \\
\begin{array}{l}\text { Major and Levenberg (1999) emphasize a major subtheme occurring within teacher } \\
\text { characteristics, which is the fact that teachers must establish clear instructions and learning } \\
\text { objectives. "Clarify expected course outcomes, which should specifically identify the behaviors } \\
\text { the successful learner will be able to perform upon completion of the learning experience" ( } \$ 15) .\end{array} \\
\text { "Online learners cannot always meet strict time demands. It is essential that faculty maintain a } \\
\text { caring, understanding attitude and provide a flexible learning environment that stresses outcomes } \\
\text { over processes" (Gibbons \& Wentworth, 2002, p. 130). }\end{array}$ \\
\hline
\end{tabular}

Table 24

Free Node 13

\begin{tabular}{|l|l|l|}
\hline \multicolumn{1}{|c|}{ Free Node } & \multicolumn{1}{|c|}{ Description } & \multicolumn{1}{|c|}{ Integrated Theme } \\
\hline Comparisons & $\begin{array}{l}\text { Comparisons between online learning and on- } \\
\text { campus learning. }\end{array}$ & $\begin{array}{l}\text { Pedagogy \& Learning } \\
\text { Theory }\end{array}$ \\
\hline
\end{tabular}

Sample Memo: Overall comparisons between online learning and face-to-face learning. These comparisons may concern discussion and/or a particular pedagogy, or they may be about learning styles and/or theory. The comparisons were not limited to a specific aspect of learning. 
Table 25

Free Node 14

\begin{tabular}{|c|c|c|}
\hline Free Node & Descr & Integrated Theme \\
\hline The Ideal & $\begin{array}{l}\text { Ideal descriptions of what online learning should look } \\
\text { like. }\end{array}$ & $?$ \\
\hline \multicolumn{3}{|c|}{$\begin{array}{l}\text { Sample Memo: The ideal - represents any comments from Subjects regarding the way they think } \\
\text { things should be. These comments are not exclusive to the online learning environment. They } \\
\text { may represent feelings about college in general, learning, pedagogy, etc. Because I made the } \\
\text { ideal such a broad area, most of these data will be combined into other existing Free Nodes. } \\
\text { There is really no consensus about what the "ideal" is anyway. Ideal meaning the "one" way to } \\
\text { run an online course. Most Subjects had all kinds of notions of what was ideal and what was } \\
\text { not. }\end{array}$} \\
\hline \multicolumn{3}{|c|}{$\begin{array}{l}\text { Supporting Literature: Many students suggested that prompt feedback (i.e., feedback given } \\
\text { within } 12 \text { hours from an instructor who visits the course site everyday) gives them a better sense } \\
\text { that they are not alone in cyberspace. Hara and Kling (1999) state, "The lack of prompt } \\
\text { feedback from the instructor was certainly a major source of frustration for students because they } \\
\text { were concerned about their performance" ( } \mathbb{7 8} \text { ). }\end{array}$} \\
\hline
\end{tabular}

Table 26

Free Node 15

\begin{tabular}{|l|l|l|}
\hline \multicolumn{1}{|c|}{ Free Node } & \multicolumn{1}{|c|}{ Description } & \multicolumn{1}{c|}{ Integrated Theme } \\
\hline Culture & Statement regarding culture or subcultures. & Culture \\
\hline
\end{tabular}

Sample Memo: Culture has always been in the back of my mind when considering online course retention. I believe that an MU online has an existing culture. This culture is very similar to the culture that defines many college campuses (i.e., liberal, conservative, party-school, academically strong). I hypothesize that this existing culture indoctrinates new students into the online learning environment. I'll have to wait and see how this pans out in the research. 
Table 27

Free Node 16

\begin{tabular}{|l|l|l|}
\hline Free Node & Description & Integrated Theme \\
\hline Metaphors & $\begin{array}{l}\text { Any descriptive metaphors that help to explain online } \\
\text { learning or a Subject's experiences. }\end{array}$ & $?$ \\
\hline $\begin{array}{l}\text { Sample Memo: A useful metaphor came from a Subject: The online class is like an orchestra. } \\
\text { The teacher is present and directing, but all of the participants create music. Without the } \\
\text { director, there would be no music, but neither would there be music if the students did not } \\
\text { contribute. I think this is headed toward pedagogy and learning theory, but at this time I'm not } \\
\text { sure. I would like to explore this metaphor and see where it goes. }\end{array}$ \\
\hline
\end{tabular}

Table 28

Free Node 17

\begin{tabular}{|l|l|l|}
\hline \multicolumn{1}{|c|}{ Free Node } & \multicolumn{1}{|c|}{ Description } & \multicolumn{1}{c|}{ Integrated Theme } \\
\hline $\begin{array}{l}\text { Online } \\
\text { Discussions }\end{array}$ & Characteristics of online discussions & $\begin{array}{l}\text { Pedagogy \& Learning } \\
\text { Theory }\end{array}$ \\
\hline $\begin{array}{l}\text { Sample Memo: Any comments that characterize the online discussion format. There were many } \\
\text { comparisons made in this section that will be cross-listed with the "comparisons" category. }\end{array}$ \\
\hline $\begin{array}{l}\text { Supporting Literature: [In online learning] "Total Communication increases and, for many } \\
\text { students, the result seems more intimate, protected, and convenient than the more intimidating } \\
\text { demands of face-to-face communication with faculty" (Chickering \& Ehrmann, 1997, \ 11). }\end{array}$ \\
\hline
\end{tabular}

Table 29

Free Node 18

\begin{tabular}{|l|l|l|}
\hline Free Node & \multicolumn{1}{|c|}{ Description } & \multicolumn{1}{c|}{ Integrated Theme } \\
\hline Preparedness & $\begin{array}{l}\text { Things that helped students prepare for online } \\
\text { courses. }\end{array}$ & $\begin{array}{l}\text { Student } \\
\text { Characteristics }\end{array}$ \\
\hline $\begin{array}{l}\text { Sample Memo: Any comments associated with how students may have prepared for the online } \\
\text { learning experience. This could also be advice given to new students entering into online } \\
\text { courses. Hopefully, this will lead me in the direction of administrative functions and how well } \\
\text { the students perceive them. Of course, I'd like to think that our WBL department is at least } \\
\text { partly responsible for online course retention. }\end{array}$ \\
\hline
\end{tabular}


Table 30

Free Node 19

\begin{tabular}{|l|l|l|}
\hline \multicolumn{1}{|c|}{ Free Node } & \multicolumn{1}{|c|}{ Description } & \multicolumn{1}{c|}{ Integrated Theme } \\
\hline $\begin{array}{l}\text { Student } \\
\text { Characteristics }\end{array}$ & Characteristics about online students & $\begin{array}{l}\text { Student } \\
\text { Characteristics }\end{array}$ \\
\hline $\begin{array}{l}\text { Sample Memo: Student characteristics - any information that helps me gain a better picture of } \\
\text { what these online learners are like (i.e., what they bring to the online environment). This may }\end{array}$ \\
$\begin{array}{l}\text { pertain to their particular learning style or preferred teaching style. It also could pertain to their } \\
\text { home/work life (i.e., how stressful it is). Regardless, online learning does provide a measure of } \\
\text { flexibility for busy adult learners. This was similar to Subject characteristics, but tried to code } \\
\text { specific things having to do with being a student at MU. }\end{array}$ \\
\hline
\end{tabular}

Table 31

Free Node 20

\begin{tabular}{|l|l|l|}
\hline \multicolumn{1}{|c|}{ Free Node } & \multicolumn{1}{|c|}{ Description } & \multicolumn{1}{c|}{ Integrated Theme } \\
\hline Time & $\begin{array}{l}\text { Time here means any relevance to how online } \\
\text { learning gives or takes more time and/or how online } \\
\text { learning enables more time to think. }\end{array}$ & Time \\
\hline $\begin{array}{l}\text { Sample Memo: More of a category for me...this is not directly supported by the data, but is } \\
\text { often indirectly mentioned in terms of flexibility and convenience; therefore, I want to explore } \\
\text { this further in Stage 2. Time also implies a sense of freedom when constructing discussion board } \\
\text { postings. Students are not constantly "on the spot" to make a witty and/or intelligent comments. }\end{array}$ \\
$\begin{array}{l}\text { Supporting Literature: "Time facilitates learner reflection about new experiences, how those } \\
\text { experiences compare to their current understandings, and how different understandings might } \\
\text { provide learners with improved understandings" (Kanuka \& Anderson, 1999, p. 52). }\end{array}$ \\
\hline
\end{tabular}


Table 32

Free Node 21

\begin{tabular}{|l|l|l|}
\hline \multicolumn{1}{|c|}{ Free Node } & \multicolumn{1}{|c|}{ Description } & \multicolumn{1}{c|}{ Integrated Theme } \\
\hline $\begin{array}{l}\text { Integrated } \\
\text { Learning }\end{array}$ & $\begin{array}{l}\text { Integrated learning comments. Generally comments } \\
\text { about how integrated learning affects retention. }\end{array}$ & $?$ \\
\hline $\begin{array}{l}\text { Sample Memo: } \\
\text { demands further exploration in Stage 2. There have been quite a few inferences made at the } \\
\text { "ILMs" (Integrated Learning Modules) at Marylhurst University. These ILMs have } 3 \text { online } \\
\text { courses from different academic disciplines all contained in a single course shell. They provide } \\
\text { an opportunity for the online students to take the course for 3, } 6 \text { or even } 9 \text { credits. They have } \\
\text { been successful and popular with the students. }\end{array}$ \\
\hline
\end{tabular}

\section{Step 4: Make a Report if Necessary}

Reports were made using N6 print options. These reports were hard copy representations of the coding and memoing process. To complete step six (formulation of Tree Nodes), the reports were essential. I used the reports to notice any patterns, repetitions of Free Nodes (i.e., areas where the same text units were used), and to gain an overall picture of the direction of the research. These visual representations also helped shape the final model.

Step 5: Look for Larger or "Core Categories" Create Tree Nodes, Then Cut and Paste Related Free Nodes into Tree Nodes

The 21 Free Nodes (previously displayed as Tables 12-32) became the basis for the formulation of nine core categories (from this point forward referred to as Tree Nodes): 
1. Student Characteristics;

2. Fit with College;

3. Online Course Organization;

4. Teacher Characteristics;

5. Teaching Methods;

6. Culture/Subculture;

7. Learning Theory;

8. Snapshot of the Learning Experience; and

9. Investment in Online Learning.

The Tree Nodes were loaded into the N6 program and coded - relevant Free Nodes and text units were placed under these Tree Nodes to give meaning and context. Many of the text units will be listed in the next section. Some Free Nodes were discarded simply because they were not supported by data (i.e., they could not fit into the Tree Nodes, and did not correspond to existing retention theory). Other Free Nodes were discarded because they were not directly or indirectly related to online, course retention. The remaining Free Nodes either stood alone (i.e., were supported by the data either by sheer volume or researcher decision), or they were combined with other Free Nodes to make an overarching Tree Node.

Seven of the Free Nodes (Subject characteristics, GED, AA/AS, move/life changes, characteristics of the MU experience, preparedness, and student characteristics) were explored under the integrated, Tree Node "Student 
Characteristics." Five Free Nodes (online course statements, course characteristics, teacher characteristics, comparisons, and online discussions) were explored under the integrated, Tree Node "Pedagogy/Learning Theory." Four Free Nodes (prior learning assessment, fit, why online?, and persistence) were explored under the integrated, Tree Node "Fit." The Free Node culture was explored under the Tree Node "Culture" and the Free Node time was explored under the Tree Node "Time." Finally, the remaining, Free Nodes the ideal, metaphors, and integrated learning were discarded due to lack of support.

After coding, I moved the Tree Nodes and Free Nodes into the Research Course for further exploration. I began to refer to Tree Nodes as "main themes" and Free Nodes as "sub themes." These themes and subthemes (Table 33) represent the product of Stage 1 research, and were carried over into Stage 2 for further exploration. As stated previously, these Tree Nodes were derived from existing Free Nodes, which were derived mainly from the supporting text units. However, this was also time for me as the researcher to think about any additional subthemes, and/or combining multiple Free Nodes into newly titled subthemes.

To achieve this goal, I had to ask myself two major questions. The first of which targeted the properties and/or "indicators" of the Tree Node. For example, "When a Subject mentioned 'Fit with the college,' what word or words provided meaning to this major category?" The second question dealt with the dimension of the Tree Node (i.e., a question aimed at judging importance of the subthemes). For example, "What subthemes appeared to be fundamental to the discussion - so 
fundamental that it would seem inappropriate, regardless of popularity, if they

were left out?"

Table 33

Themes from Stage 1

\begin{tabular}{|l|l|}
\hline \multicolumn{1}{|c|}{ Integrated/Main Themes (Tree Nodes) } & \multicolumn{1}{c|}{ Subthemes } \\
\hline Student Characteristics & $\begin{array}{l}\text { Background } \\
\text { Traditional Learning } \\
\text { Educational Goals }\end{array}$ \\
\hline Fit with College & $\begin{array}{l}\text { Views online as equivalent } \\
\text { Time/time commitment } \\
\text { Drop policies } \\
\text { Fit and educational goals }\end{array}$ \\
\hline Online Course Organization & $\begin{array}{l}\text { Clear beginning instructions } \\
\text { Structure and dialogue } \\
\text { Clear writing and schedule } \\
\text { Weekly set-up } \\
\text { Routines }\end{array}$ \\
\hline Teacher Characteristics & $\begin{array}{l}\text { Patterns of expectations } \\
\text { Clear and frequent communication } \\
\text { Engage the students }\end{array}$ \\
\hline Teaching Methods & $\begin{array}{l}\text { Idea transfer } \\
\text { Learning Style } \\
\text { The teachable moment } \\
\text { Community of teachers }\end{array}$ \\
\hline Learning Theory & $\begin{array}{l}\text { Existence of culture } \\
\text { Subcultures to decrease class size } \\
\text { Form impression of colleagues }\end{array}$ \\
\hline Culture/Subculture & $\begin{array}{l}\text { Constructivist -vs- instructivist } \\
\text { Learning from other students }\end{array}$ \\
\hline & $\begin{array}{l}\text { Permanent record } \\
\text { Can't take things back } \\
\text { Track involvement } \\
\text { Repeated use of courses }\end{array}$ \\
\hline & $\begin{array}{l}\text { Student investment } \\
\text { Student involvement }\end{array}$ \\
\hline & \\
\hline
\end{tabular}


Granted, the data (both from the Subjects, and from the literature) supported these decisions, but more importantly, it was a somewhat subjective process as well. I needed to make cuts here, and in the process prioritize and integrate data. As a final step to ensure integrity, member checks were used to ensure that all Subjects believed in these themes and subthemes. Before starting Stage 2, there was not a single dissension. All Subjects were on board and believed the themes and subthemes shown in Table 33 were representative of their experiences and the research process.

Step 6: Make Additional Subcategories as Necessary and Append/Merge any Free Nodes or Subcategories

As the first main category, I coded "Student characteristics" as anything that defined the Subjects as individuals and provided context to their backgrounds. The three properties that helped further define student characteristics were background, traditional learning and educational goals. I found background to be a very broad category where Subjects spoke of their educational careers, work careers, personal setbacks, family life, etc. The traditional learning property contained information relating to prior educational experience (traditional classrooms) with persistence in online courses. Finally, the educational goals category contained all comments correlating the attainment of goals to the persistence in online education. Here are some examples from the data with the "Researcher Memo" explaining the subtheme in greater detail (i.e., strictly for the 
reader), and the "Response" representing answers given to support the various subthemes.

Subject characteristics: Background.

Researcher Memo: The property "background" describes the rather tumultuous educational-careers, work-careers and very busy lives of online students at Marylhurst University. Many of our students are in transition (i.e., changing jobs, moving to a new geographic location, going through a divorce, or similar life change). Based on the data, it appears that background is a key factor in leading to the convenience of online learning.

Response \#1: That was eight years ago, I have since moved 6 times, transferred to 6 different colleges and in the process lost more credits then I kept. I have 182 credit hours, but no four-year degree.

Response \#2: I am married, have no children and my husband and I both work long hours. I am currently a management accountant for a steamship line, and my career goal is to finish my bachelors, obtain a master's in accounting, then sit for my CPA. Upon receiving CPA certification I would like to become a forensic accountant.

Response \#3: I retired (early) from AT\&T after a 28-year career. But I'm not good at retirement. I worked for a while for a local consulting company, and an opportunity to teach in one of the technical programs at PCC came my way. I did that for 4 years as an adjunct, and became a facilitator for Subject Area Committees who were reworking their curricula into outcome-based programs.

Subject characteristics: Traditional learning.

Researcher Memo: Does experience as a traditional, on-campus student provide the necessary experience to persist online? Perhaps, students develop a better understanding of the college experience and know what to expect online. Would it be good policy to restrict online courses to those students only having some traditional, oncampus experience? Here are two responses concerning pursuing a degree in a "traditional fashion." 
Response \#1: When people ask me about my degree experience I always tell them that $I$ feel if someone has not pursued a degree in the traditional fashion first that they may want to think twice before going strictly to the online forum. I feel I would have had a lot more struggles if I had not done traditional college first and gained experience from there before going to the online forum.

Response \#2: Maybe, web-enhanced learning is the key here. In web-enhanced learning, there are on-campus meetings mixed with online components. My only problem with this is I think you told us that the web-enhanced courses at Marylhurst have lower course retention rates than the online courses.

Subject characteristics: Educational goals.

Researcher Memo: What about educational goals? All Subjects seem to be driven to a specific educational goal, which in turn helps them accomplish career goals. Most Subjects supported the claim that clear educational goals created a highly motivated student thus, a student better able to persist online.

Response \#1: I complete online course for two reasons. 1) Online was the only way I was going to get my degree in a timely manor. 2) I don't give up on something I start unless I have a very good reason - not liking it is not a good reason to me.

Response \#2: I plan to go back to school for my master's degree here in the near future. I will look into both virtual and traditional options again when the time comes. I believe they both have good and bad points about them.

"Fit with the college" is the second theme. This theme was defined by data suggesting that the Subject viewed online learning as equivalent to on-campus learning, mentioned the time commitment factor in online learning, discussed the drop policies, and/or correlated the concept of fit with the attainment of educational goals. 
Fit with the college: Equivalency.

Researcher Memo: Concerning equivalency, I asked several Subjects, "How are you treated as an online student at Marylhurst? What is the level of service for technical assistance, student services (financial aid, registrar's office, etc.), teaching, etc.?" Thus, the category is more about perceived equivalency.

Response \#1: I have experienced Marylhurst online courses to be given the same respect as a classroom class. The expectation is to achieve a high standard whether it be online or in the classroom. All my needs are meet using the computer no matter what department or course I am trying to communicate with.

Response \#2: If there is any reaction, it's one of wonder - that someone would enjoy an online class. Anyone who has taken an online class knows it's not easier or less educational. Anyone who hasn't taken an online class doesn't seem to carry any prejudice against online class, except the technologically challenged.

Fit with the college: Time and time commitment.

Researcher Memo: Time. A very important element of "fit." It appears that online courses give students the added element of time. This added element of time can translate to more time to "think," more time with family, more time at a job, and even more thoughtful course participation. Here are some examples:

Response \#1: ...Online discussions give you time to think.

Response \#2: Online learning provides me with time to spend with my family.

Response \#3: I have a demanding job and can still find time for school because showing up is flexible. I can do it when I can do it.

Response \#4: Being able to stay on task is less stressful and gives one more time to provide thoughtfully produced work.

Researcher Memo: On the other hand, time appears to be both a blessing and a curse. Here is a quote from a Subject that spent too much time trying to decipher cryptic messages. This was from an online course experience outside of Marylhurst University. 
Response \#5: In an online situation (with another university), I have that time to read but couldn't follow his train of thought to save my soul. I never completed that course. I wanted to, and if I'd had the time, I might have gone to get some supporting materials and enhance the lesson myself, but time was one of the reasons I was taking it online. Very frustrating.

Fit with the college: Drop policies.

Researcher Memo: Drop policies concerning online courses can affect whether or not a student will persist. Working adults do not like throwing their money away. The discussion around drop policies quickly became more about the costs associated with online education. One Subject noted a reason for persistence was financial, and several others supported this claim.

Response \#1: The second factor that kicks in here is cost. If I sign up for a community college class and bail out, I'm out a couple of hundred dollars. If I do this at Marylhurst, I'm probably out a $\$ 1,000$ or more.

Fit with the college: Fit and educational goals.

Researcher Memo: The word "fit" can mean many things. Through the data, "fit" meant how well online learning suits the lives of Marylhurst online students, and to what degree this helps them attain their educational goals in a daily existence that may involve multiple roles. Two Subjects summed it up in the following passages.

Response \#1: It works well for me. It is a matter of convenience, I suppose, due to my discomfort with night driving, but it also helps me meet my life goal within the parameters of the rest of my life. I have a demanding job and can still find time for school because showing up is flexible.

Response \#2: At least with an online class I can physically be with my kids. I can do my homework when I am making them do homework, or when they are watching TV or playing. It really goes back to the day care thing. I already need someone home for them from $2: 30 \mathrm{pm}$ on. I work full time, so I do not want to sacrifice any more time away for blocks of classes. 
Course organization is the third theme and deals primarily with the logistics and set-up of the course materials. The properties were structure and dialogue this pertains to the balance of structure and dialogue provided by the instructor, clear writing, weekly discussion boards, routines, and clear beginning instructions. This theme also included many of the "good" and "bad" comments about online courses. Any clues to help me better understand the make-up of an online course were included.

Course organization: Structure and dialogue.

Researcher Memo: A prominent voice in distance learning said that courses must have a balance between structure and dialogue. These are two vital elements that help define "course organization." Structure is necessary to help organize the course; however, too much structure can stifle dialogue. Dialogue is important in online courses because most of the course is conducted on the discussion board. Too much dialogue without the necessary structural elements creates mass confusion, and students often have to help each other out. Here are two excerpts from Subjects with a clear understanding of both structure and dialogue.

Response \#1: Feedback from teachers was a large complaint with our group. For the most part instructors didn't participate too heavily in the discussion board talks. They only graded our papers and made comments to them if needed. Actual grades were slow to come as well so you didn't know if you were on track or not.

Response \#2: There were some teachers who were excellent. They were out there posting right along with us and giving us good solid feedback in a timely basis. My experience would have been much better if this were more the norm than the exception. I was left to feel that I paid a large amount of money to have peers teach me and I teach them as well. 
Course organization: Clear writing.

Researcher Memo: It seemed that many Subjects could forgive a sloppy course (i.e., couldn't find things right away) as long as when they did find things, they were clearly written. There is also the connection between clear writing and clear thinking.

Response \#1: In fact, I think most people in general are more careful when they communicate in writing. I can often go through a discussion board and read back on what a person has said and get a clearer picture of who they are and what they think.

Response \#2: The very act of writing forces articulation. (I don't mean "forces" as a violent thing. It just makes it happen.) Skillful questioning by the instructor and exposure to many points of view also gave me fuel for the fire of my own integration and taking the knowledge a step further.

Course organization: Weekly discussion boards.

Researcher Memo: The Subjects supported the use of course templates to improve course organization. Course templates provide a measure of "built-in" organization. Therefore, it would be practically impossible for instructors to be given a poorly established course. Most of the online students experience these templated courses (Response \#1); others experience courses that "lack continuity" (i.e., not consistent with the look and feel of other templated courses), which is described in Response \#2.

Response \#1: I'm not sure if all courses are set-up this way; however, the best thing I've seen an instructor do is set-up the course in a weekly format. This was so easy to understand and follow.

Response \#2: I've heard of courses that have a similar look and feel, but I have yet to see any of the courses. I think this is a very good idea and have been disappointed by the lack of continuity that I have seen.

Course organization: Routines.

Researcher Memo: Subjects noted the importance of instructors establishing course routines (i.e., think of "routines" as policies and 
procedures for working in an online course). These routines help ground the students, and give them a sense of security. The following quotes are from students describing routines they would like to see in an online syllabus.

Response \#1: I will post the week's lesson on Friday. Your assignment is due on Tuesday, and your comments on others' postings are due no later than Friday. I will be online normally at least at such and such a time and day (actually several periods over the week).

Response \#2: Clearly established routines help me navigate the course during the term. Without these routines, I am completely lost. There is a lot of freedom in online learning. I can experience the course whenever I want to. Without these routines, I might be more apt to neglect the expectations and do other stuff.

Course organization: Clear beginning instructions.

Researcher Memo: It was often mentioned that online courses must have clear beginning instructions. I suppose this would be especially important for new online students. I try to encourage this in our instructors. Clear beginning instructions often set the tone for the course and tell the student right away if the course is well organized or not. In the following excerpt, a Subject describes her ideal situation.

Response \#1: Heaven--At the beginning of class, see all of the assignments for the term, along with their due dates; see detailed instructions for communications expectations; see how each assignment will be evaluated; know what to expect from the instructor, when he will be online, what his participation will be. During the term, I'd like to see regular and cogent feedback on what needs improving. I generally get all of those things in a classroom, and I'll be darned if I can see why they couldn't be provided online as well.

Teacher characteristics is the fourth theme and deals primarily with the attributes of online teachers and how these attributes translate into student persistence. The properties were patterns of expectations - this pertains to how 
clear communication leads to the establishment of routines, clear and frequent

communication, and the ability of the instructors to engage the students in meaningful ways. This theme also included many of the "good" and "bad" comments about online instructors.

\section{Teacher characteristics: Patterns of expectations.}

Researcher Memo: In qualitative research work, the discovery of buzzwords often helps communicate ideas to the general community to which you are writing. When speaking of favorably of "teacher characteristics, " a Subject mentioned the "pattern of expectations."

Response \#1: As I mentioned above, <the students > role-modeled the behavior she < the teacher $>$ was looking for, and most of us responded in kind. Pretty quickly, we fell into a pattern of expectations and engaged with each other even when she deliberately held back awhile to make us engage with each other. But she led the way first. What it does for the students is help them understand a) what is expected and b) what success looks like. It also makes you want to $\log$ on and participate, knowing there is likely to be something new there.

\section{Teacher characteristics: Clear and frequent communication.}

Researcher Memo: I kept hearing this phrase "clear and frequent." However, I really had no idea what the Subjects meant by it. Most of the follow-up questions contained some referenced to defining (give indicators) of "clear" and "frequent" communication. Some developed their opinions into policy statements.

Response \#1: Policy statement: Instructors will reply to online postings requiring edits, corrections, clarification or answers within 24 hours. They will post at least one message per week to each online student. These postings would be of the encouraging/ clarifying/redirecting persuasion.

Response \#2: I would say the key to "clear" communication in an online environment is the initial setting of expectations in the syllabus. If we have a map to where we are going, we are all more likely to get there. "Frequent" communication is once a week for 
students doing well in the environment, but may mean daily exchanges for students having trouble with the material or format. Some teachers may not be willing to do that, and should not be included in on line staff in my opinion. The teacher has to be as committed to our success as we students are. It is not an "easy A" for us, nor should it be one for them.

\section{Teacher characteristics: Engage the students.}

Researcher Memo: Some may say that to engage online students, you need to ask the right types of questions. Others might say it's based more on "structure or course policies." I have been to many seminars on online learning and hosted a few myself. The question I am most asked is, "How can I engage the students in the learning process? I post questions but the discussion doesn't go anywhere." I have to admit to telling them, "Make it mandatory (i.e., count as part of their grade) that they post and reply a certain number of times. In addition, have a word-count that helps students monitor how long their response should be." Students believe in "engagement," they just are not sure of how to go about it.

Response \#1: Requiring me to make " $x$ " amount of posts or post of " $x$ " word length is not engaging to me at all. I believe that if instructors want to engage their students then they have to be there, comment, and make new statements themselves. If an instructor has a passion for what they are learning and they let that passion show through the students will be there following freely without the need for posting policies.

Response \#2: The classes that I have seen have the most successful engagement of the students required students to respond to at least one of their compatriot's postings (whether a short essay, an answer to a weekly question from the teacher or an article to share) during each week. Over the course of the term we all got to read commentary from each other class member as we determined which entry we would respond to. The best results came at the end of the week when the teacher would tell us how well we had taught each other and fill in any blanks they saw in the overall picture. We were ensured to get the best of our own interaction and know we had gained all the knowledge the teacher wanted us to have that way. 
Teaching methods is the fifth theme and deals primarily with the online pedagogy, and what if any methods translate into student persistence. The properties were idea transfer, learning style, teachable moment, and community of learners. This theme also included many of the "good" and "bad" comments about online teaching methodologies.

Teaching methods: Idea transfer.

Researcher Memo: Many Subjects noted the pluses and minuses about working with the discussion board. The first major property was the concept of "idea transfers." In a line of questioning during Stage 1, I asked a particular Subject if online courses reduce the learning experience to "data transfer." After all, it is just a bunch of text, transmitted via the Internet, right?

The Subjects noted that it was not the transfer of "data" but the "transfer of ideas." In classrooms, the discussion can often be centered-around a few people, emotions, pinions...otherwise WORDS. In classroom situations, it's often hard to formulate these WORDS into "ideas." Unfortunately, this topic area had little support and was by no means saturated to the point of moving it as a property of "Teaching Methods." This was a mistake on my part influenced by my own bias; I thought more information would come out of this subcategory, but it never developed.

Teaching methods: Learning style.

Researcher Memo: Through my anecdotal research over the years, I know that instructors dispute whether there is such thing as a "learning style," and how to use this information even if they do agree with the concept. Many Subjects noted the relevance of online learning because it caters specifically to their learning style - not so much the teacher, but the actual act of online learning. Here are some examples provided in the data.

Response \#1: Another thing I like about online classes is that I can indulge my long intellectual digestion phase - I take a long time to reflect on things and make them my own. Because I'm a slow 
thinker, people who are very quick with opinions and analysis of something we've just read in a live class sometimes intimidate me.

Response \#2: In an online course I can break the pieces of the information up, get up, move around as I need, work on the assignments in pieces... or at my own pace. If I am not in a "handson" learning situation, then I struggle with my focus of processing the new information. So the online classroom allows for me to learn in a way that is effective for me!

Response \#3: One of the greatest things I have learned is that we all have different learning styles. I knew that on one level from my former education, but here I saw first hand how it works and what an advantage it can be in the learning process. In our discussion group and in the class discussions, the input came from so many angles. I read what some of the class members said and was amazed at the value in those contributions.

Teaching methods: The teachable moment.

Researcher Memo: When describing the discussion board, many Subjects noted the fact that you can take your time, observe what's going on, and then post a message. It is almost as if students are waiting for just the right time. I like to call this the "teachable moment." In classroom situations, it is an art form saved for only the best teachers. The "teachable moment" is not easy to discern. It is the fine line between letting students learn from each other and stepping in to "teach." In a classroom situation, it is difficult because the pace of the course often gets out of hand. Whether or not teachers are taking advantage of the teachable moment is disputable.

Response \#1: Instructors all have their own way of teaching in online classes. Since I have taken so many online courses, I have literally discussed this with several of them just sort of off the cuff. They all seem to teach the same way we as students interact and learn. Meaning, they read through response threads as a whole, and then interject where necessary. This seems very similar to the way teachers teach in classroom situations. 
Teaching methods: Community of teachers.

Researcher Memo: Many Subjects mentioned that in online learning there is an "...inherent reality that many students must teach each other." This is due to the simple fact that even a great instructor is not online all the time. Since the primary modality of teaching is via the discussion board, many students communicate with each other directly; thus, online learning may occur if a teacher is present or not.

Response \#1: A recent buzzword in higher education has been "community of learners." Essentially, it's better to create a community of learners, where students learn from one another. However, I prefer the term "Community of Teachers" for online learning.

Response \#2: The Web is truly an accurate description of the social structure of the Internet environment. Its very nature provides for side-to-side or student-to-student interaction. Side to side interaction produces a community of teachers.

Response \#3: In face-to-face classes, students are usually seated etc. That structure is teacher dependent and fairly fixed in nature. I have had teachers who sit down and who encourage discussion, but the focus is still on the teacher and the teacher-class relationship. The power structure in a face-to-face environment is from the top down. In the rare case where an instructor of a face-to-face class had the unique ability to get students to learn from each other, one student made arrangements not to attend because he said he wasn't getting anything out of the class. It's a pity. We might have learned something from each other. This very process of learning from other students is what makes online classes effective.

The online class is structured by the teacher, but in a very different way. (If the instructor structures the class "from the top down" after the pattern of the face-to-face class, then the student experiences the static, text-based and content driven class. Without the visual and perhaps theatrical aspects of the face-to-face a topdown online class is boring). The online class is like an orchestra. The teacher is present and directing, but all of the participants create music. Without the director, there would be no music, but neither would there be music if the students did not contribute. 
Culture/Subculture is the sixth theme and deals primarily with the online existence and/or development of online culture. The properties were pre-existence of culture, subcultures to decrease class size (i.e., subdividing the larger group into smaller, independent groups), and form impression of colleagues.

Culture/subculture: Existence of culture.

Researcher Memo: I brought into the study the belief that online learning has a pre-existing culture at Marylhurst. This bias implies that there are so many on-campus students who take online courses as well - that sense of culture is transferred into the online environment. Much of what is the Marylhurst experience (i.e., that special something about Marylhurst University) is somehow transferred to the online experience. The Subjects had different notions of the existence of culture.

Response \#1: I'm thinking of culture in terms of personality and values that show up in discussions, about the level of freedom of expression that students feel, and the role that the instructor takes. I see that the teacher sets a tone that becomes the classroom culture, whether it's online or not.

Response \#2: I see a strong cultural element at Marylhurst. It is very different from the culture of the college I attended 30 years ago. There is an openness to life experiences at Marylhurst. That is so refreshing to have people - students and faculty - respect my process and me as an individual. At Marylhurst, critical thinking doesn't mean demeaning or belittling other students. From what I have seen, the faculty is a support group for the students. And there is a willingness to foster individual choice and creativity within the requirements of the college. I have designed two of my own courses under the direction of interested and dedicated faculty members so that I can gain the most value from my experience at Marylhurst.

\section{Culture/subculture: Subcultures to decrease class size.}

Researcher Memo: When discussing persistence, many Subjects were quick to point to the fact that Marylhurst online courses are small in size. I believe that most of our undergraduate, online courses enroll from 5-15 students. With that number, someone 
reading the results of this research might say something like, "Well, of course you're going to retain students with class sizes so small. Tell me something I don't know! We're a big college and can't run small classes." The answer (as suggested by research Subjects) might be to use subculture to decrease the class size.

Response \#1: ...the second successful class I took at Marylhurst was much larger; I think there were $30-40$ participants. But we rather bonded into groups of similar interests and developed mutual interest cultures in that manner.

Response \#2: The word cliques by using private emails possibly is there but through my experience it was a way to advise me from other students offering direction of help to make my participation more beneficial for all in the class. There were private emails also that would let me in on if a classmate was interested in becoming study partners, etc.

Culture/subculture: Form impression of colleagues.

Researcher Memo: In online learning, are you better able to form impressions of your colleagues? I often email with colleagues from other universities around the country. They find out about my research and we start emailing on a regular basis. I have to admit, sometimes I form these very vivid impressions of who they are...just like I do when I read books. I end up knowing so much about them, way more than if we just talked on the phone or bumped into each other once and awhile. I remember one person in particular. We had quite an online relationship, but when we actually met at the WebCT conference, we did not have much to say. We already knew everything about each other! It was so strange. Here are two responses from data.

Response \#1: I've found that I learn more about people online because we discuss a Subject in more depth. Chatting in person is important, too, but it doesn't give one the chance to give a full opinion the way e-mail and online discussion does. I give a more detailed opinion online.

Response \#2: I think yes you get to "know" people better because each of us has to post discussion answers or thoughts. In a classroom some people never let their thoughts be known for whatever reason, so you don't get to engage with their "thought" 
process. I did get to meet someone that I had in an online class, in a real classroom. My impression of the person was lukewarm online and in person I found them to be delightful.

Learning theory is the seventh theme and deals primarily with the "why" of online pedagogy. Essentially, what theoretical position justifies using a specific teaching methodology? The properties were constructivist versus instructivist and learning from other students. The evidence supporting further exploration in learning theory was not as robust as other categories.

Learning theory: Constructivist versus instructivist.

Researcher Memo: Constructivism is a philosophy of learning founded on the premise that, by reflecting on our experiences, we construct our own understanding of the world in which we live. Each of us generates our own "rules" and "mental models," which we use to make sense of our experiences. Learning, therefore, is simply the process of adjusting our mental models to accommodate new experiences. Many students observed and supported the use of constructivism; however, many contradicted their zeal for constructivism by advocating a great deal of organization, structure and involvement from the instructor.

Response \#1: I would hope for a little more than that, or I could sit down with the Harvard 5-foot bookshelf and the instructional guide that goes along with that and call myself liberally educated. I look to my professors to provide me some direction about what in the material I'm studying is generally regarded as important and to stimulate discussion about those things and anything else that anyone in the class finds striking. My experience at Marylhurst has been very positive in this regard.

Response \#2: Often times it seems like students are making significant contributions to the course. This can be in terms of general discussion, asking important questions, helping other students understand concepts, and even contributing to the content of the course. In online situations, students have a better chance of changing the "course" of action - this is due to the fact that 
instructors aren't always around to dictate the exact direction a course will take.

Learning theory: Learning from other students.

Researcher Memo: Many Subjects noted the fact that online learning is great because they get to learn from other students. If the teacher is not there, learning still occurs.

Response \#1: I also learn from other students. My classmates have such varied backgrounds that we each bring a different perspective to the same material. This almost inevitably happens in a face-toface class; I think it takes a little more effort to make it happen in an online class. But it is one of the things that makes a successful class in any venue. And I have heard more than one professor comment that he/she had learned as much from the class as they did from him/her.

Snapshot of the learning experience is the eighth theme and deals primarily with how WebCT captures and records all online course interactions. Essentially, whatever happens in the course is electronically documented throughout the term, and then cataloged by the instructor. The properties were permanent record, can't take things back, tracking involvement, and repeated use of the courses.

Snapshot of the experience: Permanent record.

Researcher Memo: I didn't expect this category - it was a total surprise. Online learning using WebCT creates a permanent (or at least semi-permanent) record of what happens in the course. With on-campus learning, students may take some notes but often times, cannot remember what happened in class last week. In the online format (especially if it's set-up in weeks), discussion topics are easily found by taking a look back at the discussion board and/or private mail. The course content is available throughout the term. Many instructors are moving their on-campus courses to the "webenhanced" format for that very reason.

Response \#1: Permanent records were great for me. There were times I forgot something and looked through the files to find the 
information I wanted with ease. Also many papers I wrote encompassed statements from others papers or discussion postings to bring more of a personal touch to our experiences. Permanent records in my opinion are a big plus for that very reason.

Response \#2: I took one class where the teacher pointed out that we as a class had created two great resources, an annotated bibliography and definitions of course terms. I downloaded and printed both documents. I often compose offline and COPY (rather than cut) and paste so I have a record of my own documents. I have also downloaded messages that had particular relevance to me. In one of those, I told another student about my first online class.

Snapshot of the experience: Can't take things back.

Researcher Memo: Often times, students and instructors say things they wish they could take back. On-campus situations allow students and teachers to approach the offended person after class or make it right during class.

Response \#1: I can relate to this one, too. I once posted a flip response to someone's post, then immediately started to worry that it would be taken wrong. No one on the board said a word, and the person to whom I'd directed the comment did not respond or make another posting. After about 3 days of stewing I used private e-mail to write the person and tell him I hope I hadn't offended, that I had simply meant it to be funny. He answered that he'd been way too busy to even check in, but would keep my comments in mind when he did. Then he sent a message with the "tongue sticking out" silly face, so I knew it was OK. But it is difficult. Face to face, you can see what effect your remarks are having, and it's very difficult to gauge that in typed messages. It's something you really have to be sensitive to.

Snapshot of the experience: Tracking involvement.

Researcher Memo: MU online faculty can track a student's every move in WebCT. Instructors have full access to tracking data, which reveals how many times students have logged into a course, how much they have read and posted, etc. Often times, this prompts teachers to send tardy students an email or a call to see how they are doing. 
Response \#1: I happened along the information that they tracked every move that you did and had a time log of how long you were on the course. I was taken aback and furious when a teacher made a comment about how much time I log in.

I was not one to log in minimally; I did it every night to keep abreast with posts and comments. I think this information is unnecessary and an invasion of my space. If I was one to not log on to my class much by nature and I knew this information. I would $\log$ on while I was surfing the web and randomly click classes and posts every so often just to appease the time log.

Response \#2: I don't log on for the teacher. I log on for me. It should not matter how much time I spend logged on, as most of the work is done off line anyway. It should only matter that I have met the requirements in a timely manner. If they want to use the data of how long we spend on line to improve the quality of their instruction, or to see if a student is in trouble, I have no quarrel with that. For a teacher to tell me I am not spending enough time logged in, however, if I am meeting requirements, is out of line entirely.

Snapshot of the experience: Repeated use of courses.

Researcher Memo: At the end of each term, instructors are encouraged to "backup" their courses and save them onto their personal computers. This keeps a permanent record of the course interactions. After the instructors have been informed, the courses are "reset." Resetting erases all traces of students being in the course. This resetting of the courses does not erase all the course content, websites, discussion board set-up, assignments, etc. After resetting, all blank course-shells are archived to our server. Next time the course runs, the Marylhurst University Web-based Learning department simply uploads the latest "blank" version - instant course!

Response \#1: I know that Marylhurst University reuses online courses. I discovered this through conversations I had with my instructor. We just started talking about how online courses are setup, and he told us he "inherited" the course. At first, I thought that sounded pretty strange. However, after I thought about it for a while, it sounded like a very sensible thing to have happen. Why invent the wheel? It's not like he was absolutely forbidden to 
change anything. Plus, the whole concept is rather unique to online learning.

Investment is the ninth and final theme produced by the Subjects' data.

This topic addresses the level of investment associated with online learning and if this investment has any connection to online course retention. The properties were student investment and student involvement.

Investment: Student investment.

Researcher Memo: When asked specifically about retention, many Subjects implied that the investment in the learning process was just too great to quit. Online courses demand more time than expected and students were simply in too deep.

Response \#1: Online does push for self-motivation. If you don't have it when you start you are left with two options 1) learn it, or 2) dropout. This may sound harsh; however, reality sometimes is. It is a lot easier to not log into the computer than it is to not go to a physical class.

Response \#2: In my opinion being an online student takes the same self-motivation that starting your own business takes. No one is going to do it for you so you better get to what needs to be done or it won't happen.

Investment: Student involvement.

Researcher Memo: Some of the comments from certain Subjects made me wonder if there should be strict, school-wide policies concerning how often online students must check into their courses. This would assure that students are at least logging into the course, but will not assure that they are participating and/or learning.

Response \#1: Like I said student involvement is an added element, an enhancement, not the whole platform. The learning experience in the face-to-face class I had had a lot of student involvement and experiences to draw from. The instructor was there to question, guide, and show us. 
Response \#2: Students have a richer encounter when they both teach and learn. Involvement and participation enhance the learning experience and are essential elements of Marylhurst online classes. When there is a high level of shared experience, and personal contribution more of the student is invested in the online community creating a greater probability of completing the course.

\section{Professional Review: Stage 1}

As stated in chapter 3 , the review process brought an expert in at each stage of analysis to provide support, monitor the process and to ask critical questions. The professional reviewer neither read and interpreted data, nor made judgments that might influence the researcher's findings.

During Stage 1 professional review, the collection and analysis process was reviewed - both proposed actions and what actually occurred. This was done using documents pertaining to the "audit trail." The discussion began with a review of the sample group and then progressed into a step-by-step review of the collection and analysis process. The conversation focused on the development of initial themes and subthemes and how the process should be documented to ensure that other researchers could understand the flow, logic, and decision-making that occurred to move from Stage 1 to Stage 2. Dr. McVay-Lynch served as the external reviewer and gave her approval on the process.

\section{Research Question \#2}

Stage 2: How do the properties (main attributes) of each category relate and/or interconnect, and how do these relationships lead to the development of a core category? 
The research process for Stage 2 involved three steps. These steps were used to report the findings.

1. Clarification of Subject feedback - assigning value and importance

2. Axial coding - connecting properties using dimensions

3. Narrow the themes and subthemes to the core category and its central themes.

While Stage 1 focused on generating categories and subcategories, Stage 2 addressed these new categories and built interconnectedness between them. Characterized by public, asynchronous, group discussions between the Subjects and me, stage two lasted 2 weeks with an additional week set aside for clarification and/or elaboration if necessary. During this second stage, specific Subjects were asked to clarify their responses around specific subthemes.

The subthemes were established for each main theme in an attempt to better understand, define, and explore their properties. (Note: At this point, properties and subthemes are the same thing.) In order to do this, the concept of "dimension" was introduced into the research course and process. Essentially, I wanted to find out what exactly the Subjects meant (i.e., how they would define the properties), how important they were in relation to each other and the model as a whole, and if any connections could be discovered. The major products of Stage 2 were the "core category" and the model itself - a model that not only showed more than just important factors in online course retention, but how these factors interconnect and relate. The core category was used to help construct the model, which was then brought to Stage 3 for final validation. 
level. Essentially, I was trying to notice connections in order to put together a theoretical model, and not just list a bunch of considerations for online course retention.

Dimensionalizing properties was a two-step process. The first step was capturing the true indicators - the subthemes that really defined the main categories. In the second step, the connections were observed. On the pages to follow are all major themes and subthemes with notes concerning their importance and support. If a subtheme was "supported," it meant there was sufficient evidence gathered from the research process, existing literature and the researcher's judgment for the subtheme to be considered as part of the final model. If subthemes were "unsupported," it did not mean they were unimportant in relation to online course retention. It simply meant there was insufficient evidence in this particular study, and thus pulled from the final model.

How was "sufficient evidence" judged? It certainly was not an objective process that was "...reduced to precise, statistical relationships" (Hatch, 2002, p. 224) or an analysis rubric. Rather, judging sufficient evidence was an ongoing, subjective, and complex process. Considering many methods, usually not in a linear process, I asked myself the following questions.

- Does external research support the concepts?

- Do statements found in the data support the concepts?

- Do the concepts address the research questions?

- Did the Subjects agree with the judgments? 
After considering these questions, I made the final judgment concerning whether there was sufficient or insufficient data. The following section summarizes the process of defining properties and assigning value.

\section{Student Characteristics}

- Background - unsupported

- Traditional Learning - unsupported

- Educational Goals - supported with a high level of importance

In looking at background, my line of questioning aimed at trying to associate anything within the students' backgrounds to persistence in online courses. I explored everything from a student's computer experience to whether or not they felt supported by their family. Traditional learning looked at the association (which one student made) between having some traditional college work before taking online classes, and being able to complete online courses.

Essentially, if this were true, students without any prior on-campus experience would ultimately struggle with online education. This was not the case. The only property under "Student characteristics" with support was educational goals.

All data led me to believe that the attainment of educational goals was a vital part of the course retention issue at MU. As a matter of fact, educational goals emerged as one of four central variables in explaining the MU phenomenon. In the final model, educational goals simply became the variable "motivation." In N6, I started doing word searches for "motivation" and the searches kept bringing me to coded text files under educational goals. 
Subject response: When I started noticing how single, online courses could add up to a degree, I started to become motivated toward a goal of completing my degree online.

Subject response: I was never motivated toward a goal of graduating from Marylhurst. Motivation came when I realized I could do it mostly online. I just never imagined that I could get this much education online. Despite the convenience, I would have never taken it seriously if it didn't seem like Marylhurst administrators, faculty and students also take it seriously. Obviously by how well the courses are run, it's taken seriously by all.

Plainly stated, MU students are highly motivated toward completing their degree no matter their age. More importantly, and this will be investigated further, motivation is closely related to the students' "belief in an organized system" that will help them meet their goals. As stated by one student,

I've taken online classes with other institutions. It was just a big mess. You're organized at MU. Even though the courses are mainly "stand alone" (i.e., meaning not part of a cohort degree program), they all fit very nicely into most degree programs.

K. Moore et al. (2002) cited "Got behind and couldn't catch up; Couldn't handle study plus responsibilities; and Lack of motivation" (p. 9) as the three top reasons why students do not complete online courses. Identifying educational goals can help students juggle the many responsibilities in life, and as noted in this study, can help students stay motivated in their online courses.

\section{Fit with College}

- Views online as equivalent - supported

- Time/time commitment - supported

- Drop policies - unsupported 
- Fit and educational goals - supported

Views online as equivalent was simply a way for the students to say that online learning is taken seriously at MU, and in no way is viewed as "lesser than" the classroom experience. M. G. Moore and Kearsley (1996) state,

One of the major concerns of administrators responsible for distance education programs is equivalence. They want to be sure that courses offered by distance education meet the same standards of teaching and provided the same learning opportunities as any traditional class in any system or institution. (p. 182)

A recent research article compared retention rates between two sections of the same course - one online section, and one face-to-face section. Neuhauser (2002) reported retention rates of $84 \%$ for both sections, which was partially attributed to "...equivalent learning activities" (p. 99) for both online and face-toface learners.

Time/time commitment spoke mainly to the amount of time that students save by taking an online course, and due to the nature of an online course the more time to spend with family at home. Later, views online as equivalent and Time/time commitment were both usurped in a larger variable called "meeting the needs." It was very important to the Subjects that online courses were offered to meet their needs. Most felt that online courses were a way of MU showing that they are contemporary, and in touch with what students need and want. Washington State had the highest online course retention rates for community colleges $(71 \%)$ in this study. In the Washington community college system, $82 \%$ of online students take courses because they offer the "Flexibility to Take Courses 
at a Convenient Time" and (68\%) because of "Family Concerns" (Valdez, 2001, p. $31)$.

The drop policies discussion centered around trying to find out if colleges added strict drop policies to their online courses, and if this would improve retention. If colleges are struggling with online course retention, perhaps they should initiate a drop-fee on top of money they will already lose from dropping the class. None of the Subjects supported this idea, and the initial discussion was a Subject just making a suggestion. All Subjects agreed that the drop policies should be made clear on an administrative level (i.e., meaning the policy is formulated by Marylhurst University, and cannot be altered within the context of the course).

Fit and educational goals was an overlap of much of the discussion that occurred in the educational goals property. N6 analysis revealed much of the coded data overlapping with similar Free Nodes. As stated previously, this was a supported subtheme and was put under the variable motivation.

\section{Online Course Organization}

- Clear beginning instructions - supported

- Structure and dialogue - supported

- Clear writing and schedule - supported

- Weekly set-up - supported

- Routines - supported 
Online course organization was well supported by all of its properties, and would become one of four, vital, major-variables in the theoretical model. Essentially, a well-organized course reflects three of these properties: clear writing, establishing routines, and establishing a weekly set-up (e.g., templates) on the discussion boards. These properties are all equally vital to the course organization as a whole.

M. G. Moore and Kearsley (1996) provide supporting commentary with "Good Structure" being the most important design element in their "General Design Principles."

The organization of the course and materials must be well defined and clear to the student; there must be internal consistency among the different parts of the course. Students should at all times know what they are trying to learn, what is expected of them to achieve the learning, and when they have arrived at the goal. It is easy to become lost as a distant learner, and good design always takes care that this does not happen. (p. 122)

Also of note, "Clear objectives, planned participation (routines), completeness, repetition (templates)" all were part of their design principles. Out of the course organization discussions came a robust conversation regarding the already supported notion of structure and dialogue. The concept of "structure and dialogue" ended up being associated more with the instructor rather than the course. To better understand the concepts of structure and dialogue, one must first understand the theory of Transactional Distance as proposed by M. G. Moore and Kearsley (1996) in their book Distance Education: A Systems View. 
In Transactional Distance, "distance" is not viewed as a geographical phenomenon, but rather, a pedagogical phenomenon. In distance education, if pedagogical strategies are used to increase the level of structure and dialogue in a course, the geographical distance is irrelevant (M. G. Moore \& Kearsley, 1996). For example, if a student takes an online class from a college that is literally blocks away from their home, the "transactional distance" could be quite high. In this scenario, it is likely that there is limited dialogue coming from the institution to help the student better understand the course.

On the other hand, a student could live on the other side of the world and experience a low level of transactional distance because the instructor constantly provided high levels of both structure and dialogue to the student. The use of structure and dialogue was well supported by the Subjects, and most believed that it was a strong factor in their retention in online courses. Thus, structure and dialogue became the second most important variable under the major theme Teacher.

In the final model, clear writing and schedule, and clear beginning instructions were fused into one supporting subtheme called, "clear writing." Clear writing can be thought of as a direct reflection of the thought process; therefore, it is equally important for both instructors and students to bring precision-writing to the course. Because online courses are inherently text-based, many Subjects believed that clear writing could make or break a course. 
While different as subthemes, Weekly set-up and routines work well together. The weekly set-up of the discussion boards is based-on a templated course design, and more than $90 \%$ of MU's online courses have this feature. Since the discussion boards are where the majority of the online classes take place, these weekly topic areas help break the course down into manageable bits. Within these weeks, MU teachers have been trained to offer the students routines. Here is an example of such a routine.

Monday: Check the discussion board for my initial, weekly posting. This posting will set the tone for the entire week. You will have Monday and Tuesday to do the necessary research and homework to address my questions from Monday.

Tuesday: Research and homework day

Wednesday: Post a reply to my initial, weekly posting and respond to at least two of your colleagues outside your discussion thread.

Thursday \& Friday: Spend time in the course interacting with your colleagues and looking for instructor input.

Saturday \& Sunday: Prepare any external assignments (e.g., papers, Internet research) to hand in on Sunday evening.

\section{Teacher Characteristics}

- Patterns of expectations - supported

- Clear and frequent communication - supported

- Engage the students - supported

These three properties help define the variable organization under the main theme Teacher Characteristics. Organized teachers show a pattern of expectations; 
they offer clear and frequent communication; and they engage the students in the class. With these three defining properties, teacher organization becomes one of the four most important variables in the final theoretical model.

Hara and Kling (1999) found that "...students' frustrations with Web-based courses originate from minimal and not timely feedback from the instructor and ambiguous instructions on the Web site as well as via e-mail" (23). Frankly, it was difficult to find an article that did not sing the praises of these three subthemes. In a dissertation study, which had a sample pool of 1,129 students enrolled in 50 online courses, Fox (2000) discovers, "The most important interaction and feedback variables were in response to the instructor returning assignments quickly" (p. 64).

\section{Teaching Methods}

- Idea transfer - unsupported

- Learning Style - unsupported

- The teachable moment - supported

- Community of teachers - supported

The notion of idea transfer - meaning that online courses can be broken down into the transfer of ideas versus any real teaching methods, was not supported. The issue of learning style was also investigated, but to no avail. The Subjects did not believe that learning styles affected their ability to complete a particular course. It may prove a significant variable when investigating the 
"quality of the learning experience," but concerning retention, it is not supported as something that helps define and shape the theme teaching methods. As a category, teaching methods is more about the teachable moment and the idea of a community of teachers.

The teachable moment was more about how faculty are trained at MU to interact on the course discussion boards. Faculty are trained to scan entire discussion threads rather than viewing each individual message. As stated by an MU faculty member, "I was trained to 'find an opening' in the discussion - an area that demands the art of teaching. When I find that area, that is when I make a contribution, or teach." The Subjects supported the notion of the teachable moment - they liked how this teaching art is a direct reflection of what can happen inside the classroom. Young (1999) references Tomball College in the Chronicle of Higher Education. Tomball was struggling with $40 \%$ online course retention rates until creating a mandatory 40 -hour training program for distance education instructors, which improved online course retention rates to $57 \%$.

The community of teachers is something that develops in online courses at MU, and most likely occurs in online courses in general. The fact that online students at MU help teach each other is vital to online course retention. Often times, in asynchronous formats, faculty are just not available. Garrison and Shale (1990) describe the role of teacher in forming a community of teachers.

Teaching is not just producing and transmitting course content. A teacher is more than an information resource and an arranger of the educational environment. The emphasis on education as a 
collaborative process is not just to ensure voluntariness [i.e., ensure that the students will engage in the learning process] on the part of the learner but, more importantly, to ensure the integration of social and personal knowledge by challenging existing views and considering alternative perspectives. (p. 125)

MU encourages our faculty to be present as often as possible, but they cannot be in the course all the time. Thus, it is inevitable that students start interacting with each other asking both intellectual questions about the material, and general questions about clarifying assignments/course outcomes.

\section{Culture/Subculture}

- Existence of culture - supported with previsions

- Subcultures to decrease class size - supported

- Form impression of colleagues - unsupported

The existence of culture was fully supported with previsions. The Subjects did not believe that culture pre-existed in their online courses, which was something I believed at the beginning of the study. Culture is created in online courses through interactions on the discussion board, but more importantly through private mail.

The private mail tool allows students to interact in small groups or one-onone with another student. This interaction helps create and define the culture as those who seek out "systems of shared meaning." They are not necessarily drawn together to build a relationship [although, relationships can be developed in the online classroom]; their primary motive is to reduce the class-size by sharing with 
others in a smaller setting. You see this type of behavior in classrooms where certain students build unspoken alliances, and will often support or "piggyback" on each other's comments.

Thus, private mail offers a haven of sorts, a subculture to decrease class size, for students struggling with the larger class interaction and wanting a smaller more connected feel to the class. Despite its importance, culture (as described by the two supporting subthemes) is the least important of three variables concerning the student experience.

Subjects did believe that one is able to form impressions of his/her online colleagues. However, the feelings from most Subjects were that this subtheme had little to do with online course retention. As stated by the following Subject:

Subject: It's great to get to know people in online courses. It actually surprised me with how well you actually get to know people. However, I don't think there is any connection between forming impressions, or even relationships for that matter, and my ability to finish a course.

The Subject went on to describe two prior courses where there was little interaction in terms of "getting to know people." I checked the course retention rates for both classes, and his (and others) assumptions held true - all the students in both courses finished.

Unfortunately, I was unable to locate any studies that correlated culture with online course retention or distance education courses in general. If I define culture as "systems of shared meaning," then it is possible for culture and subcultures to exist almost anywhere, including an online course. Since culture 
obviously pervades online courses, it is interesting to me that little research has been done on how the culture affects student retention and/or satisfaction. Based on the results of this study, there is evidence that knowing and understanding the existing culture can help with online course retention.

\section{Learning Theory}

- Constructivist -vs- instructivist - unsupported

- Learning from other students - unsupported

I began this theme with an introduction to what constructivism - vsinstructivism means. I did this by couching these terms inside actual examples provided in Stage 1 by the Subjects. Thus, instead of relying on jargon and textbook definitions, I tried to associate meaning from the data. I took several of the Subjects' examples and showed how these could be construed as constructivist or instructivist, and tried to focus the discussion on retention versus the quality of the learning.

Frankly, I thought learning theory would have a lot to do with online course retention. I even went as far in my own mind to imagine the Subjects saying something like, "High retention is due to the fact that many of your online courses use constructivist teaching models, which work well with my learning style and adult learning theory in general." Well, this lofty perception of the online experience was soon shattered, and best stated by the following Subjects.

Subject: You know what? I don't care how you teach the classes. If you want to give multiple-choice tests, fine. If you want to give a 
series of lecture notes with PowerPoint presentations, fine. I don't even care if you want to use a role-play like what was done in the Reading the Genome course. If we're just talking about retention (i.e., can I finish this course?), then these factors have nothing to do with it. It's not how you teach the class, it's how well it's run and managed by the administrators, faculty and students that will determine retention.

Now, if we're talking about the quality of the learning, well, that's a different story altogether. I do prefer certain ways of learning, but at this point in my life, that won't affect me finishing the course.

Subject: Learning theory? What's that? Constructivist/instructivist all means very little to me - that's your business not mine. Add all these great components on after you're done designing a clearly written course where things are easy to find, and I don't have to ask many questions to know what to do next.

Although both subthemes (constructivist - vs- instructivist, and learning from other students) did not support a direct link to online course retention, they were both important elements of other variables. The data gathered to this point led me to create a separate Tree Node for Learning Theory, but this was probably a mistake due to my own bias concerning the use of learning theory in online instruction. More than likely, the Subjects were not addressing learning theory specifically, but rather individual characteristics of the learning experience, which were incorrectly categorized by the researcher as Learning Theory.

The discussion concerning constructivist versus instructivist teaching practices was more about the level of acceptable interaction and guidance from the instructor. This matched well with the major variable of structure and dialogue under the Course Organization main theme. The learning from other students subtheme worked well with the major variable community of teachers under the 
Teacher Characteristics main theme. Essentially, students form a community of teachers due to the fact that instructors cannot possibly be online all the time. Thus, students are often forced to interact and learn from each other. Though unsupported as subthemes, enough data were gathered to add the subtheme presence under the Teacher category.

The subtheme presence captures much of the Learning Theory discussion, but does not specifically call it "Learning Theory." While I do not think I can equate a specific learning theory to online course retention, the Subjects in this particular study did like instructors with presence. The amount of time an instructor spends in a course, or the number of postings does not necessarily determine presence. Presence means that they are paying close attention to the two other subthemes (structure and dialogue and organization) in the same major category Teacher.

\section{Snapshot of the Learning Experience}

- Permanent record - unsupported

- Can't take things back - unsupported

- Track involvement - unsupported

- Repeated use of courses - supported

Due to the lack of depth and interest (i.e., very few postings and interactions) in the first three subthemes, I have marked them as unsupported. As stated earlier in this chapter, I never imagined that this Tree Node would 
materialize. Subjects just started mentioning these subthemes, and I was intrigued enough to explore them further. Most knew about them through interactions with various online instructors.

The only subtheme in this group supported by the data was the repeated use of online courses, which appears in the final model as "recycled courses." At MU, for the most part, we keep using the same courses term after term. How do the Subjects know courses are reused? Apparently, this was common knowledge among the Subjects. It seems that many have either asked while taking online classes, or it has been mentioned in WebCT orientations. One Subject equated this to building successful "products" and continued, "If it ain't broke, don't fix it."

All Subjects unanimously agreed that by reusing effective, online courses over and over again would inevitably lead to higher course retention. After talking with several WebCT administrators at other institutions, I have found that this is fairly common practice. Therefore, the repeated use of classes is a variable that demands further attention in the final model. Also, this whole notion of reusing online courses fits into the even more important theme of developing an administrative system for delivering online courses.

\section{Investment in Online Learning}

- Student investment - unsupported

- Student involvement - unsupported 
Both of these properties under Investment in Online Learning were unsupported. There was no connection between the student investment (defined as either monetary or time) and the ability to persist in online courses. Student involvement was identified as a property under a subtheme with the assumption that the more students interacted in an online course, the greater the chances for persistence. Once again, this was just not supported, with the Subjects providing contradictory information at best. Subjects completed some courses with mass amounts of involvement (i.e., posting and responding to messages several times per day), and others with practically none. Table 34 summarizes all supported subthemes.

\section{STEP 2: Axial Coding - Connecting}

\section{Properties Using Dimensions}

After giving the properties a sense of value and importance, and connecting them with any relevant literature, it was time to interconnect the properties in the form of a theoretical model. Besides the "levels of importance," this step needed to somehow reflect any other relational characteristics that were present in the data and observed by the researcher. At this point, all subthemes judged as "unsupported" were removed from the study, and the focus turned to integrating existing themes and subthemes into a larger, cohesive picture. The first step was to create a visualization of the themes and subthemes after dimensionalization. Table 34 illustrates how main themes and subthemes were condensed within the four, new thematic areas with common properties. 
Table 34

Condensed Themes with Properties

\begin{tabular}{|c|c|c|c|}
\hline Main Themes & Subthemes & $\begin{array}{l}\text { Condensed } \\
\text { Themes }\end{array}$ & Properties \\
\hline $\begin{array}{l}\text { Student } \\
\text { Characteristics }\end{array}$ & Educational Goals & Student & Motivation \\
\hline $\begin{array}{l}\text { Fit with } \\
\text { College }\end{array}$ & $\begin{array}{l}\text { - Views online as equivalent } \\
\text { - Time/time commitment } \\
\text { - Fit and educational goals }\end{array}$ & Administrative & $\begin{array}{l}\text { Meeting Needs } \\
\text { Technical Support } \\
\end{array}$ \\
\hline $\begin{array}{l}\text { Online Course } \\
\text { Organization }\end{array}$ & $\begin{array}{l}\text { - Clear beginning instructions } \\
\text { - Clear writing and schedule } \\
\text { - Weekly set-up } \\
\text { - Routines } \\
\text { - Structure and dialogue }\end{array}$ & $\begin{array}{l}\text { Course/Student } \\
\text { Community of } \\
\text { Teachers }\end{array}$ & $\begin{array}{l}\text { Course Organization } \\
\text { Structure \& Dialogue }\end{array}$ \\
\hline $\begin{array}{l}\text { Teacher } \\
\text { Characteristics }\end{array}$ & $\begin{array}{l}\text { - Patterns of expectations } \\
\text { - Clear and frequent comm. } \\
\text { - Engage the students }\end{array}$ & Teacher & $\begin{array}{l}\text { Teacher Organization } \\
\text { Presence }\end{array}$ \\
\hline $\begin{array}{l}\text { Teaching } \\
\text { Methods }\end{array}$ & $\begin{array}{l}\text { - The teachable moment } \\
\text { - Community of teachers }\end{array}$ & Teacher & $\begin{array}{l}\text { Training \& Development } \\
\text { Community of Teachers } \\
\end{array}$ \\
\hline $\begin{array}{l}\text { Culture/ } \\
\text { Subculture }\end{array}$ & $\begin{array}{l}\text { - Existence of culture } \\
\text { - Subcultures to decrease } \\
\text { class size }\end{array}$ & Course & Create Culture \\
\hline $\begin{array}{l}\text { Learning } \\
\text { Theory }\end{array}$ & - No Support & & \\
\hline $\begin{array}{l}\text { Snapshot of } \\
\text { the Learning } \\
\text { Experience }\end{array}$ & - Repeated use of courses & $\begin{array}{l}\text { Administrative/ } \\
\text { Course }\end{array}$ & $\begin{array}{l}\text { Develop a System } \\
\text { Recycle Courses }\end{array}$ \\
\hline $\begin{array}{l}\text { Investment in } \\
\text { Online } \\
\text { Learning }\end{array}$ & - No Support & & \\
\hline
\end{tabular}

In Table 34, the Main Themes and Subthemes columns were utilized to create two new columns "Condensed Themes" and "Properties." The process began by asking myself the question, "What areas are represented by the existing 
thematic areas?" Most of these were very easy to decide. For example, "Student Characteristics" represented the "Student" experience, "Online Course Organization" was representative of the "Course" set-up, and the new Condensed Category "Teacher" came from "Teacher Characteristics." The remaining two themes: (a) Fit with the College; and (b) Snapshot of the Learning Experience were more difficult due to the fact they dealt with administration, and as a group, we did not specifically mention or discuss "administration" up to this point. Therefore, I had to create a new condensed theme.

STEP 3: Narrow the Themes and Subthemes to the Core Category and its Central Themes

For the nine themes shown in Table 34, I went back into N6 and tried some keyword searches, and reread the text units. The word I kept seeing over and over was "administrator" or "administrative." I also noticed many references to the "foundation that makes these online course run effectively." It did not take long to realize that the respective properties for these two main themes were generated not by the student, course or teacher, but rather on the administrative level. I then realized I had four central themes to this model (student, teacher, courses, administrative), and thus visualized a four-cornered model (Figure 13). 


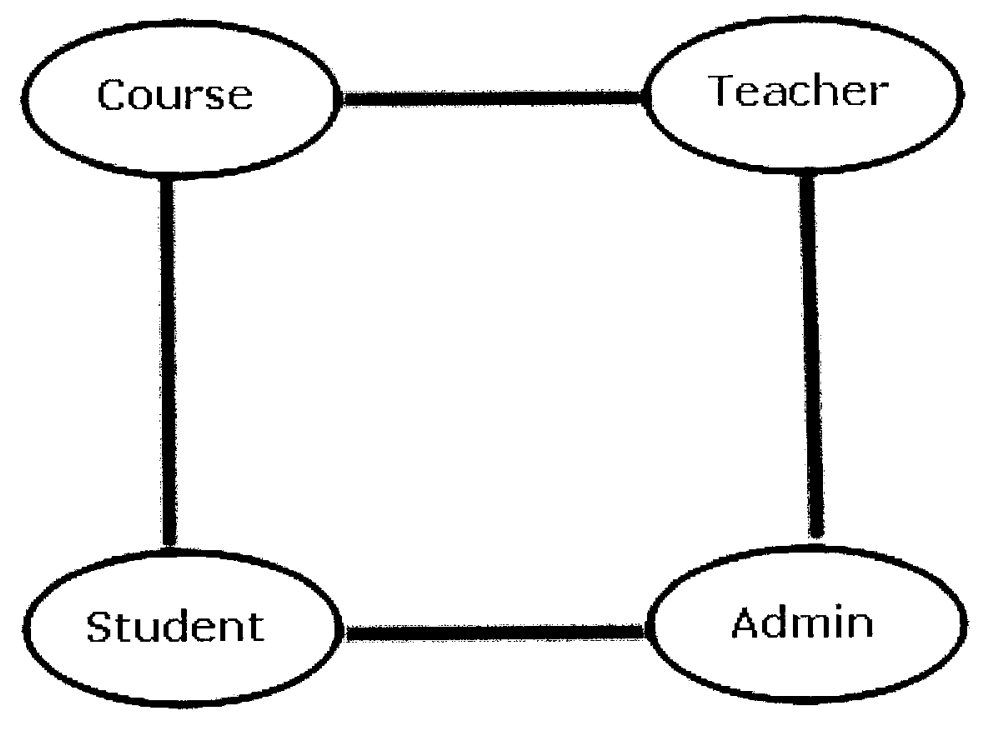

Figure 13. Initial four-cornered model.

By joining the four categories in a square with connecting bars, I was able to show the equal foundation for the future model. These thematic categories were not formulated to show value, they are merely "in-routes" or gateways to the eventual model. However, administration may be the reasonable starting point for most institutions interested in this model. I state this because I believe administrators will be the primary audience for this research, and are those who can affect policy decisions. Based on the data, the Subjects would not weigh one category over another. My hypothesis is that considering all four categories as a whole unit can have the greatest gains in online retention.

For the most part, examining the subthemes derived the new properties. For example, if I was looking at the student theme with an existing subtheme of educational goals, the word that kept appearing was "motivation." N6 was also 
used to create keyword searches for defining properties. Thus, motivation became a primary property/indicator in the major theme student. The pre-existing subthemes helped further define these new properties; thus, the educational goals led to a motivated student. For another example, an organized course is a property of the course structure. The pre-existing subthemes "routines, clear writing, and templating" help define what is meant by an organized course.

It was difficult to identify a "core category" from the existing categories. Therefore, I took the focus off categories and/or themes and thought about what was truly essential. From what I gathered, successful retention is directly related to the four main themes, and all subthemes can be categorized within these four main themes. Thus, the central or core theme was actually very obvious - Online Course Retention.

Table 35 shows the main themes (represented in the columns) with the supporting properties for each theme. The most important properties are in the top row of the table, and build off the properties below them in the hierarchy. The "Connection" column represents the level of connection among the three rows of properties. 
Table 35

Themes, Properties and Connections

\begin{tabular}{|c|c|c|c|c|}
\hline Student & Teacher & Course & Administrative & CONNECTIONS \\
\hline Motivation & Organization & Organization & Develop a System & STRONGEST \\
\hline $\begin{array}{c}\text { Community of } \\
\text { Teachers }\end{array}$ & $\begin{array}{c}\text { Structure \& } \\
\text { Dialogue }\end{array}$ & Meet the Needs & Technical Support & STRONG \\
\hline $\begin{array}{c}\text { Create } \\
\text { Culture }\end{array}$ & Presence & Recycle & $\begin{array}{c}\text { Training \& } \\
\text { Development }\end{array}$ & NEGLIGIBLE \\
\hline
\end{tabular}

Note: Themes are Underlined, Properties are in Italics, Connections are in UPPER CASE.

For example, when interacting in online courses, students create culture, that leads to the creation of a community of teachers. Within a strong learning community, students can meet their educational goals, which develop highly motivated students. Teachers must have an online presence using the concepts of structure and dialogue. A balanced sense of structure and dialogue will yield a highly organized teacher. An organized teacher is one who reflects a pattern of expectations, provides clear and frequent communication, and engages the students.

Besides showing a connection and building on each other within each theme, the properties extend within each row reflecting relationships among properties. The top-row (student motivation, course organization, teacher organization, and developing an administrative system) forms the strongest connections in the theoretical model. I formulated the following statement in an attempt to illustrate how the properties connect across the top row (strongest connections), and Figure 14 is a visual description of this passage. 
Marylhurst develops the type of online system where I can truly meet my educational goals, which helps me maintain a high-level of motivation. This "system" trickles down into organized courses and instructors. These four elements are crucial in your persistence in online courses at Marylhurst University.

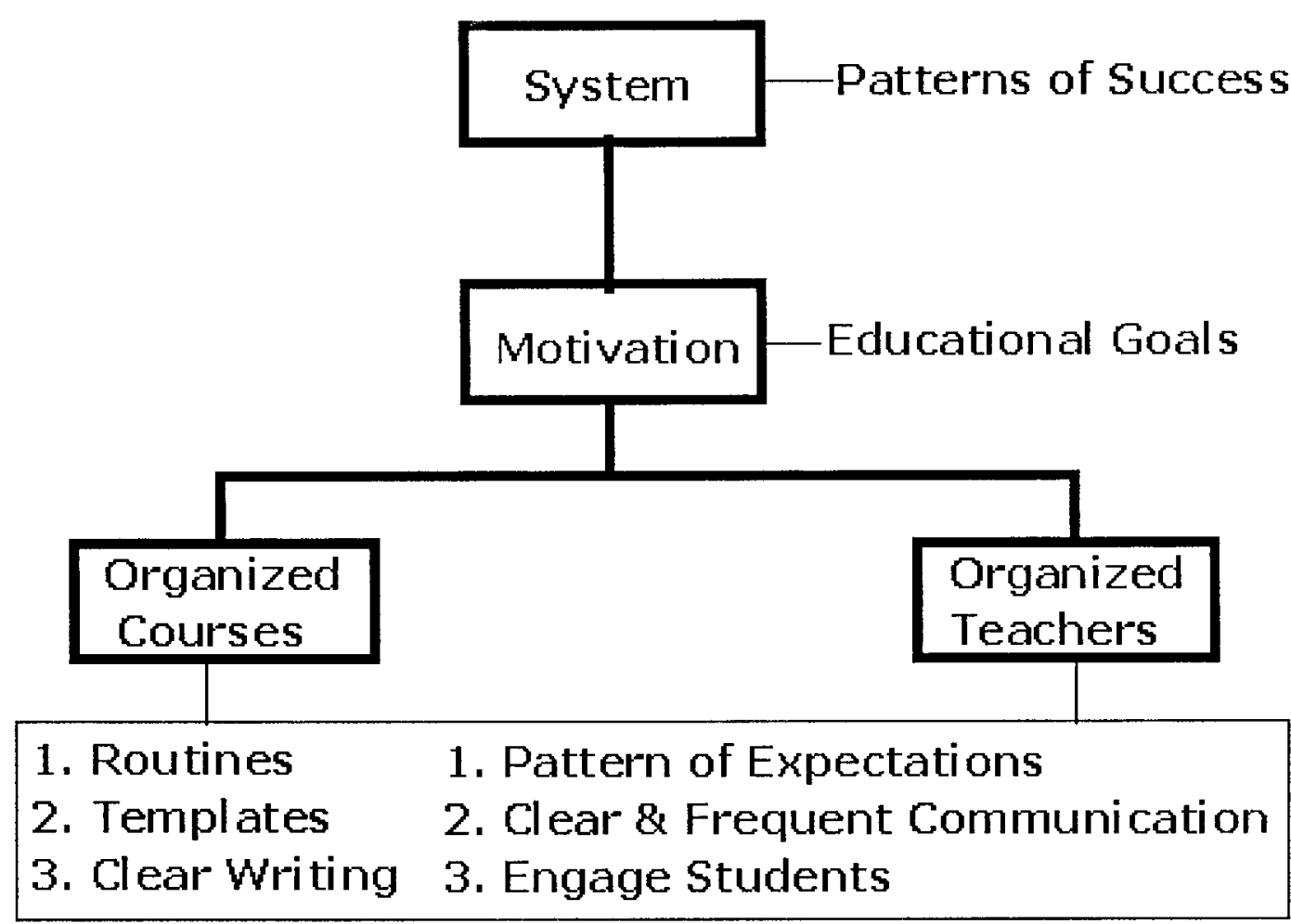

Figure 14. Strongest axial coding properties.

The connections among the second row of properties (see Table 35)

Technical Support, Meet the Needs, Community of Teachers, and Structure and Dialogue are strong, but not as strong as the properties illustrated in Figure 14. Rather than trickling down from an administrative theme, the second row (represented in Figure 15) of properties revolves around meeting the needs of students. In Figure 15, technical support helps provide the necessary conditions 
where the concepts of structure and dialogue can interact and help fuel the community of teachers. If this is operating efficiently, the needs of the students will be met.

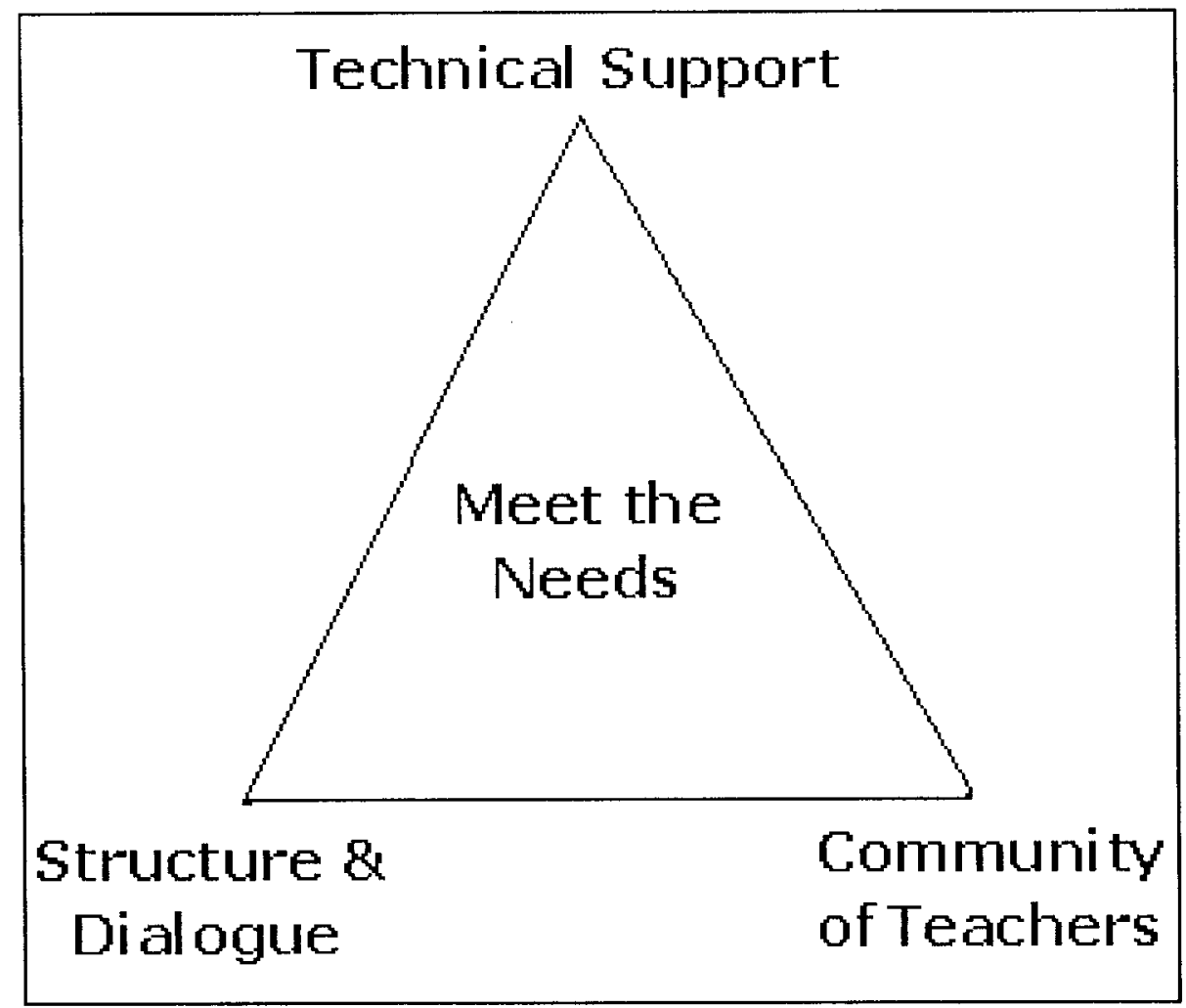

Figure 15. Second strongest axial coding properties.

The bottom row of the previously mentioned Table 35 (create culture, teacher presence, course recycling, and training and development), showed the weakest connections. After dimensionalizing the top and middle rows of Table 35, I added remaining properties under each respective category.

By dimensionalizing and organizing major themes and properties, I was in a better position to start thinking about a theoretical model. I had my central theme 
(Online Course Retention), four major categories organized in a four-cornered model, and dimensionalized properties in order of importance for each respective theme. With this information organized, I began sketching visual representations knowing that a hierarchical model leading to the core theme would best represent my interpretation of the Subjects' data. This sketch seemed to fit with how I characterized the data previously in Table 35. My previous four-cornered model started to take shape as shown in Figure 16.

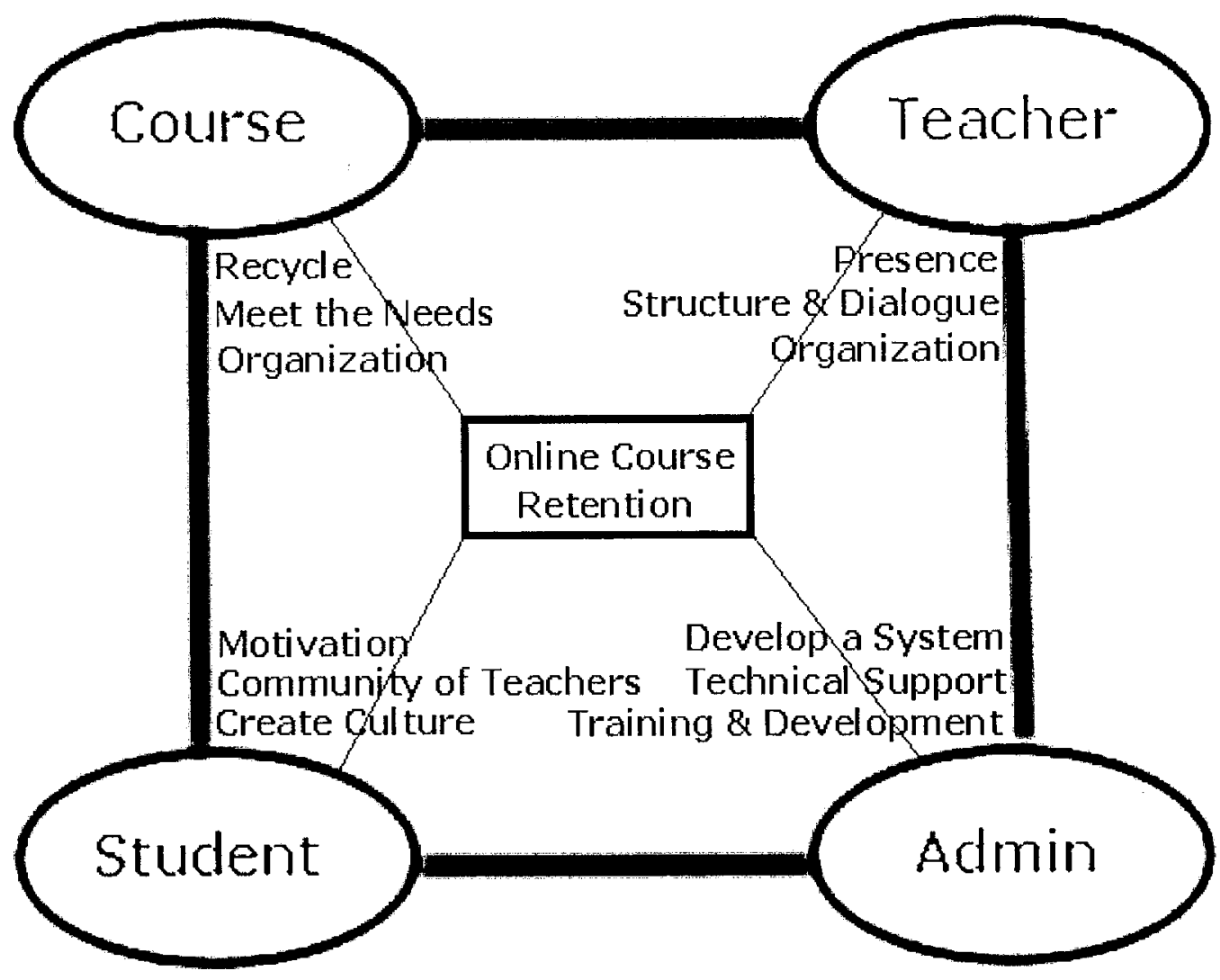

Figure 16. Building the model. 
I pictured "Online Course Retention" to be the pinnacle of this hierarchy the ultimate goal of anyone interested in applying this model. Therefore, when viewing the model, imagine it starting to take the shape of a pyramid with "Online Course Retention" being the apex of the pyramid. To get to the apex, there must be steps, and so I started to organize the pyramid with three tiers representing the three properties from each respective category. The strongest properties (i.e., properties that were independent, and envelope the other properties from the same category) were closest to the apex, and the closeness of each step represents the stronger connections as you ascend the pyramid. Figure 17 represents the final evolution of the Online Course Retention Model (OCRM).

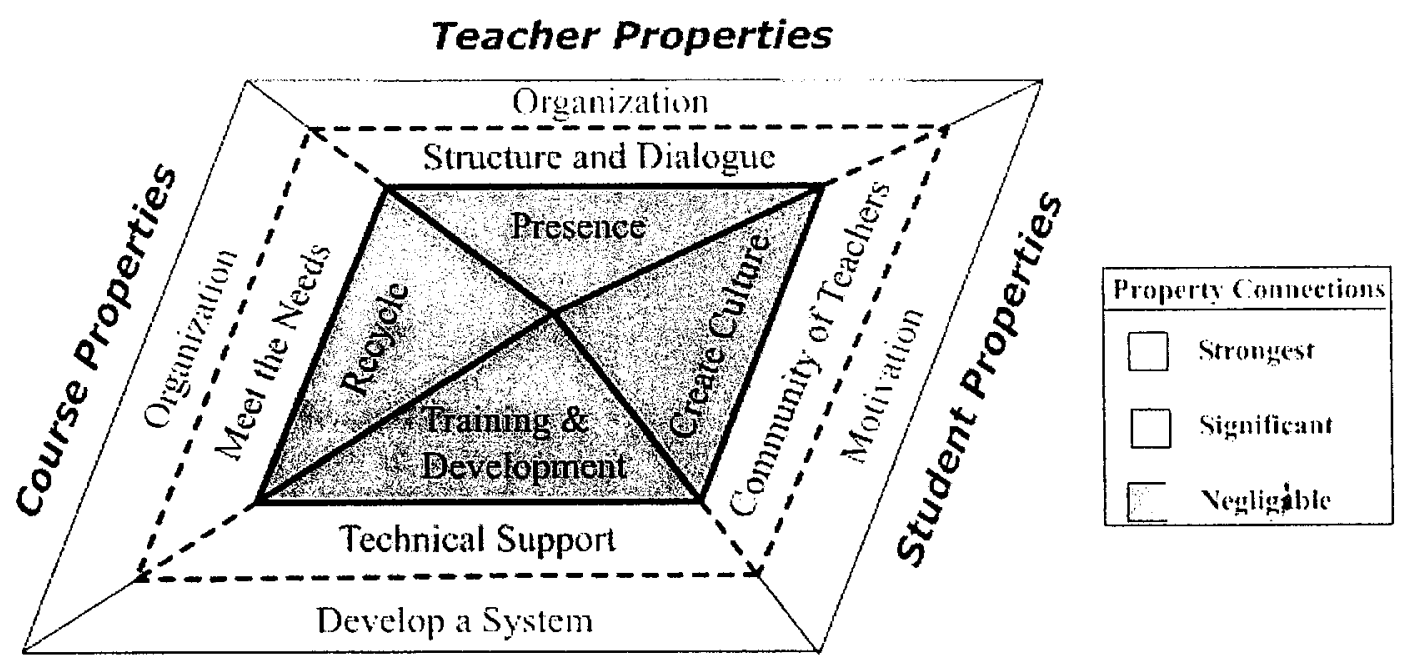

Administrative Properties

Figure 17. Model to stage 3.

Viewing the model, I believe three distinctive characteristics are immediately evident: 
1. this is not an "input/output" based model like the models covered in chapter 2;

2. the darker the color, the stronger the connections and;

3. the view is of a pyramid, looking down from above.

Also, the properties are not centered between themes because to me that would have symbolized a relationship between the surrounding categories only. To summarize, the OCRM model not only suggests that the presence of the major variables leads to improved online course retention, but also suggests that relationships among properties make the model even stronger. Therefore, the relationships among the various properties bring this model together, not the connection among the four major themes. Knowing this, one can turn the model any way and it will not lose its meaning and/or integrity.

Professional Review - Stage 2 (What

was Discussed and Outcomes)

For the review of Stage 2, I met with Dr. McVay-Lynch and discussed the following.

- Overall report of research process;

- Recap of the proposed collection process;

- Collection - what actually happened versus what was proposed;

- Analysis - how data were analyzed and;

- The preparation for Stage 3. 
Dr. McVay-Lynch's primary concern was that I had the necessary memos and/or text units to define and dimensionalize the properties. I told Dr. McVayLynch about my trepidation when creating a model for the Subjects' to review. I was concerned that once a model was created, it would be hard to go back and make any changes. Therefore, I wanted to be sure that the model I presented to the Subjects in Stage 3 was an accurate representation of the data and the research process itself. After the review, Dr. McVay-Lynch gave her approval to continue the research process.

\section{Research Question \#3}

STAGE 3: After each category's properties were dimensionalized on a continuum, how was the theoretical model built and did it lead to discursive theoretical propositions about online course retention.

In Stage 3, the model was finally disclosed to the Subjects for their review, which was an important piece of establishing internal validity. The actually building of the model was explained in the previous section. Therefore, this section focuses primarily on the second part of the above-mentioned question. Does the model represent any discursive theoretical propositions? Basically, what can one know about the MU situation by studying and understanding the model? This section also covers the validation of the model. I have put together the following propositions based on my construction of the model. 


\section{Discursive Theoretical Propositions}

- Online course retention is a direct reflection of how well an institution establishes an inquiry process (i.e., how well they research, build understanding, and implement that understanding) into four major areas: courses, teachers, students, and administrative.

- If one of the four major areas (courses, teachers, students, and administrative) is missing, the strength of the model diminishes. Therefore, all four areas should be considered when trying to improve online course retention.

- Strengthening the relationship between variables in the model is more important than improving variables in isolation.

- Highly organized courses and teachers (defined in the following propositions), and knowledge of what motivates online students improve the administrative system for delivery.

- Highly organized courses feature routines, clear writing, and a templated, weekly layout for discussions.

- Highly organized teachers focus on establishing a pattern of expectations, offer clear and frequent communication, and engage the students in the learning process.

- Meeting the needs of students requires strong technical support and training faculty to create a balance between structure and dialogue. This will lead to a community of teachers - students helping students. 
Validation of Model - Credibility

as Internal Validity

Bringing the final product to the Subjects was the final step in the internal validation process (i.e., in the research process this was known as Stage 3).

Subjects were asked to review the online course retention model at:

http://www.mandala-designs.com/marylhurst/model.htm and address the following questions:

1. Please comment and evaluate the research process Stage 1, Stage 2 and Stage 3;

2. Make some general comments about the model;

3. Do you have any concerns? Do you have any questions?

4. If you feel so inclined, please offer your endorsement of the model.

Or, please tell me why you cannot endorse the model.

Thirteen of 14 Subjects offered their endorsement of the model. Some had problems with the look of the model and their suggestions were implemented in a new design. These suggestions had nothing to do with how the model works conceptually. Thus, when considering validity, the conceptual-endorsement (i.e., do the Subjects believe the model accurately represents the research process) is what was most important. Therefore, based on the following data, the Online Course Retention Model (OCRM) had an acceptable level of internal validation.

Subject 12: The benefits I have received from participating in this study are reflection and clarification of my own online experience. I also learned some valuable things about how qualitative research is conducted and about the insights and opinions of other online 
students. I participated in this study so that I could make a contribution to online learning and to Marylhurst University.

I feel that the researcher asked questions that facilitated my own clarification process. I feel satisfied that my voice was heard and understood and that together with the other Subjects, we will make a positive difference in the field of online learning.

Participation in this study was a very satisfying experience.

Although I did not expect or receive college credit for involvement, I feel that I received the value and education of a well-presented college class. Education is one of the areas of focus of my Interdisciplinary Studies degree. It was exciting to be involved in this aspect of education.

Subject 10: The timing for stage 1 was good! Stage 2 came at the start of term and I found my time limited to take part in the discussions. So maybe stage 2 was not tedious but me with limited time. I felt that the questions asked in stage 2 were good ones that were gleaned from stage 1 comments etc. it is a good way to build a model in that you get the Subjects to develop their own core areas into the model.

I had no problem with signing on to the chat room or getting the link to work to Mandala-Designs. But then I graduate this term so any of my configurations have long be worked out. I think the model is representative of results of stage 1 and stage 2 . I would endorse the model.

Subject 3: The research process was easy to follow. You are a master at articulating clear instructions and making sure we receive them. The timing was unfortunate, since I was finishing up a number of classes at the end of the term. I had to really put my head down and charge ahead to keep up with the posts...

...but the posts were very insightful and thought provoking. I enjoyed having deeper issues to consider and knowing my opinion would be helpful. One always enjoys being asked one's opinion. I enjoyed reading about others' experiences, too, and realized how lucky I've been to get good online instructors. 
I like your model. It covers the major things that we discussed and that were important. Is it just coincidence that each of the four corners had 3 subthemes, or did you edit?

All of the inner subthemes are related to goal setting, in a way. I'm still trying to find the "core category," the Mother Lode, the Holy Grail.

It's interesting that you have the "course" and "administrative" corners opposite one another, which are more concrete when contrasted with "student" and "teacher," which, being human, are more dynamic and unpredictable. Mechanics (administrative), content (course), delivery (teacher), reception (student). I like synonyms.

Thank you for the opportunity to help our educational community. If you have more questions, I'd be pleased to elaborate. Good luck finishing-up your project! It's very timely and useful.

Subject 1 (the only non-endorsement): Each stage has given the appearance of building off of each other. If stage one of general information findings were not done then stage two never would have taken development to the extent that it did. In my opinion, good follow up questions were asked in attempt to clarify or find hidden aspects that were not yet uncovered.

\section{Online Course Retention Model}

This model looks good however some questions arise when I look at this model. Is the model based only on people who have been a success at online learning? If so, can a true success model be generated without looking at students who didn't make it through the education process since they have insight to problem areas that the success group may not see or chose to ignore because self motivation overruled anything else?

I like how subthemes hold more weight the closer they get to the final outcome (pattern of success). What is the deciding factor that creates the position for each subtheme? Are the subthemes positions decided on gut feeling or is there a scoring process each theme goes through to graph its position in comparison to others? 
Under the heading courses, the subthemes are listed as recycled courses, meet the needs, and organization. With organization in the position of the most important subtheme within the heading, I am puzzled how organization can be weighted more important than meeting the needs of the students. If the courses are not what the student needs no amount of organization will cause one to enroll in the class. Because of the above questions I have listed I am unable to endorse the model as it stands.

While I believe the research process established a high level of internal validity, it is important to address a few concerns based on the size of the sample. Due to the small sample size, it is possible that a "culture of agreement and cooperation" was established. After all, when the Subjects viewed the model, there might have been a natural tendency to agree with the model because my interpretations of their words built the model. The term "groupthink" is often associated with this type of phenomenon.

I believe I established early on in the research process the importance of the individual. Because I started with a one-on-one experience, all Subjects were comfortable knowing their input was respected and responsible for the outcome of the research project. I also took care in preparing each Stage by offering instructions that discouraged "groupthink" and encouraged contentious debate.

Here is an excerpt from the beginning of the second stage.

I want to see a discussion develop here that is more than rudimentarily answering a bunch of questions in isolation. This is where the study will most reflect a normal online course. In this stage, discourse, discussion, contentiousness as well as cooperation are all welcome.

This is not a focus group. We are not necessarily trying to converge on an issue, formulate an opinion and/or discuss a solution. There 
are no right or wrong answers. Please let your voice be heard. If it aligns with what others are saying, please let us all know. If not, let us know. as well.

I believe all Subjects would agree that the necessary precautions were taken to avoid groupthink and/or agreeing to validate their own contributions.

I would also like to address a comment made by the lone dissenter in the validation process. Subject 1 stated:

With organization in the position of the most important subtheme within the heading, I am puzzled how organization can be weighted more important than meeting the needs of the students. If the courses are not what the student needs no amount of organization will cause one to enroll in the class. Because of the above questions I have listed I am unable to endorse the model as it stands.

I have to agree with Subject 1 that if a college does not offer the appropriate courses, students will not even enroll in the first place. This is why "Meet the Needs" is an important property in the model.

However, the study was not about what attracts students to enroll in online courses. The study was about what keeps them enrolled once they are in the courses. Therefore, I stand firm in my belief that organization (i.e., the way a course is put together and clearly articulated throughout the experience) is the key to online course retention. However, Subject 1 made the mistake of evaluating the model by looking at isolated properties. The model does not isolate properties, but rather, demonstrates how properties are valued and how they interact with other properties on the same level. 


\section{Chapter IV Summary}

In chapter 4 , I reported research findings from a highly structured, rigorous, three stage collection and analysis process. Four major thematic areas (Administrative, Course, Teacher, and Student) emerged from this process. These thematic areas serve as doorways into the OCRM and major areas for inquiry into an institution's own distance learning department. Each thematic area has three main properties of hierarchical importance.

More important are the relationships expressed and later synthesized into the OCRM. Without the relationships, this research represents mere recommendations for variables, and whether or not those variables were supported in a single research study. As stated earlier, developing an administrative system with highly organized courses and teachers will help meet the educational goals of your students, which in turn will keep them motivated in online courses. Providing strong technical support will help faculty and students develop a community of teachers through the use of structure and dialogue. This in turn will help create courses that meet the needs of your online learners. The bottom row has negligible connections, but the importance of the variables is still prominent. 
CHAPTER V

\section{RECOMMENDATIONS AND DISCUSSION}

The final chapter addresses the two remaining research questions having to do with recommending "best practices" associated with improving online course retention and identifying future research needs. The chapter ends with a metaphorical summary of the OCRM.

\section{Research Question \#4}

Whether a model is constructed or not, can anything be discovered in the raw data to inform the distance learning community about "best practices" for online course retention?

The following best practices are based-on a consideration of the OCRM. The "best practices" recommendations are reported in order of importance based on the hierarchy of the OCRM itself. The most important recommendations reflect the upper-two-levels of the OCRM where the connections between constructs are the strongest. The best practices recommendations are directed at a practitioner audience, and/or others in a position to implement these best practices. 
Fully Understand What Motivates

Your Student Population

Based-on the OCRM, fully understanding what motivates your student population is the first step in improving online course retention. Consequently, it is also the first step in the instructional design process for constructing courses. The data in this study suggest that to motivate students, administrators must offer courses that help students meet their educational goals. These educational goals may differ from institution to institution, but understanding your student population is key to understanding their educational goals. In the case of online MU students, the primary goal is to get a college degree.

If you do not know what motivates your own student population, you may want to start with a simple survey aimed at identifying student motivation and goals. Also, the Marylhurst University, Web-based Learning Department (MU WBL/D) works with the admissions staff and other campus departments and committees in an effort to better understand the student experience. Institutions that are struggling with online course retention may want to consider this type of integrative discourse.

Develop an Administrative System that Supports Students' Educational Goals

Data in this study suggest that online students believe the MU Web-based Learning Department runs online courses like a "fine-tuned machine." The Subjects believe that the MU WBL/D offers many courses in a systematic fashion 
that are designed based on templates so there are no surprises, and that are clearly constructed with easy-to-understand routines. The Subjects also believe that help is readily available via a "technical support system." The MU WBL/D has taken the time to reorganize job functions to optimize the systematic delivery of online education.

This work was not easy, and was accomplished via a concerted, team effort. Due to this effort and cooperation, there are periods at MU when the entire online education system is running so smoothly it is as though it is on auto-pilot. The data suggest the following components are important pieces of an "administrative system."

The administrative system should meet the needs of online students. MU online students have an understanding of why online learning is being offered at MU and how it fits in to the larger educational picture. As online students, they feel that they are being treated exactly the same as on-campus students and appear to have faith that the system will continue to deliver quality courses.

The system should have a versatile but defined support staff. Several Subjects were thrilled with the fact that they knew where to go for help. The entire MU WBL staff is on the "online.marylhurst.edu" website with short job descriptions and email links listed. Data also suggest that even if online learners do not get the "right person," their experience is that someone can usually provide assistance. 
The system should schedule courses in a predictable way. The data suggest that MU online learners are driven toward meeting their educational goals - at MU, that means getting a college degree. Thus, a measure of predictability is needed in the courses that are being offered from term to term. If MU students understand that online courses are an option for completing their degrees, they can schedule courses accordingly with a great amount of flexibility. In addition, systematic scheduling using predictability helps administrative, course-builders (e.g., instructional designers) because old courses are easy to locate and reuse. For example, as an instructional designer, I know that the course "Reading the Genome" is offered every spring term. Therefore, I can easily track down the last copy of the course and copy it for current use with a previous instructor, or for a new instructor hired to teach the course.

\section{Create and Foster Highly Organized}

\section{$\underline{\text { Courses and Teachers }}$}

The administrative system should have the type of training and development and technical support to create and foster organized courses and teachers.

Organized courses: (a) are based-on a template integrating common tools and weekly discussion board topic areas, (b) offer weekly routines throughout the term, and (c) are clearly written. Organized teachers: (a) offer clear and frequent communication, (b) engage the learner, and (c) establish a pattern of expectations. The following paragraphs describe these best practices and their relationships. 
Concerning the organization of courses, encourage routines that describe what students should be doing Monday through Friday in their online courses . This in turn will help create courses that establish a pattern of expectations for their online students. These routines generally pertain to course actions, such as interacting on the discussion board, checking private email, and/or checking in with a peer work group. Data suggest routines should address the weekly topic, accompanying reading, discussion board topics/questions and any assignments that are due.

MU Web-based Learning does not train faculty in the art of clear writing for online learning. However, data suggest that the writing used to prepare online courses has a direct impact on the course retention. This value of clear writing is also reflected via clear and frequent communication during the course. Students need to understand the expectations of the course, and they need subsequent instructions articulated clearly.

Finally, as an administrator, start "templating" your online courses. At MU, we have developed a course template that has an online orientation, browser checkup, an online technical help request form (dynamic HTML programmed in Cold Fusion), an area for web links, weekly discussion board topics, and course set-up notes for the instructors. By establishing a weekly format for the course, students develop their own routines around the topic of the week, readings for the week, discussing board topics, and any assignments that are currently due. 
Faculty complaints over the lack of student participation sparked the need for templates. Data suggest that students can be actively engaged in a course by its set-up and design. As one Subject stated, "...an organized online course almost demands exploration. It's almost like a well-designed computer program: if you know how to work one program, you usually can just mess around with similar programs and figure them out."

Offer Online Courses Focused on

Meeting the Needs of Your

Student Population

In the OCRM, "Meet the Needs" refers to offering the types of courses directly aimed at helping students meet educational, degree requirements, and meeting their educational needs within each respective online course. Once students are enrolled in relevant courses (i.e., courses that will help them complete a degree), support the concept of "meeting the needs" by offering technical support, a balance between course structure and dialogue, and developing a community of teachers. Data suggest that online students need intense amounts of structure and dialogue in the beginning of an online class. Over the course of the term, establishing a community of teachers can decrease the reliance on structure and dialogue between the teacher and the student, and increase the dialogue between the students themselves. 


\section{$\underline{\text { Recycle Online Courses }}$}

An entire online course can be placed on a computer disc. Therefore, at the end of each term, faculty members should backup their courses and save them to their personal computers. In addition, recycling courses should be part of the administrative system described earlier. This means administrators should make every attempt to backup and save used online courses. If the same faculty members return to teach the same classes, backed-up courses can easily be restored to the current term. This will save time and keep effective courses continually running. Of course, the danger is that it also may keep ineffective courses running continually. Counter this by developing an online course evaluation system, which should be part of the larger administrative system. Finally, if online faculty members do not return, their courses are readily available for the next instructor.

\section{Develop a "Presence" Policy for all}

\section{Online Instructors}

The data from the Subjects revealed a need for mandating instructor presence (i.e., presence meaning how often an instructor checks into the online course and interacts with students). One Subject went as far as stating that online instructors should be present at least five days per week. The majority of Subjects suggested four days per week. When I looked beneath the numbers, what Subjects really wanted was simply to know the instructors were available. Furthermore, when the instructors were in the courses, the Subjects wanted "significant contributions" - just like the instructors expect from students. Therefore, by 
telling your instructors to check into the course a specific number of times, you are not automatically creating "presence." However, you are creating an opportunity for "presence," and the students will appreciate the fact that the instructor cares about the course.

\section{Training and Development}

While the Subjects never mentioned that MU has an excellent training and development department, it became obvious to me through the data that this is important. During the study, three different Subjects made comments concerning the importance of training online faculty. They speculated that proper training is an essential part of teaching online. A few Subjects mentioned that some online instructors have even discussed their WebCT training with the class. This was evident because several Subjects knew we offered one-on-one training for new faculty.

I also made inferences based on various Subjects' comments. For example one Subject said, "I had one online instructor that seemed like he was a WebCT specialist. He provided a quality experience and was very good at using the advanced WebCT tools. You don't see too many instructors using the assignment drop box." After seeing many comments like this throughout the research, I concluded that training and development is essential. 


\section{Allow and Encourage Online Students}

to Create a Classroom Culture

Just as an on-campus teacher may smile in remembrance of "that special class" they once had, MU online faculty do the same thing. This reaction is often due to the classroom culture that was established during the class. The data suggest that culture is created using both the private mail tool and the discussion board. However, the most profound emergence of culture was not solely due to the efforts of the students alone.

The best online teachers have a hand in creating culture. This means they create interesting course topics, areas of discussion, and engaging assignments, which draw the students into a larger system of shared meaning or collective culture. A collective culture is not subversive (i.e., a subversive culture often becomes many different subcultures or "cliques" members of which communicate via the private mail tool) and functions within the realms of the course structure. This collective culture works well with the community of teachers (i.e., the students) construct because students are working together to create a culture that is helpful and supportive to all.

\section{Other "Best Practices" Considerations}

What other inferences can be made from a careful examination of the OCRM and the supporting data? As stated previously, many pedagogical issues (e.g., teachable moment, time, constructivist -vs- instructivist, attention to learning styles) were dispersed throughout the OCRM into existing categories. And, while 
grounded theory primarily uses inductive reasoning, it may be safe to deduce that pedagogy (i.e., the way online courses are taught - the specific methods, assignments, assessment and style) plays a significant role in online course retention.

Not only can pedagogy be found buried beneath several constructs, some may even say that many of the main properties (e.g., presence, structure and dialogue, community of teachers and creating culture) all have to do with pedagogical strategies. Even the most important properties in the OCRM (teacher organization, course organization, student motivation, and developing an administrative system) are laced with common pedagogical strategies such as: clear writing, building routines, creating assignment templates, creating a pattern of expectations, engaging the learner, etc. Therefore, without stating it specifically, pedagogy does matter in online course retention.

\section{Research Question \#5}

What is next for further development and research into this model for online course retention?

I hope the OCRM motivates further research and development in online course retention. Of interest to me specifically is to see the model help an institution struggling with online course retention. Further study of online course retention using a qualitative approach should be encouraged. Because this research used a postpositivist paradigm, it would be interesting to apply a qualitative design 
such as the case study using the constructivist paradigm. A case study approach could be used in an effort to validate the OCRM model as a whole or some of its parts. The following list of future research projects is recommended.

\section{Further Exploration into Course}

Retention

While the OCRM isolates specific constructs and demonstrates their interconnectedness, the real concern may go beyond this new model. Many colleges and universities are moving entire programs online. Many, however, continue to offer groups of courses to help students complete their degrees. If this is indeed the dominant model for offering online education (i.e., an emphasis on courses -vs- programs), then course retention needs further research. Such research is needed as well where the emphasis is on whole degree programs since high degree program completion rates are dependent on high individual course retention rates. I am unaware of any studies that provide empirical evidence of how to retain students in courses.

Elements of the OCRM (i.e., technical support) are directly associated with online learning, or at least the use of technology. However, data suggest that many of the constructs of the OCRM would work well in a face-to-face environment as well. Many Subjects would often preface their comments with "Just like in the classroom..." or "It's the same for on-campus courses." If that is indeed the case, research concerning on-campus, course retention might yield similar results. 
A Quantitative Analysis of the Variables and Their Relationships

The data in this study suggest that the relationships between major constructs are what really define the OCRM. Rather than just validating individual variables, a quantitative analysis could describe relationships among variables with numerical correlation. These correlations could describe the statistical significance of the relationships that exist. This process would have the potential to give the OCRM internal validity from a positivist perspective.

Do the Variables, Subvariables and Their

Relationships in the OCRM Have

Importance Beyond the Realm of "Course Retention?"

This is probably the question that most intrigues me concerning future research. My hypothesis would be that by strengthening the OCRM variables, institutions will not only increase online course retention, they will also increase student satisfaction (e.g., better course evaluations) and student learning (e.g., better work as reported by the faculty, higher grades and feedback from the students that they are learning more).

\section{Other Research Considerations}

Due to the narrow focus of this study, future studies are needed that examine the validity of the model in various institutional settings, including twoand four-year, public and private colleges and universities, technical colleges as well as in businesses that use online learning or training. 
As it stands, the OCRM currently does not differentiate the importance of the four major themes - Course, Student, Teacher, Administrative. While these themes seemed like a natural way to group for the topics inside the model, future research is needed to see if any of these major themes have more importance than others in the area of online course retention. The OCRM as currently developed suggests making "connected-changes" (i.e., changes brought on by examining the connectedness in variables throughout different layers of the model), and not weighing any of the four major themes differently.

Built by focusing on "successful completers" (i.e., in this study, all 14 Subjects had $100 \%$ completion for online courses at MU), would the OCRM look the same if "non-completers" were included in the study or used exclusively? In addition, two major user groups were absent from this study (faculty members and administrators). A study including both faculty and administrators may shed more light onto the issue of online course retention.

Finally, the Subjects in the study came from various academic majors; there is an obvious lack of those from science and mathematics majors. This reflects the lack of science and mathematics courses offered online at MU (e.g., chemistry, physics, algebra, calculus). One of the online faculty members at MU believes MU high online course retention rates are associated with courses from departments such as Human Sciences, Cultural and Historical Studies, Liberal Arts Core, Interdisciplinary Studies and Communications. I am unaware of any research that investigates the relationship between course retention rates with the 
subject matter of the courses. While the Subjects discussed learning theory and pedagogy, they did not associate these characteristics with courses from different disciplines.

Important Limitations to Consider for Further Research

Careful consideration was given to portray the "Marylhurst Phenomenon," and not overgeneralize the findings based on research conducted solely at MU. After carefully examining the OCRM, it has become evident that several key variables may not have surfaced due to the nature of the MU learner. For example, socioeconomic variables never surfaced in the data primarily because they were not addressed in the demographic profile. Due to the location of MU in a somewhat affluent area, and the higher tuition costs, there is reason to believe that MU students are higher income and more academically prepared than most higher education students in general.

Furthermore, the average age of online students at MU is around 37 years old, which might lead some to the conclusion that MU learners are self-directed. MU freely advertises itself as an "Adult Learning Institution." Therefore, several other concepts of adult learning theory may also apply to online students at MU. The Bean and Metzner (1985) Model of Nontraditional Student Retention states many key background variables that may also affect the adult, online learner. For example, age, enrollment status, residence, educational goals, high school performance, ethnicity and gender all are important variables to the adult learner. 
In the OCRM, "educational goals" proved to be an important concept in understanding the main theme "motivation."

\section{Overall Conclusions}

If I have learned anything from the Subjects, it is this: keep it simple. It may be online, and it may be using technology, but it still boils down to teaching and learning. Teaching and learning can be a lot of fun under the right conditions; it can also be a nightmare under the wrong conditions. While the exact "right" conditions may vary from institution to institution, the data of this study suggest that all these varying "right" conditions most likely have one thing in common - a highly organized system focused on what motivates the students.

Dr. Jennifer Sasser, department chair of MU Human Sciences has been teaching courses online for more than four years, and routinely receives outstanding course evaluations. Dr. Sasser's online courses provide excellent examples of focusing on the teaching and learning process in an organized fashion without getting lost in the technology.

I personally have added several instructional and aesthetic embellishments to enhance and supplement the WebCT course environment (e.g., linked image maps, Flash movies, dynamic glossary and bibliography tools). There have been numerous occasions (sometimes lengthy periods) where these "bells and whistles" simply failed to work. Despite these setbacks, Dr. Sasser's results with teaching 
and learning online remain the same. She states (personal communication, October 1, 2003):

In my experience, technology has the potential to enhance or detract from the teaching and learning experience, but it can never be a substitution for a well designed course with clear learning objectives attached to innovative, relevant learning projects. Online courses that are successful from a student standpoint are considered successful for the same reasons that on-campus courses are--students and instructors are co-creators of a rich, multi-faceted learning community; new learning can be clearly demonstrated and assessed; students feel that their personhood is respected and supported; and the teacher has a commitment to and mastery of not only a particular area of expertise or content, but to a deeper transformative process as well.

Rather than conclude with a traditional summary of conclusions in this final chapter, I would like to introduce two metaphors that capture the essence of the OCRM and what it truly represents. The first metaphor has to do with the broader implications of the OCRM and retention in general. The second has to do with the foundations of the OCRM. The two metaphors are based on my experience with yoga, both as a student and as a teacher.

\section{Metaphor 1: Broader Implications}

About three years ago, I started doing Ashtanga Vinyasa Yoga. For at least two of those years, I often struggled with the poses. I rarely struggle with them now, and it is not because I "figured them out." Rather, I slowly figured out that yoga is far more than getting into poses. Now, I like to think of the poses like weather reports. Weather reports are estimations of prevailing conditions. If you hear one, you can get an idea of what it is like outside. However, they are not 
always correct, even the best meteorologists make mistakes. While weather reports convey the conditions outside, my yoga poses are physical representations of what is going on inside.

Some days, my poses reflect a beautiful, sunny day. On the inside, I have that same clarity and crispness to my thoughts. Other times, I struggle with my poses, and if I look inward, I see the same struggle mentally, usually worrying about something that has no impact on me at that particular moment. Most of the time, my pose is a true indication (weather report) of what is actually happening inside. However, there are days when the report is wrong (e.g., my strong pose is simply a decoy to try to hide the turmoil or resistance inside). Thus, we all know that weather reports cannot always be trusted, but most of the time they are usually right.

That brings me back to the OCRM, and retention in general. Retention can be a good indicator of the prevailing conditions in your online program, and at your particular institution in general. Indeed, MU's online course retention rates reflect high student satisfaction, and an overall positive view of online learning. However, it is not a fair indication of the quality of the learning experience. Therefore, even though we have high online course retention at MU, we continue to work hard at improving the learning experience in hopes of improving the student experience. If you improve your online course retention, do not make the mistake of assuming your students are learning more or better. 
Also, if your institution is struggling with online course retention, do not automatically assume that students are not learning. In this research, I have referred to many colleges that are struggling with online course retention. This should not necessarily reflect negatively on the quality of the teaching and learning at those institutions. Based on the OCRM, such retention rates may be due to many factors originating from not having an organized system based on student motivation. It may be faculty not understanding the balance between structure and dialogue, your students' inability to create a community of teachers, and a system lacking the proper technical support for your students. Retention is simply the yoga pose (i.e., weather report). To fully understand retention, one must understand what is going on beneath the report.

\section{Metaphor 2: Foundations}

In Western culture, we have misconstrued the purpose of the yoga tradition. Plainly stated, yoga has become all about the postures, and how these postures can make a person physically fit. Often times, students hurt themselves by practicing advanced postures before their body is ready (i.e., they simply do not have the foundation in place to hold advanced postures). I would equate advanced yoga postures to complicated pedagogical models in online learning. Why do a role-play or collaborative group work when students do not even understand how to interact on the discussion board? 
Because online courses use technology, instructors and administrators often believe there should be a push for flashy uses of pedagogy (e.g., streaming video, flash tutorials, synchronous chat rooms). The Subjects in this study did not agree with this. Pedagogy is important, but it is just a small piece used to enhance the learning experience once a firm foundation is in place. In yoga, it is the same way - the postures are merely a small step in achieving the ultimate goal, which is self-discovery (i.e., often referred to as Enlightenment).

I think of yoga postures as the skin on an onion. If the skin is sturdy and well maintained, one can start to peel it away and see all the various layers on the inside. Thus, the postures become meditative poses - they become the foundation to get at the heart of a yoga practice. If your yoga poses cannot form a firm foundation, your practice will never reap the true benefits of yoga. Therefore, I view the model the same way I view a yoga posture. It is merely a gateway to further understanding, and at its core is a "foundations model." This suggests the OCRM is not about a lot of fancy pedagogy, learning theory, technology or collaborations. This model focuses on the very basic concept of organized courses. 


\section{REFERENCES}

Allen, I. E., \& Seaman, J. (2003). Sizing the opportunity: The quality and extent of online education in the United States, 2002 and 2003. The Sloan Consortium. Retrieved October 15, 2003, from www.sloan-c.org

Ashar, H., \& Skenes, R. (1993). Can Tinto's student departure model be applied to nontraditional students? Adult Education Quarterly, 43(2), 90-100.

Astin, A. (1975). Preventing students from dropping out. San Francisco: JosseyBass Publishers.

Astin, A. (1977). Four critical years. San Francisco: Jossey-Bass Publishers.

Astin, A. W. (1984). Student involvement: A developmental theory for higher education. Journal of College Student Personnel, 25, 297-308.

Astin, A. W. (1993). What matters in college: Four critical years revisited. San Francisco: Jossey-Bass.

Babchuk, W. (1996). Glaser or Strauss?: Grounded theory and adult education. Paper presented at the Midwest Research-to-Practice Conference in Adult, Continuing and Community Education. Retrieved December 10, 2002, from http://www.anrecs.msu.edu/research/gradpr96.htm

Bean, J. (1982). Conceptual models of student attrition. In E. T. Pascarella (Ed.), New directions for institutional research: Studying student attrition (pp. 17-28). San Francisco: Jossey-Bass.

Bean, J. P., \& Metzner, B. S. (1985). A conceptual model of nontraditional undergraduate student attrition. Review of Educational Research, 55, 485540 .

Beatty-Guenter, P. (2001, October 30). Distance education: Does access override success? Paper presented at the Canadian Institutional Research and Planning Association Pacific Northwest Association for Institutional Research and Planning, Victoria, BC. 
Berg, B. L. (1998). Qualitative research methods for the social sciences. Boston: Allyn and Bacon.

Bergmann, M., \& Raleigh, D. (1998). Student orientation in the distance education classroom. Proceedings of the 14th Annual Conference on Distance Teaching and Learning, 61-66.

Braxton, J. (1999). Theory elaboration and research and development: Toward a fuller understanding of college student retention. Journal of College Student Retention, 1(2), 93-97.

Braxton, J., \& Sullivan, A. (1997). Appraising Tinto's Theory of College Student Departure. In J. C. Smart (Ed.), Higher education: Handbook of theory and research (Vol. XII, pp. 107-164). New York: Agathon Press.

Cabrera, A. F., Castaneda, M B., Nora, A., \& Hengstler, D. (1992). The convergence between two theories of college persistence. Journal of Higher Education, 63(2), 143-164.

Care, W. D. (1995, January). Helping students to persist in a distance education program: The role of the teacher. Paper presented to the faculty of Nursing, University of Manitoba, Winnipeg.

Carr, S. (2000). As distance education comes of age, the challenge is keeping the students: Colleges are using online courses to raise enrollment, but retaining it is another matter. The Chronicle of Higher Education. Retrieved February 5th, 2002, from http://chronicle.com/free/v46/i23/23a00101.htm

Carr, S. (2001). Is anyone making money in distance education? Colleges struggle to figure out how much they are spending on online programs. The Chronicle of Higher Education. Retrieved May 21, 2002, from http://chronicle.com/free/v47/i23/23a04101.htm

Charmaz, K. (2000). Grounded theory: Objectivist and constructivist methods. In N. K. Denzin \& Y. S. Lincoln (Eds.), Handbook of qualitative research (2nd ed., pp. 509-536). London: Sage Publications.

Chickering, A. W., \& Ehrmann, S. C. (1997, August). Implementing the seven principles: Technology as lever. Bulletin of the American Association for Higher Education, 49. Available at: http://www.aahe.org/technology/ ehrmann.htm 
Chickering, A. W., \& Gamson, Z. F. (1991). Seven principles for good practice in undergraduate education. San Francisco: Jossey-Bass.

Cooper, H. (1984). The integrative research review: A systematic approach. Beverly Hills, CA: Sage.

Course completion report 1999-2000. (2001). Office of Research and Planning, Mesa Community College. Retrieved January 8th, 2002, from http://www.mc.maricopa.edu/organizations/employee/orp/briefs/ course_completion_reportv3.pdf

Crabtree, L. F. (2000). A comparison of community college student performance, retention and demographics in online and onground courses. Unpublished doctoral dissertation, University of Missouri-Columbia, Columbia.

Creswell, J. W. (1994). Research design: Quantitative and qualitative approaches. Thousand Oaks: Sage Publications.

Creswell, J. W. (1998). Qualitative inquiry and research design. Thousand Oaks: Sage Publications.

Creswell, J. W. (2002). Research design: Quantitative and qualitative approaches (2nd ed.). Thousand Oaks: Sage Publications.

Cutler, J. (2000). Distance learning performance/completion rates: Are there any predictors? Institutional Planning and Research, Sinclair Community College. Retrieved February 4, 2002, from http://www.sinclair.edu/ departments/ipr/survey_reports/s_distance_learning01.pdf

Distance ed. course completion rates: Spring quarter summary. (2001). Washington State Board for Community and Technical Colleges, electronic mail. Retrieved February 5th, 2001, from http://www.sinclair.edu/ departments/ipr/survey_reports/f_distance_learning_report01.pdf

Dixon, P. (1996). Virtual college: A quick guide to all you need to know how to get the degree you want with computer, TV, video, audio, and other distance learning tools. Princeton, NJ: Peterson's Guides.

Fox, J. I. (2000). Review of the factors influencing the satisfaction of learning in online courses at Marshall University. Unpublished doctoral dissertation, West Virginia University, Morgantown. 
Frankola, K. (2001, June). The e-learning taboo: High dropout rates in online courses. Syllabus, 14, 14-16.

Fredericksen, E., Pelz, W., Pickett, A., Shea, P., \& Swan, K. (2001). Student satisfaction and perceived learning with online courses: Principles and examples from the SUNY Learning Network. Retrieved May 1, 2002, from http://www.aln.org

Garrison, D. R., \& Shale, D. (1990). A new framework and perspective. In D. R. Garrison \& D. Shale (Eds.), Education at a distance (pp. 123-134). Malabar, FL: Krieger.

Gibbons, H. S., \& Wentworth, G. P. (2002). Andrological and pedagogical training differences for online instructors. Online Journal of Distance Learning Administration, 4(3). Retrieved May 24, 2003, from http://www.westga.edu/ distance/ojdla/fall43/gibbons_wentworth32.html

Glaser, B. G., \& Strauss, A. L. (1967). The discovery of grounded theory: Strategies for qualitative research. Chicago: Aldine.

Greene, B. (1999). Distance education at postsecondary institutions: 1997-1998. National Center for Educational Statistics. Retrieved March 5, 2002, from http://nces.ed.gov/pubs2000/2000013.pdf

Guba, E. G., \& Lincoln, Y. S. (1989). Fourth generation evaluation. Newbury Park, CA: Sage Publications.

Hafner, K. (2002, May 2). Lessons learned at dot-com u. The New York Times, p. G1.

Haig, B. D. (1995). Grounded theory as scientific method. University of Canterbury. Retrieved December 14, 2002, from http://www.ed.uiuc.edu/ EPS/PES-yearbook/95_docs/haig.html

Hara, N., \& Kling, R. (1999). Students' frustrations with a Web-based distance education course. Retrieved January 3, 2002, from http://www.slis. indiana.edu/CSI/wp00-01.html

Hatch, J. A. (2002). Doing qualitative research in education settings. State University Press. 
Hovey, H. A. (1999). State spending for higher education in the next decade: The battle to sustain current support. The National Center for Public Policy and Higher Education. Retrieved February 25th, 2002, from http://www.highereducation.org/reports/hovey/hovey2.shtml

Hueser, N. G. (1999). Grounded theory research: Not for the novice. Retrieved December 10, 2002, from http://www.users.qwest.net/ nhueser/ grounded.html

Johnson, N., Lav, I. J., \& Carey, K. (2001). New estimates show state fiscal conditions continue to worsen: State budgets show need for congress to assist, rather than undermine, state efforts to balance budgets. Center on Budget and Policy Priorities. Retrieved March 10th, 2002, from http://www.cbpp.org/12-11-01sfp.pdf

Kalsner, L. (1991). Issues in college student retention. Higher Education Extension Service Review, 3(1), x.

Kanuka, H., \& Anderson, T. (1999). Using constructivism in technologymediated learning: Constructing order out of the chaos in the literature. Radical Pedagogy, 1(2), 51-59.

Kinach, B. M. (1995). Grounded theory as scientific method: Haig-inspired reflections on educational research methodology. Vanderbilt University. Retrieved December 10, 2002, from http://www.ed.uiuc.edu/EPS/PESyearbook/95_docs/kinach.html

Lewis, L., Farris, E., Snow, K., \& Levin, D. (1999). Distance education at postsecondary education institutions (1997-1998). U.S. Department of Education, National Center for Educational Statistics. Retrieved May 24, 2002, from http://www.nces.ed.gov/pubsearch/pubsinfo. asp?pubid $=$ 2000013

Lorenzo, G. (2002). Experiencing rapid enrollment increases: Three successful online distance education programs talk about scaling up. Educational Pathways. Retrieved May 2nd, 2002, from http://www.edpath.com/ enrollup.htm

Major, H., \& Levenberg, N. (1999). Learner success in distance education environments: A shared responsibility. Retrieved September 21, 2001, from http:www.horizon.unc.edu/TS/commentary/1999-01.asp 
Marshall, C. R., \& Rossman, G. B. (1999). Designing qualitative research (3rd ed.). Thousand Oaks: Sage Publications.

Marylhurst University information. (n.d.). Retrieved April 10th, 2002, from http://www.marylhurst.edu/universityinfo/mission/mission-fm.html

May, K. A. (1986). Writing and evaluating the grounded theory research report. In W. C. Chenitz \& J. M. Swanson (Eds.), From practice to grounded theory (pp. 146-154). Menlo Park, CA: Addison-Wesley.

McLoughlin, C., \& Winnips, J. C., \& Oliver, R. (2000). Supporting constructivist learning through learner support on-line. Retrieved March 30, 2002, from http://users.edte.utwente.nl/winnips/papers/support.html

McVay-Lynch, M. (2002). The online educator: A guide to creating the virtual classroom. New York: RoutledgeFalmer.

Merriam, S. B., \& Associates. (2002). Qualitative research in practice. JosseyBass.

Mesa Community College. (2001). Course completion report: $A Y$ 1999-2000. Office of Research and Planning, Mesa Community College. Retrieved March 3, 2002, from http://www.sinclair.edu/departments/ipr/survey_ reports/s_distance_learning01.pdf

Moore, K., Bartkovich, J., Fetzner, M., \& Ison, S. (2002, June 5). Success in cyberspace: Student retention in online courses. Paper presented at the AIR Annual Forum, Toronto.

Moore, M. G., \& Kearsley, G. (1996). Distance education: A systems view. Wadsworth Publishing Company, CA.

Morrow, V. P., Woodyard, L. Mora, C, \& Nather K. (2001). Distance education report. Sacramento: California Community Colleges.

National Education Association. (2000). Distance education at postsecondary education institutions: 1997-1998. Update, 6(2). Retrieved January 15, 2002, from http://www.nea.org/he/heupdate/vol6no2.pdf

Nessler, M. (1999, November). Factors associated with retention in a distancebased liberal arts program. Paper presented at the 26th North East Association for Institutional Research Conference, Newport, RI. 
Neuhauser, C. (2002). Learning style and effectiveness of online and face-to-face instruction. The American Journal of Distance Education, 16(2), 99-113.

Payne, C. (2002). Good practice and motivation in online courses. Get Educated.com: Motivating Retaining Adult Learners Online - Virtual University Gazette, 119-126. Retrieved December 2, 2002, from http://geteducated.com/vug/aug02/Journal/Motivate/Retain02.PDF

Rankin, W. P. (2002). Maximal interaction in the virtual classroom: Establishing connections with adult online learners. Get Educated.com: Motivating Retaining Adult Learners Online - Virtual University Gazette, 142-148. Retrieved December 2, 2002, from http://geteducated.com/vug/ aug02/Journal/Motivate/Retain02.PDF

Richards, L. (2002). Introducing N6: A workshop handbook. Available for download at: http://www.qsr.com.au/freedemos/freedemos.html\#n6.

Rootman, I. (1972). Voluntary withdrawal from a total adult socializing organization: A model. Sociology of Education, 45, 258-270.

Schreck, V. (2002, July). Marylhurst University: An institutional report examining 6 years of online course retention. Paper presented at the WebCT User's Conference, Boston, MA.

Schreck, V. (2003, September 10). Marylhurst University, the 3rd place phenomenon: Five factors that influence student satisfaction and perceptions. Research Study Presented to the University Faculty Council, Marylhurst University, Marylhurst, OR.

Strauss, A., \& Corbin, J. (1998). Basics of qualitative research: Techniques and procedures for developing grounded theory. Thousand Oaks: Sage Publications.

Tinto, V. (1975). Dropout from higher education: A theoretical synthesis of recent research. Review of Educational Research, 45(1), 89-125.

Tinto, V. (1987). Leaving college: The causes and cures of student attrition. Chicago: The University of Chicago Press.

Tinto, V. (1993). Leaving college: Rethinking the causes and cures of student attrition (2nd ed.). Chicago: The University of Chicago Press. 
Tinto, V. (1997). Classrooms as communities: Exploring the educational character of student persistence. Journal of Higher Education, 68(6), 599623.

Trochim, M. K. (2002). Qualitative validity [Web Page]. Retrieved from http://trochim.human.cornell.edu/kb/qualval.htm

Valdez, J. R. (2001). Second year evaluation report of the Washington learning anywhere partnership (LAAP). FIPSE, U.S. Department of Education. Retrieved February 5th, 2001, from http://www.sbctc.ctc.edu/dl/eval/ laap_final_2001.doc

WebCT institutes. (n.d.). Retrieved April 10th, 2002, from http://www.webct. com/institutes/

Young, J. R. (1999). Course for instructors helps keep students. The Chronicle of Higher Education, 46(11), PA59, 1-6. 
APPENDIX A

ONLINE COURSE RETENTION STUDIES 
Online Course Retention Studies, 2-year Colleges

\begin{tabular}{|c|c|c|c|c|}
\hline Study/Author & School & Course Retention & Criteria & $\begin{array}{c}\text { On-campus } \\
\text { Retention }\end{array}$ \\
\hline Cutler (2000) & $\begin{array}{l}\text { Sinclair } \\
\text { Community } \\
\text { College }\end{array}$ & $\begin{array}{l}50.6 \% \text { or } \\
32.6 \%\end{array}$ & $\begin{array}{l}\text { All distance courses }(99-00) \\
50.6 \% \text { includes all grades } \\
32.6 \% \text { retained w/ A,B,C }\end{array}$ & $68.1 \%$ \\
\hline Valdez (2001) & $\begin{array}{l}\text { All community } \\
\text { colleges and } \\
\text { technical schools } \\
\text { in Washington }\end{array}$ & $\begin{array}{l}\text { Sp. } 99-68 \% \\
\text { Sp. } 00-68 \% \\
\text { Sp. } 01-71 \% \\
\text { 87\% - Interactive } \\
\text { Television }\end{array}$ & $\begin{array}{l}\text { Online courses } \\
\text { No other criterion were } \\
\text { available. }\end{array}$ & $83 \%$ \\
\hline $\begin{array}{l}\text { Office of } \\
\text { Research and } \\
\text { Planning } \\
(1999-2000)\end{array}$ & $\begin{array}{l}\text { Mesa } \\
\text { Community } \\
\text { College }\end{array}$ & $47 \%$ & $\begin{array}{l}\text { Internet courses } 1999-2000 \\
\text { Needed }(A, B, C \text { or } P) \\
8 \% \text { considered unsuccessful } \\
11 \% \text { were "F" grades }\end{array}$ & $68 \%$ \\
\hline $\begin{array}{l}\text { Kevin Keefe via } \\
\text { e-mail }(2002)\end{array}$ & $\begin{array}{l}\text { Raritan Valley } \\
\text { Community } \\
\text { College }\end{array}$ & $50 \%$ & $\begin{array}{l}\text { Online courses } 2000-2001 \\
\text { Needed }(A, B, C \text {, or } P) \text { to } \\
\text { retain. } \\
\text { Humanities, English, SS }\end{array}$ & $72-75 \%$ \\
\hline $\begin{array}{l}\text { Terri Manning } \\
\text { via e-mail }(2002)\end{array}$ & $\begin{array}{l}\text { Central Piedmont } \\
\text { Community } \\
\text { College }\end{array}$ & $69.7 \%$ & $\begin{array}{l}\text { Distance Learning Courses } \\
\text { Fall } 2001\end{array}$ & $82 \%$ \\
\hline Morrow (2001) & $\begin{array}{l}\text { California } \\
\text { Community } \\
\text { Colleges }\end{array}$ & $\begin{array}{l}95-96-52 \% \\
95-97-51 \% \\
97-98-51 \% \\
98-99-51 \% \\
99-00-54 \%\end{array}$ & $\begin{array}{l}\text { Reports rates } 1995-2000 \\
\text { Distance Learning courses } \\
\text { "C" or better for successful } \\
\text { completion of course. }\end{array}$ & $\begin{array}{l}65 \% \\
\text { average } \\
\text { over } 5 \\
\text { years. } \\
\end{array}$ \\
\hline Crabtree (2000) & $\begin{array}{l}4 \text { Metro. } \\
\text { Community } \\
\text { Colleges }\end{array}$ & $66.2 \%$ & $\begin{array}{l}\text { Comparison study between } \\
\text { on-campus and on-ground } \\
\text { students. } \\
\text { Online and on-ground } \\
\text { courses had the same } \\
\text { instructors. } \\
\text { Online courses were mainly } \\
\text { computer courses. } \\
\text { Completers (A-F) }\end{array}$ & $77.8 \%$ \\
\hline
\end{tabular}


Online Course Retention Studies, 4-year Colleges

\begin{tabular}{|c|c|c|c|c|}
\hline Study/Author & School & Course Retention & Criteria & $\begin{array}{l}\text { On-campus } \\
\text { Retention }\end{array}$ \\
\hline $\begin{array}{l}\text { Beatty-Guenter } \\
1999-2000\end{array}$ & $\begin{array}{l}\text { Camsun } \\
\text { North Island }\end{array}$ & $\begin{array}{l}69.5 \% \\
42 \% \text { Internet } \\
82.3 \% \text { Telecourse }\end{array}$ & $\begin{array}{l}\text { Camsun courses were D.L. } \\
\text { Criteria for retention were } \\
\text { not clear but defined as } \\
\text { "passed." }\end{array}$ & $\begin{array}{l}\text { Cam. } 84.6 \% \\
\text { N.I. (N/A) }\end{array}$ \\
\hline $\begin{array}{l}\text { Ray Schroeder } \\
(2001)\end{array}$ & $\begin{array}{l}\text { University of } \\
\text { Illinois at } \\
\text { Springfield }\end{array}$ & $\begin{array}{l}\text { Sp99 - } 91.2 \% \\
\text { Sm99 - 93.1\% } \\
\text { Fall99 - 88.8\% } \\
\text { Sp00 - } 89.9 \% \\
\text { Sm00 - } 93.0 \% \\
\text { Fall00 - 89.9\% } \\
\text { Sp01 - 88.2\% } \\
\text { Sm01 - } 90.0 \%\end{array}$ & $\begin{array}{l}\text { Online courses. } \\
\text { Drops only count after the } \\
10^{\text {th }} \text { day of term. }\end{array}$ & $94 \%$ \\
\hline Fox $(2000)$ & $\begin{array}{l}\text { Marshall } \\
\text { University }\end{array}$ & $\begin{array}{l}82 \% \text { - Overall } \\
74 \% \text { - Undergrad. } \\
94 \% \text { - Graduate }\end{array}$ & $\begin{array}{l}\text { Fall } 1999 \\
\text { Undergraduate and } \\
\text { Graduate courses. } \\
\text { All online }\end{array}$ & $?$ \\
\hline
\end{tabular}


APPENDIX B

INFORMED CONSENT LETTER 


\section{Online Course Retention Studies Informed Consent Letter}

You are invited to participate in a research study conducted by Vince Schreck from Portland State University, department of Postsecondary, Adult and Continuing Education. Under the supervision of Dr. Mary Kinnick and in partial fulfillment of requirements for a doctoral degree in Educational Leadership, this study aims at explicating the reasons. why Marylhurst University online students complete courses at current rates and develop this understanding into an online student retention model.

If you decide to participate, you will be asked to be part of a WebCT course set-up as a research area. Therefore, the research process will be very similar to taking an online course - just much shorter. You will be given an alias login to protect your identity - no one except Schreck will know your true identity. Just as in a regular online course, your comments will be saved on the WebCT server for later review. The research process will be in three stages and you must be able to commit to all three stages during a six-week-period.

\section{Stage 1: Duration (1-2 weeks)}

Characterized by asynchronous, private discussions between you and Schreck, Stage 1 will last one week with an additional week set aside for clarification and/or elaboration. Not all participants will be asked for clarification and/or elaboration. During this first stage, you will be asked to check-in at least 5 days out of 7 and at least once during the second week if applicable.

\section{---TWO WEEK BREAK---}

\section{Stage 2: Duration (1-2 weeks)}

After a two-week break, you will be asked to participate in a weeklong asynchronous group discussion based on themes discovered during the first stage. Your colleagues for this discussion will be the other participants in the study. You will be asked to login at least five days during Stage 2 . Remember that your anonymity will be protected by use of the alias login.

\section{---TWO-WEEK BREAK---}

\section{Stage 3: Duration (1-2 hours)}

After a second two-week break, you will be asked to login once more for a one-time, synchronous (live) chat. The purpose of this chat will be for Schreck to reveal the results of the research process and to reveal the initial development of a 
retention model. Schreck will ask for specific feedback concerning his generalizations of specific comments made during the research process and to check for accuracy. The total chat time will not exceed 2 hours.

While not completely void of risks, the risks involved in this study are minimal since Marylhurst University operates WebCT over a secure, encrypted connection. Even if your private comments were revealed, no one would know your true identity unless they also were able to obtain a copy of Schreck's research notes. You may not receive any direct benefit from taking part in this study, but the study may help to increase knowledge and improve online course retention in distance education. Results of the study will be available to all participants online and you will receive a $\$ 25.00$ gift certificate to Marylhurst University's bookstore as soon as you've completed your expectations during the eight-week research period.

Please note that your participation is voluntary. You do not have to take part in this study, and it will not affect your relationship with Marylhurst University or Portland State University. You may also withdraw from this study at any time without affecting your relationship with Marylhurst University or Portland State University.

If you have concerns or problems about your participation in this study or your rights as a research Subject, please contact the Human Subjects Research Review Committee, Office of Research and Sponsored Projects, 111 Cramer Hall, Portland State University, (503) 725-8182. If you have questions about the study itself, contact Vince Schreck at 5311 NE Mason, Portland, OR 97218, (503) 6368141, extension 3362 .

By posting your first message in your private topic area, you are thereby agreeing to the terms outlined in this informed consent letter. After reading the letter, you may proceed to the Stage 1 Question area. You are encouraged to print this letter and keep it for your records.

Thank you. 
APPENDIX C

RESEARCH JOURNAL SAMPLE 


\begin{tabular}{|l|l|l|l|}
\hline \multicolumn{5}{|c|}{ Stage 1 Collection Journal } \\
\hline Stage 1 Process & \multicolumn{1}{|c|}{ Proposed } & \multicolumn{1}{|c|}{ Actual } & \multicolumn{1}{c|}{ Evidence } \\
\hline $\begin{array}{l}\text { Read and reread } \\
\text { text files }\end{array}$ & $\begin{array}{l}\text { Text files will be } \\
\text { read and reread } \\
\text { before assigning } \\
\text { categories. }\end{array}$ & $\begin{array}{l}\text { Text files were read } \\
\text { through once. Second } \\
\text { read, I grouped the } \\
\text { responses to similar } \\
\text { questions. }\end{array}$ & $\begin{array}{l}\text { Memo: "After first read } \\
\text { through, I started to think } \\
\text { thematically about the } \\
\text { answers. It made sense to } \\
\text { group their responses } \\
\text { around similar questions I } \\
\text { asked." }\end{array}$ \\
\hline $\begin{array}{l}\text { Create necessary } \\
\text { memos }\end{array}$ & $\begin{array}{l}\text { The first stage of } \\
\text { memos represent } \\
\text { initial concerns, } \\
\text { thoughts, and } \\
\text { feelings about the } \\
\text { text files. }\end{array}$ & $\begin{array}{l}\text { Rather than memos } \\
\text { representing the entire } \\
\text { "batch" of data, I } \\
\text { found myself creating } \\
\text { memos around } \\
\text { individuals and like- } \\
\text { questions. }\end{array}$ & $\begin{array}{l}\text { Memo: "Subject_1 did not } \\
\text { understand the line of } \\
\text { questioning and his } \\
\text { answers are rather sparse } \\
\text { when compared to the } \\
\text { entire group. I'm going to } \\
\text { have to ask him to } \\
\text { elaborate." }\end{array}$ \\
\hline $\begin{array}{l}\text { Begin coding by } \\
\text { identifying relevant } \\
\text { text units - make } \\
\text { annotations as } \\
\text { necessary }\end{array}$ & $\begin{array}{l}\text { Text units come } \\
\text { from line-by-line } \\
\text { analysis of the data } \\
\text { and are labeled and } \\
\text { become "Free } \\
\text { Nodes," the } \\
\text { building blocks of } \\
\text { categories. }\end{array}$ & $\begin{array}{l}\text { The creation of text } \\
\text { units was exactly how } \\
\text { I defined it in chapter } \\
\text { 3. I found using N6 } \\
\text { really helped here } \\
\text { because it } \\
\text { automatically assigns } \\
\text { a coding protocol. }\end{array}$ & $\begin{array}{l}\text { Memo: "Subject 1's } \\
\text { statement here implies a } \\
\text { strong connection with } \\
\text { Social Integration. They } \\
\text { even offered some } \\
\text { properties, which may be } \\
\text { useful in the near future." }\end{array}$ \\
\hline
\end{tabular}

